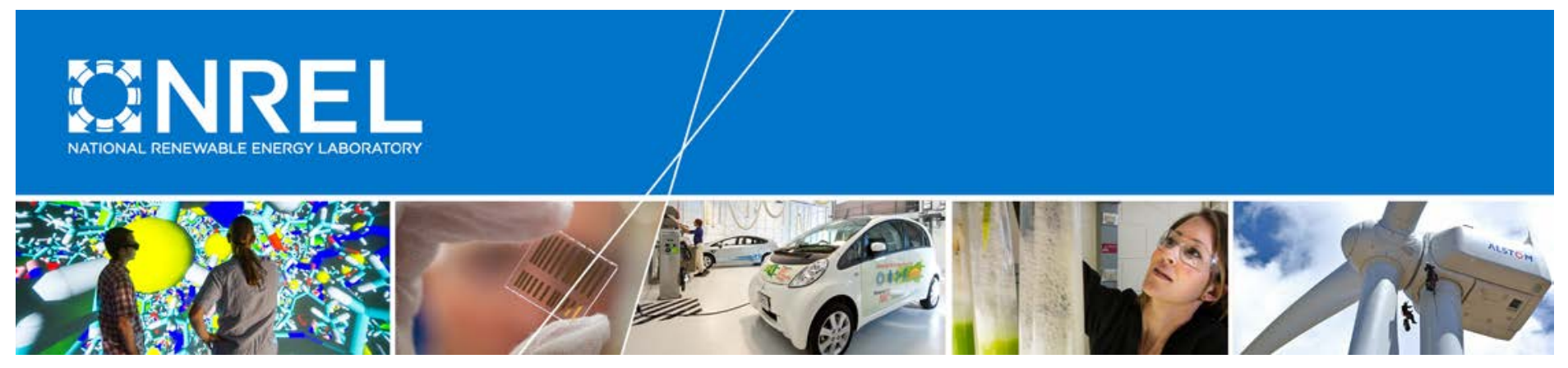

\title{
Advanced Inverter Voltage Controls: Simulation and Field Pilot Findings
}

Julieta Giraldez, Andy Hoke, Peter Gotseff, Nick Wunder, Michael Blonsky, Michael Emmanuel, and Aadil Latif National Renewable Energy Laboratory

Earle Ifuku, Marc Asano, Thomas Aukai, and Reid Sasaki

Hawaiian Electric

NREL is a national laboratory of the U.S. Department of Energy Office of Energy Efficiency \& Renewable Energy Operated by the Alliance for Sustainable Energy, LLC

This report is available at no cost from the National Renewable Energy Laboratory (NREL) at www.nrel.gov/publications.

Technical Report

NREL/TP-5D00-72298

October 2018 


\section{Advanced Inverter Voltage Controls: Simulation and Field Pilot Findings}

Julieta Giraldez, Andy Hoke, Peter Gotseff, Nick Wunder, Michael Blonsky, Michael Emmanuel, and Aadil Latif National Renewable Energy Laboratory

Earle Ifuku, Marc Asano, Thomas Aukai, and Reid Sasaki Hawaiian Electric

\section{Suggested Citation}

Giraldez, J., A. Hoke, P. Gotseff, N. Wunder, M. Blonsky, M. Emmanuel, A. Latif, E. Ifuku, M. Asano, T. Aukai, and R. Sasaki. 2018. Advanced Inverter Voltage Controls: Simulation and Field Pilot Findings. Golden, CO: National Renewable Energy Laboratory.

NREL/TP-5D00-72298. https://www.nrel.gov/docs/fy19osti/72298.pdf.

NREL is a national laboratory of the U.S. Department of Energy

Office of Energy Efficiency \& Renewable Energy

Operated by the Alliance for Sustainable Energy, LLC

This report is available at no cost from the National Renewable Energy Laboratory (NREL) at www.nrel.gov/publications.

National Renewable Energy Laboratory 15013 Denver West Parkway Golden, CO 80401

303-275-3000 • www.nrel.gov

\section{Technical Report}

NREL/TP-5D00-72298

October 2018

Contract No. DE-AC36-08GO28308 


\section{NOTICE}

This work was authored in part by the National Renewable Energy Laboratory, operated by Alliance for Sustainable Energy, LLC, for the U.S. Department of Energy (DOE) under Contract No. DE-AC36-08G028308. Funding provided by the U.S. Department of Energy Office of Energy Efficiency and Renewable Energy Solar Energy Technologies Office and Hawaiian Electric. The views expressed in the article do not necessarily represent the views of the DOE or the U.S. Government.

This report is available at no cost from the National Renewable Energy Laboratory (NREL) at www.nrel.gov/publications.

U.S. Department of Energy (DOE) reports produced after 1991 and a growing number of pre-1991 documents are available free via www.OSTI.gov.

Cover Photos by Dennis Schroeder: (left to right) NREL 26173, NREL 18302, NREL 19758, NREL 29642, NREL 19795.

NREL prints on paper that contains recycled content. 


\section{Acknowledgments}

The National Renewable Energy Laboratory (NREL) is grateful for the opportunity to work with Hawaiian Electric and the other Hawaii stakeholders in support of the state's ambitious energy transition goals. We thank the Hawaiian Electric team members that have supported the project and provided valuable comments to the report such as Reid Ueda, Meredith Chee, Blaine Hironaga, Riley Ceria, Alan Hirayama and Alan Lee. Members of the Hawaii Advanced Inverter Technical Working Group (AITWG) have provided valuable feedback both on the report itself and on the research described here. This report was greatly improved through feedback from Tom Bialek, Jason Bobruk, Mike McCarty, and Phuoc Tran.

The advanced inverter field pilot project would not have been possible without the generous support of Enphase Energy and SolarEdge Technologies and their photovoltaic system installer networks. Hawaiian Electric and NREL are grateful for their invaluable assistance.

The NREL team is also thankful to the staff of NREL's High Performance Computing Center for their technical expertise in facilitating the integration, synchronization, analysis, and visualization of numerous disparate field data streams. 


\section{List of Acronyms}

AMI

ANSI

API

CSV

DER

DOE

ESIF

FIT

GSUI

HPC

IEEE

IoT

IP

NREL

p.u.

PV

QSTS

RTU

SCADA

TCP

VAR

VROS
Advanced metering infrastructure

American National Standards Institute

Application Programming Interface

Comma-separated value

Distributed energy resource

U.S. Department of Energy

Energy Systems Integration Facility

Feed-in tariff

Grid-Support Utility-Interactive

High-performance computing

Institute of Electrical and Electronics Engineers

Internet of Things

Internet Protocol

National Renewable Energy Laboratory

Per unit

Photovoltaic

Quasi-static time-series

Remote terminal unit

Supervisory Control and Data Acquisition

Transmission Control Protocol

Volt-ampere reactive

Voltage Regulation Operational Strategies 


\section{Executive Summary}

This report describes work performed by the Hawaiian Electric Companies and the National Renewable Energy Laboratory (NREL) to model and simulate advanced inverter grid-support utility-interactive $^{1}$ (GSUI) functions and to validate and expand on those simulations through a field pilot study. This work builds on earlier research, referred to as the Voltage Regulation Operational Strategies (VROS) study (Giraldez, et al., 2017) (and is referred to as "VROS 2017" in this report). The objective of both the original VROS 2017 study and this update is to investigate functionalities available in most photovoltaic (PV) systems equipped with advanced inverters to modulate active and reactive power autonomously based on local voltage measurements for the purpose of mitigating off-nominal grid voltage conditions. Specifically of interest are volt/volt-ampere reactive (VAR) control and volt/Watt control ${ }^{2}$, the effect of those functions on quasi-steady-state feeder voltages, and the impact of the functions on PV energy production. Because volt/VAR in combination with volt/Watt (volt/Var-volt/Watt) control autonomously adjust inverter output based on local conditions without requiring communication with any other devices, they are good candidates for non-wire alternatives to increase PV hosting capacity when the limiting factor is voltage constraints in a transformer secondary service with very large numbers of PV systems.

Past work by this project team and others has shown that volt/VAR and volt/Watt control can be effective voltage management tools and that their impacts on PV energy production are typically minimal. However, based upon the finding from the VROS 2017 study, some stakeholders remained concerned that in a small number of outlier cases curtailment amounts would significantly affect the economics of PV ownership. One of the major results of this report is to update the prior VROS 2017 study's simulation results for the high penetration PV case. ${ }^{3}$ The major updates are in the algorithm implementation and convergence of the volt/Watt algorithm for the large number of PV systems included in the model, which results in lower energy curtailment numbers, especially for the few customer outliers that were previously reported to experience larger curtailment numbers.

This report seeks to address concerns about the impacts of volt/VAR and volt/Watt control through a combination of detailed quasi-static time series simulations and field data. Current findings indicate that in the vast majority of locations (99\% of customers) any curtailed PV production resulting from system-wide activation of volt/VAR-volt/Watt control for all new DERs is expected to be negligible (i.e., less than $2 \%$ of weekly energy production for a high

\footnotetext{
${ }^{1}$ Grid support functions are often associated with functional capabilities of advanced inverters also referred to as "grid support utility interactive inverters" in Underwriters Laboratories (UL) 1741 Supplement A (UL 1741 SA), which is intended to validate compliance with grid interactive functions which were not originally covered in IEEE 1547-2003. The grid support functions that are included in UL 1741 Supplement A include, but are not limited to, voltage and frequency ride through and active and reactive power control. Some of the functional requirements of UL $1741 \mathrm{SA}$ such as frequency/watt control, and volt/Watt control are defined as optional for purposes of certification and marking as a "Grid Support Utility Interactive Inverter."

${ }^{2}$ In the recently published 2018 update of IEEE Std 1547 (IEEE 1547-2018), IEEE requires that Category B DERs shall be capable of providing voltage regulation capability by changes in active power. Enabling/disabling the volt/Watt function is at the discretion of the Area EPS operator. The default is that this function is disabled.

${ }^{3}$ In the Hawaii PUC Decision and Order No. 34924, Docket No. 2014-0192, various parties including Hawaiian Electric attempted to characterize the expected level of curtailment based upon multiple scenarios.
} 
voltage week, typically much less on an annualized basis since the average customer weekly curtailment is $0.23 \%$ for the high voltage week.). (See further discussion in Section 2.4.1.2.) The initial phase of the advanced inverter field pilot confirmed the expectation from the VROS simulations that curtailment caused by volt/VAR-volt/Watt is typically low or negligible even though pilot project participants were selected from customers that failed interconnection subscreens.

Another key concern is that it is difficult for anyone (the utility, its customers, or PV installers) to accurately predict in advance whether a given location will experience high voltage issues (and resulting PV energy curtailment) before PV has been installed, especially given the absence of smart meters (i.e., advanced metering infrastructure, AMI) in most Hawaii locations and the lack of customer inverter data available to utility planners.

A key finding of both the computer simulations and the field pilot is that for the volt/VAR and volt/Watt curves studied here, curtailment of energy production is negligible as long as typical peak voltages are inside the ranges specified in American National Standards Institute (ANSI) Standard C $84.1^{4}$. Thus, for any location where curtailment would be a problem, voltage is high enough that it would likely require mitigation even if curtailment were not a concern. Therefore, it may be reasonable to trigger mitigation on voltage thresholds rather than deploy sensing or advanced analytics to estimate curtailment. These mitigations would then address both voltage and curtailment issues.

The Hawaiian Electric Companies have embarked on a new business process improvement to streamline the interconnection of distributed energy resource (DER) systems by integrating new methods, including early deployment of smart meters, to proactively identify and address problem locations. This business process improvement will benefit customers by allowing more streamlined interconnections while protecting system reliability. Through pre-installation and post-installation monitoring, Hawaiian Electric will be able verify when and where secondary upgrades are needed to avoid out-of-tariff voltages and the associated curtailment. In the absence of the grid support functions being applied system-wide, Hawaiian Electric may continue to require voltage studies and installation of equipment in order to maintain voltage within tariff.

Other findings and recommendations so far include:

- In the very high PV penetration cases simulated, volt/VAR is very effective at reducing voltages during PV production hours. Volt/Watt activation is limited during normal operation.

- The simulations show that total PV production is actually greater with volt/Watt active than without when lost production from inverters tripping offline at the IEEE 1547 overvoltage limit of 1.1 per unit (p.u.) is accounted for. Volt/Watt allows more PV inverters to continue

\footnotetext{
${ }^{4}$ For more information on voltage tolerance boundaries refer to Pacific Gas and Electric Company description of ANSI C84.1 Standard, available online at: (ANSI,

2016)https://www.pge.com/includes/docs/pdfs/mybusiness/customerservice/energystatus/powerquality/voltage_toler ance.pdf
} 
to produce during high voltage conditions rather than disconnecting when voltages are high. In reality, utilities have the obligation to maintain voltages within the permitted operating range (below 1.06 p.u. in Hawaiian Electric Rule 2 limits for character of service). ${ }^{5}$ As such the outlier cases modeled in the simulated very high-PV penetration scenarios with no network upgrades would be fixed by the utility via infrastructure upgrades or other means, as reflected in the scenarios with secondary circuit upgrades.

- Field measurements tend to corroborate the conclusions from simulations that the impacts of volt/VAR and volt/Watt on PV energy production are typically negligible, but they can be non-negligible (though still small) in a few outlier cases (which would be addressed through secondary upgrades or other means).

- Current Hawaiian Electric technical sub-screens identify potential high-curtailment customers that can be monitored while secondary upgrades are underway.

- Voltages in the field are typically not as high as predicted by interconnection sub-screens, which lack detailed load, PV, and feeder data and therefore need to make assumptions designed to avoid possible field voltage problems.

- When volt/Watt has a significant impact to a particular customer, it occurs because actual voltage levels at that location are regularly outside Hawaiian Electric Rule 2 (and ANSI C84.1) limits for character of service. ${ }^{5}$ In these cases, the utility is obligated to resolve issues pursuant to its Rule 2 tariff. When these outlier cases arise, persistent voltage issues can and should be mitigated through circuit upgrades or other means, both to maintain utility voltages within tariff requirements and to avoid burdensome curtailment.

- When temporary situations such as feeder reconfigurations produce high voltage conditions in the field, volt/Watt is effective at reducing voltage, and the impacts on annual energy production are minimal (much less than 1\% for the 6-day event observed in the field).

- When high voltages occur at PV inverter terminals in the field, one contributing factor can be behind-the-meter voltage rise. This is not typically modeled, but it can be mitigated in various ways.

- Voltage issues can arise from one DER system being added to the circuit, or they can arise from the collective impact of many DER systems, or they can arise because of a change in the circuit's load. Due to the complexity of the cause of voltage problems and the fact that these problems can arise at any time during the lifetime of a DER system, the proactive combined activation of volt/VAR and volt/Watt will avoid or delay problems as voltage issues arise.

- When voltages are elevated into the volt/Watt region temporarily (e.g. for a few hours or days because of a temporary feeder reconfiguration), volt/Watt protects against excessive high voltage without significantly impacting monthly or annual energy production. Because temporary high voltage conditions are difficult to predict, volt/Watt has little benefit if not enabled system-wide. In contrast, where voltages are elevated regularly or persistently, the utility has an existing obligation to resolve the underlying issue.

- When activated system-wide, volt/Watt serves as a protection against occasional high voltages, and has no impact when voltages are not out of tariff, as is typically the case.

\footnotetext{
${ }^{5}$ Rule 2 - Character of Service, defines the service voltages that are designed and operated to deliver to customers. The service voltages are generally $+/-5 \%$ from nominal voltage at the service point or point of common coupling (PCC) and are established by ANSI, specifically ANSI Standard C84.1.
} 
- In future PV scenarios that include a mix of exporting and non-exporting PV tariffs, overall voltages are lower than in scenarios with exporting tariffs only, and volt/VAR and volt/Watt are less active. 


\section{Table of Contents}

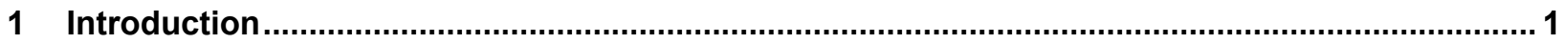

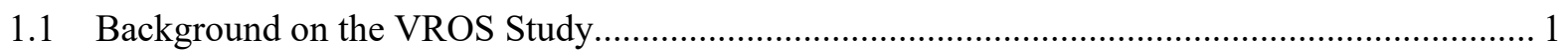

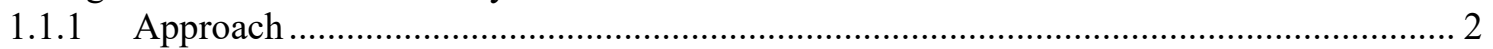

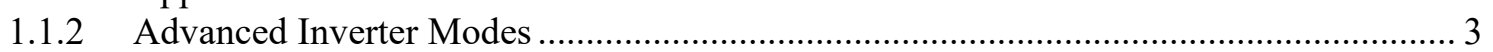

1.1.3 Exporting Versus Non-exporting Tariffs ............................................................ 3

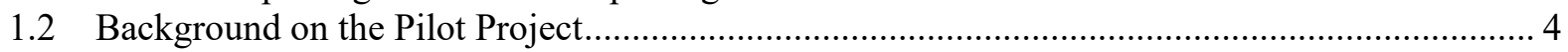

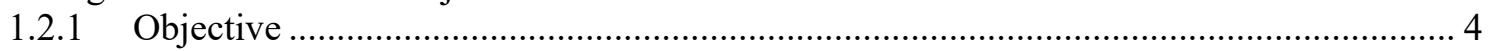

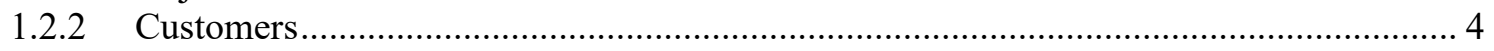

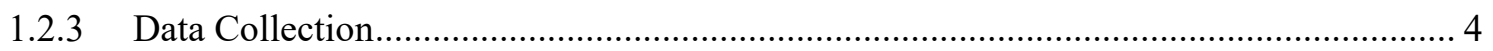

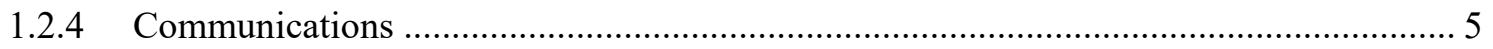

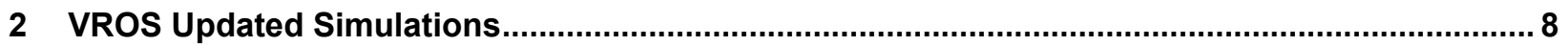

2.1 PyDSS 8

2.2 High-Penetration PV Scenarios on a $12 \mathrm{kV}$ Oahu Feeder................................................... 9

2.2.1 M34 Feeder High-Penetration PV Case and Scenarios ............................................... 9

2.3 Metrics 11

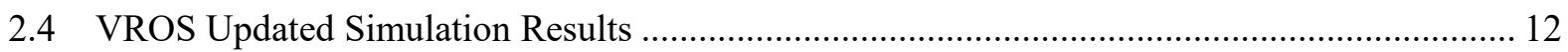

2.4.1 Disconnect Versus Nondisconnect Above 1.1 p.u. Voltage........................................... 12

2.4.2 Volt/VAR and Volt/VAR-Volt/Watt on New PV and Current Network ....................... 12

2.4.3 Volt/VAR and Volt/VAR-Volt/Watt on New PV with Secondary Upgrades................. 18

2.4.4 70\% New PV Exporting with Volt/VAR and 30\% New PV Non-exporting ................. 21

2.4.5 Current Hawaiian Electric Technical Sub-Screens and Recommended NREL Sub-

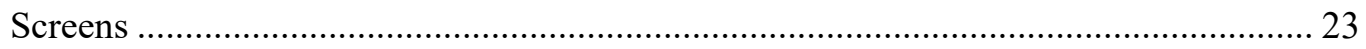

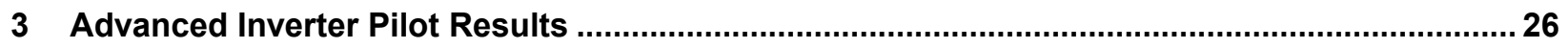

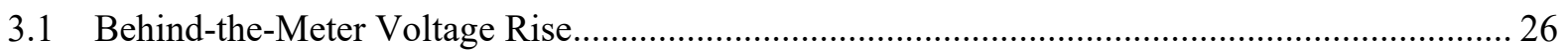

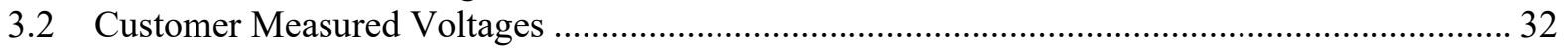

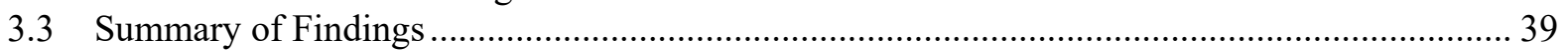

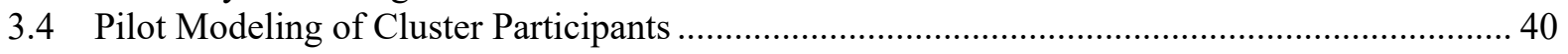

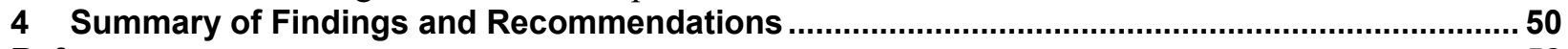

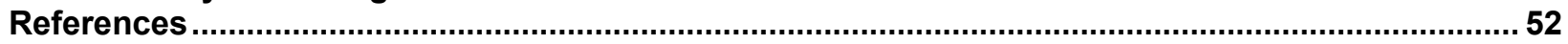

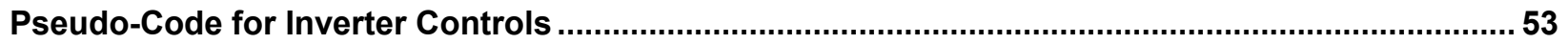




\section{List of Figures}

Figure 1. Volt/VAR and volt/Watt curves in Hawaii Rule 14H ........................................................ 3

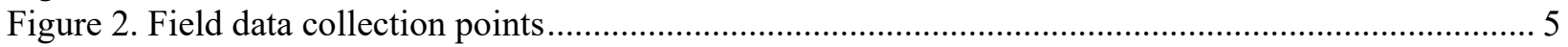

Figure 3. Hardware located at customer sites to provide inverter communications ................................. 6

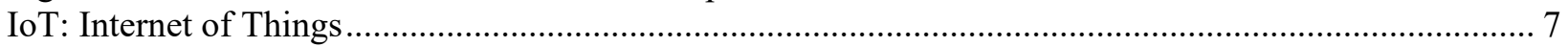

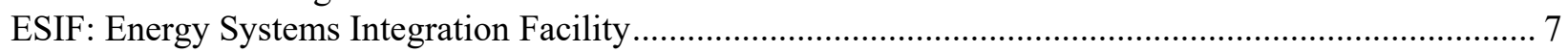

Figure 4. Data collection, storage, and visualization platform. ESIF is the Energy Systems Integration

Facility, the laboratory housing NREL's High Performance Computing Center. ................... 7

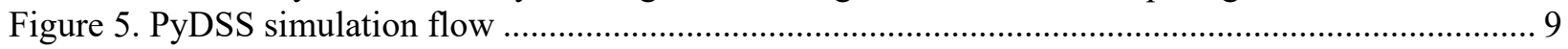

Figure 6. Voltage envelops for all loads in the M34 feeder for scenarios 1.a without disconnection (left plot) and 1.b with disconnection (right plot) of inverters above $1.1 \mathrm{p} . \mathrm{u}$. voltage for a highvoltage week in June. "CPF1" indicates that inverters are operating without volt/VARvolt/Watt enabled.

Figure 7. Voltage envelops for all loads in the M34 feeder for scenarios 1.a without disconnection (left plot) and 1.b with disconnection (right plot) of inverters above 1.1 p.u. voltage for a lowvoltage week in April

Figure 8. Voltage envelops for all loads in the M34 feeder for scenarios 2.a "100\% New PV ExportingVolt/VAR" (left) and 2.b "100\% New PV Exporting—Volt/VAR-Volt/Watt" (right) for a high-voltage week in June.

Figure 9. Voltage envelops for all loads in the M34 feeder for scenarios 2.a "100\% New PV ExportingVolt/VAR" (left) and 2.b "100\% New PV Exporting—Volt/VAR-Volt/Watt” (right) for a low-voltage week in April.

Figure 10. Customer energy percentage curtailment histograms for a low-voltage week in April (left) and a high-voltage week in June (right). Each plot compares customer weekly curtailment percentages between scenarios 2.a (volt/VAR on the new PV in blue) versus 2.b (Volt/VARVolt/Watt on the new PV in pink). The dashed vertical lines represent the average customer curtailment for each scenario.

Figure 11. Assumed worst-case secondary design for rural customers in the M34 feeder...................... 16

Figure 12. Secondary design for highest curtailed customer (dark red dot) in the M34 feeder................. 17

Figure 13. Voltage envelops for all loads in the M34 feeder for scenarios 2.a "100\% New PV ExportingVolt/VAR" (left) and 3.a "100\% New PV Exporting_Volt/VAR with Secondary Upgrades" (right) for a high-voltage week in June

Figure 14. Voltage envelops for all loads in the M34 feeder for scenarios $2 . b$ " $100 \%$ New PV Exporting —Volt/VAR-Volt/Watt" (left) and 3.b "100\% New PV Exporting—Volt/VARVolt/Watt with Secondary Upgrades" (right) for a high-voltage week in June .....

Figure 15. Customer energy percentage curtailment histograms without upgrades (left) and with secondary upgrades (right) for a high-voltage week in June. Each plot compares customer weekly curtailment percentages of volt/VAR on the new PV (in blue) to Volt/VARVolt/Watt on new PV (in pink). The dashed vertical lines represent the average customer curtailment for each scenario.

Figure 16. Histogram of voltages for Scenario 2.a "100\% New PV Exporting — Volt/VAR" (in light blue) and Scenario 4 “70\% New PV Exporting-Volt/VAR and 30\% New PV Non-exporting” (in pink).

Figure 17. Customer energy curtailment percentages for Scenario 2.a "100\% New PV ExportingVolt/VAR" (in light blue) and Scenario 4 "70\% New PV Exporting-Volt/VAR and 30\% New PV Non-exporting" (in pink) for a high-voltage week in June. The dashed lines show the average customer energy curtailment.

Figure 18. Customer energy curtailment percentages as a function of weekly maximum customer voltage for a high-voltage week in June. 
Figure 19. Behind-the-meter voltage rise is one of several factors affecting inverter terminal voltage and system losses........................................................................................................... 26

Figure 20. Voltage differences as small as $2 \%$ can have a significant impact on volt/VAR and volt/Watt performance because the entire sloping regions of the curves cover $3 \%$ or $4 \%$ of nominal voltage. Pictured here are Hawaiian Electric's approved volt/VAR curve and optional volt/Watt curve.

Figure 21 . Voltage differences as small as $2 \%$ can have a significant impact on volt/VAR and volt/Watt performance.

Figure 22. Behind-the-meter voltage rise for all string inverter customers as a function of inverter output

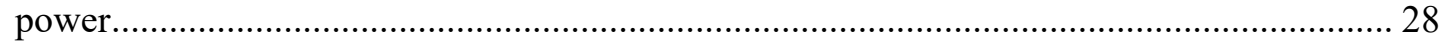

Figure 23. Behind-the-meter voltage rise as a function of inverter current for the string inverter system

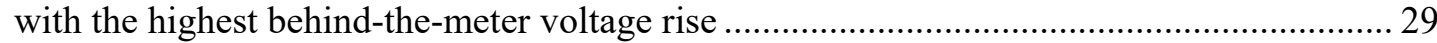

Figure 24. Behind-the-meter voltage rise during 2 mostly sunny days for an example microinverter system. Meter voltage is shown in green, and each inverter's reported voltage is plotted separately in other colors.

Figure 25. Behind-the-meter voltage rise for the microinverter system with the highest voltage rise. A linear regression fit of voltage rise versus inverter current for each individual inverter is shown in turquoise. The regression fit lines are clearly clustered into two groups with similar slopes; the two groups represent two PV subarrays on different roof pitches. .

Figure 26. PV power and reactive power, irradiance, and inverter voltage for one of the two smart PV
systems in Cluster 1 during a partially sunny day. Voltage is highly correlated with irradiance and inverter active power at this location. Reactive power absorption is defined as positive in this plot (opposite of the typical generator sign convention).

Figure 27. Inverter power, reactive power, and voltage for one of the three smart PV systems in Cluster 2 during a partially sunny day. Voltage is largely independent of irradiance and inverter active power at this location. Reactive power absorption is defined as positive in this plot (opposite of the typical generator sign convention).

Figure 28. Histogram of inverter and AMI voltages for Cluster 1 (the second-highest voltage location in the pilot).

Figure 29. Histogram of inverter and AMI voltages for a typical location with well-regulated voltage.... 35

Figure 30. Histogram of inverter and AMI voltages for the highest voltage location in the pilot.............. 36

Figure 31. Inverter and AMI voltage profiles for the second-highest voltage location in the pilot. Note the period of unusually high voltages in late October.....

Figure 32. Comparison of curtailment due to volt/VAR-volt/Watt during two periods: on the left, a normal period, and on the right, the period of unusually high voltages in late October ........ 37

Figure 33. Using instantaneous AMI meter power and voltage data to estimate the impact of PV on voltage before the PV is installed.

Figure 34. Secondary circuit for Cluster 1 of the pilot project. The last four customers in the second branch from the service transformer have PV systems (star shapes).

Figure 35. Measured voltage (dashed orange) versus modeled voltage (dotted blue line) at a customer in Cluster 1. The maximum instantaneous error between the measured and simulated voltage is 0.005 p.u.

Figure 36. Measured versus modeled real (top) and reactive (bottom) power at the service transformer of the Cluster 1 secondary .....

Figure 37. Inverter measured power versus irradiance (dark blue); estimation of expected inverter power based on measured irradiance (red); and, measured inverter power when identified as curtailed (light blue). Curtailment was identified when measured power fell below the expected power estimate by a small tolerance.

Figure 38. Voltage envelopes for Cluster 1 customers with five PV legacy systems connected at the end of Branch 2 (far from transformer) and eight PV systems in volt/VAR (left) versus Volt/VAR-

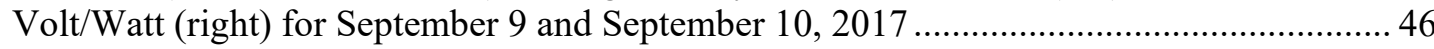


Figure 39. Voltage envelopes for Cluster 1 customers with five PV legacy systems connected towards the front of Branch 2 (close to the transformer) and eight PV systems in volt/VAR (left) versus volt/VAR-volt/Watt (right) for September 9 and 10, 2017

Figure 40. Energy curtailment percentage heat map for Cluster 1 with all customers with PV, five legacy PV systems connected first on Branch 2, and the remaining eight in volt/VAR (left) and Volt/VAR-Volt/Watt modes (right).

Figure 41. Voltage envelop for Cluster 1 with all customers with PV with advanced inverter functionalities in volt/VAR (left) and Volt/VAR-Volt/Watt (right) for two high-voltage days in September...

Figure 42. Customer energy curtailment heat map for Cluster 1 with all customers with PV with advanced inverter functionalities in volt/VAR (left) and Volt/VAR-Volt/Watt (right)......................... 48

Figure A-1. 53

Figure A-2. 54

Figure A-3 54

\section{List of Tables}

Table 1. Scenario Description for M34 Feeder High-PV Penetration Case....

Table 2. Energy Curtailment and Increased Generation Metrics for Scenarios 2.a "100\% New PV Exporting —Volt/VAR" and 2.b "100\% New PV Exporting—Volt/VAR-Volt/Watt" for a high-voltage week in June and a low-voltage week in April

Table 3: Energy Curtailment and Increased Generation Metrics for Scenario 2.a and Scenario 2.b (No Upgrades) and 3.a and 3.b (with Secondary Upgrades) for a High-Voltage Week in June... 21

Table 4. Hawaiian Electric Technical Review Sub-screens for PV Interconnection Applications ............ 23

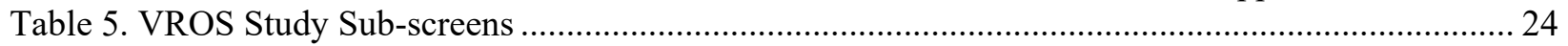

Table 6. Behind-the-Meter Voltage Rise During Peak PV Production Hours.......................................... 31

Table 7. Comparison of Expected Maximum Voltages to Measured Maximum Voltages ......................... 38

Table 8. Scenarios for Cluster 1 with 690\% PV Penetration of Day Time Minimum Load...................... 45

Table 9. Customer Energy Curtailment Metrics for the Different Scenarios with All Customers with PV

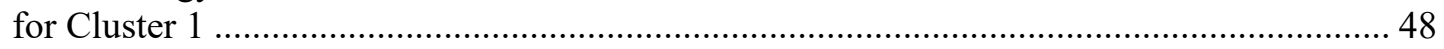

Table 10. Energy Curtailment Metrics Comparison Between 1-Minute and 15-Minute Time-Step Resolutions for Scenario "5 Legacy Close 8 Grid-Support Function Far" 


\section{Introduction}

This report is a continuation of the work presented in (Giraldez, et al., 2017) of the collaboration among the U.S. Department of Energy (DOE), National Renewable Energy Laboratory (NREL) and Hawaiian Electric Companies to research the implementation of advanced inverter gridsupport functions. It includes some updated results of the simulation of a high-penetration photovoltaic (PV) scenario of a Hawaiian Electric distribution feeder with advanced inverters and different penetrations of non-exporting versus exporting new PV customers as well as the findings of the field validation of inverter-based voltage regulation functions at approximately 15 customer locations.

In parallel to the Voltage Regulation Operational Strategies (VROS) study in 2017, NREL published a report conducted under the DOE Grid Modernization Laboratory Consortium by a regional partnership for Hawaii that recommended the blanket activation of the frequency/watt function to minimize negative impacts on frequency stability. That report also found that the impact of frequency/watt control on PV system owners' energy production is predicted to be negligible (Hoke, et al., 2017).

Hawaiian Electric filed an advanced inverter stipulation to the Hawaii Public Utilities Commission in September 2017, and in October 2017 the Commission approved the activation of volt/volt-ampere reactive (VAR) and frequency/watt functions as well as the option to offer volt/Watt to PV applicants who did not pass the technical supplemental review process and whose interconnection was delayed because of the required secondary upgrade work.

\subsection{Background on the VROS Study}

In 2016, NREL and Hawaiian Electric, in collaboration with members of the Smart Inverter Technical Working Group (SITWG, later Advanced Inverter Function Working Group, AIFWG), identified a need to perform modeling and simulation of feeder operations with solar PV system advanced inverters covering a longer (year-long) period. The key concern expressed by the members of the SITWG was that the activation of voltage regulation grid-support functions - especially volt/VAR with reactive power priority and volt/Watt—would cause significant curtailment to the PV customer. The VROS work was published in September 2017 (and is referred to as "VROS 2017" in the remaining of this report), and it provided a series of recommendations, such as activating reactive power-based grid-support functions in reactive power priority mode (versus active power priority mode), the benefits of volt/VAR compared to constant power factor mode, the activation of volt/VAR in combination with volt/Watt to provide a backstop against voltages above American National Standards Institute (ANSI) Standard C84.1 levels ${ }^{6}$, and the overall low annual energy curtailment impacts (less than 5\%) on PV customers due to the activation of volt/VAR in combination with volt/Watt (Giraldez, et al., 2017).

\footnotetext{
${ }^{6}$ For more information on voltage tolerance boundaries refer to Pacific Gas and Electric Company description of ANSI C84.1 Standard, available online at: (ANSI, 2016)https:/www.pge.com/includes/docs/pdfs/mybusiness/customerservice/energystatus/powerquality/voltage_toler ance.pdf
} 
However, the VROS 2017 work also had some caveats, as described in (Giraldez, et al., 2017):

- PV systems as modeled in the VROS 2017 study do not turn off at 1.1 per unit (p.u.) voltage as they would in the field according to the Institute of Electrical and Electronics Engineers (IEEE) 1547 (IEEE, 2003). This causes overall higher voltages in the range of the voltage control-based grid-support functions such as volt/VAR and volt/Watt. As such, these functions are called upon more often than they would be if feeder voltages were not as high. Because the VROS project simulated voltages higher than 1.1 p.u., the curtailment for PV systems above 1.1 p.u. voltage was not counted as curtailment associated with a grid-support function; however, it is likely that volt/VAR and volt/Watt in the simulation were activated more often than they would have been observed in the field.

- The volt/Watt algorithm was programmed outside the OpenDSS software. It was observed that during clear-sky days, the volt/Watt algorithm used in this project resulted in overcurtailment of up to $10 \%$ more than the active power value expected for a 15 -minute time step, and the algorithm overcorrected voltages to the 1.05 p.u. range in some cases. This implies that the volt/Watt annual energy curtailment values were slightly overestimated.

These two modeling and simulation issues have been corrected in the work presented in this report, and as such NREL and Hawaiian Electric can more accurately characterize and quantify the activation of volt/Watt and its impacts on solar PV customers.

In addition, the VROS 2017 study findings evaluated scenarios in which all the new PV systems modeled had the ability to export (as in net energy meter or customer grid-supply tariffs offered by Hawaiian Electric). In this report, we also include scenarios with new PV systems interconnected in a non-exporting agreement and describe the implications on overall voltage profiles and on other exporting PV customers.

\subsubsection{Approach}

Leveraging prior DOE and other industry-funded research in distribution modeling and analysis tools for high-penetration PV analysis, NREL proposed to Hawaiian Electric that the VROS project use quasi-static time-series (QSTS) analysis to address the higher level technical voltage management operation strategies and impacts of activating advanced inverter voltage regulation grid-support functions.

To address the voltage management problem previously described, the project leveraged the distribution feeder models prepared in (Giraldez, et al., 2017), which included the necessary level of detail to more accurately capture the voltage drop/rise that occurs in the secondary lowvoltage circuits. The simulation in this project was run using PyDSS, which is an NRELdeveloped Python programming language wrapper around the OpenDSS tool that has PV and storage inverter controllers that can be flexibly programmed outside OpenDSS (Latif et. al. 2018); this provides improved control over the advanced inverter and battery grid-support function algorithms and their convergence. More detailed information on PyDSS is provided in Section 2.1. Time-series simulation for the highest voltage week of the year is performed under different scenarios, and voltage profiles and energy curtailment estimates are provided for PV customers. 


\subsubsection{Advanced Inverter Modes}

The advanced inverter modes considered in this study are volt/VAR, and volt/VAR in combination with volt/Watt, with the following settings proposed by Hawaiian Electric shown in Figure 1.
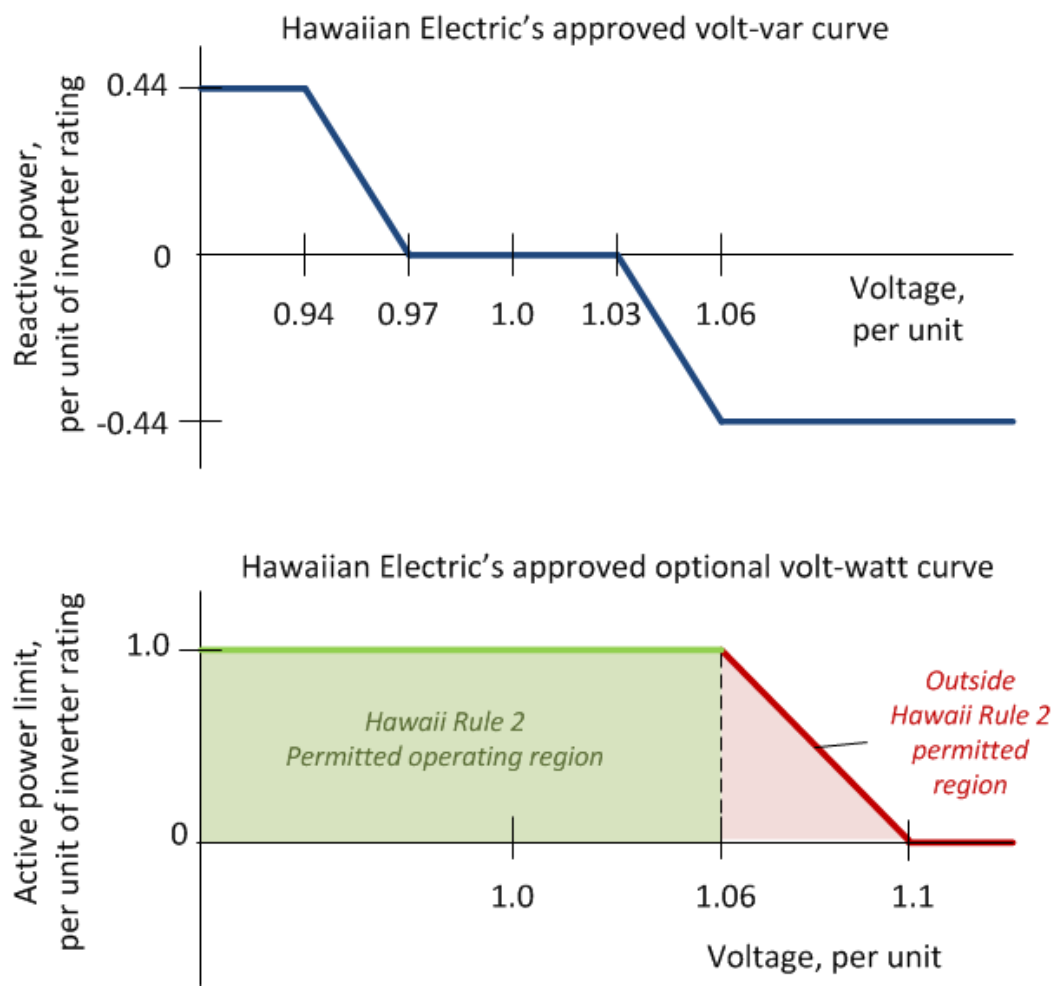

Figure 1. Volt/VAR and volt/Watt curves in Hawaii Rule 14H

The volt-VAR curve corresponds to a moderate curve with a deadband of \pm 0.03 p.u. and a droop curve above 1.03 p.u. and below 0.93 p.u. The droop slope reaches full VAR absorption at 1.06 p.u. and full VAR generation at 0.94 p.u. Full VARs are defined as $44 \%$ of the inverter apparent power rating, which corresponds to power factor of 0.9 at full apparent power. Thus, volt/VAR can absorb (or produce) more reactive power than a constant power factor of 0.95 . The full VAR capability, however, is used only when the voltage is far from nominal. In the circuit models, the volt/Watt function initiates reduction in active power when the voltage at the point of common coupling (not necessarily the inverter terminals) crosses 1.06 p.u. ANSI C84.1 (ANSI, 2016) provides that voltage delivered at the point of common coupling generally should not exceed 1.05 p.u., so volt/Watt provides means to protect utility voltages from greatly exceeding the ANSI C84.1 service voltage range. The difference between the ANSI C84.1 standard (1.05 p.u.) and the volt/Watt setting (1.06 p.u., as measured at the inverter terminals in the field) provides a 0.01 p.u. allowance to compensate for behind the meter voltage drop (see further discussion in Section 3.1).

\subsubsection{Exporting Versus Non-exporting Tariffs}

As mentioned, Hawaiian Electric currently has both exporting and non-exporting types of tariffs for residential PV interconnection. For exporting tariffs, there is currently no limit on the power that can be exported during the course of a specific time period. For non-exporting PV systems, 
there should be no reverse power flow at the point of common coupling of the customer with the utility grid (aside from brief periods of inadvertent export). The non-exporting PV-battery control algorithm was programmed in the PyDSS platform. Currently, in-built storage controls in OpenDSS were not suited to program a non-exporting PV storage system because the in-built storage controller element in OpenDSS is not able to perform "valley-filling" charging, i.e., to charge the battery storage system while a threshold (import or export) is maintained at a point of common coupling.

\subsection{Background on the Pilot Project}

\subsubsection{Objective}

To validate the VROS simulation results with field data, several PV customers were recruited for a pilot program to activate grid-support functions and allow monitoring of related data.

Provisions were made for NREL to remotely modify which grid-support functions and settings were active in each system. The pilot program technical details and preliminary results are described in (Gotseff, et. al., 2018) and summarized here.

\subsubsection{Customers}

Pilot customers were recruited from among queued net energy metering (NEM) PV customers whose installations had been delayed because of expected voltage or thermal issues. Customers were allowed to be interconnected sooner (without waiting for circuit upgrades) if they allowed NREL to control inverter settings and collect data. Fifteen customers accepted the invitation and were incorporated into the pilot. The customers included nine with string inverters and six with microinverter arrays. In all pilot customer locations, neighboring PV systems without voltage support active already existed on the same distribution secondary transformer. All customers had residential rooftop PV systems ranging in size from $3.8 \mathrm{~kW}$ to $10 \mathrm{~kW}$. In some cases, an existing legacy (non-smart) PV system was located on the same residence as the pilot PV system.

In two locations, referred to as clusters, multiple pilot PV systems were connected to the same distribution secondary alongside existing legacy PV systems. The two clusters are as follows:

- Cluster 1 consisted of two PV systems with advanced inverters and three legacy PV systems sharing a secondary with long overhead conductors on the M3 circuit. Cluster 1 is the focus of further modeling and simulation efforts described elsewhere in this report.

- Cluster 2 consisted of three PV systems with advanced inverters and two legacy PV systems sharing an underground secondary.

A significant portion of the analysis focused on these clusters because of the controllability of multiple inverters and the ability to derive more benefits from irradiance and Grid2020 sensors.

\subsubsection{Data Collection}

Field pilot data were collected at the locations shown in Figure 2. Grid2020 devices captured 1minute data on power, reactive power, voltage, and other variables (faster than the usual 15minute intervals) on the low-voltage side of each distribution transformer in the pilot. Smart meters (i.e., advanced metering infrastructure [AMI]) captured 1-minute data on power, reactive power, voltage, and other parameters (in addition to the conventional 15-minute data). String inverters were polled via MODBUS Transmission Control Protocol (TCP) on approximately 1- 
second intervals for data including $\mathrm{AC}$ voltage, $\mathrm{AC}$ power and reactive power, $\mathrm{DC}$ voltage, and other variables. Microinverter data were collected on 5-minute intervals from each microinverter using the manufacturer's existing proprietary system. Irradiance sensors were installed on one PV system at each cluster location in plane-of-array and polled on 1-second intervals using MODBUS TCP.

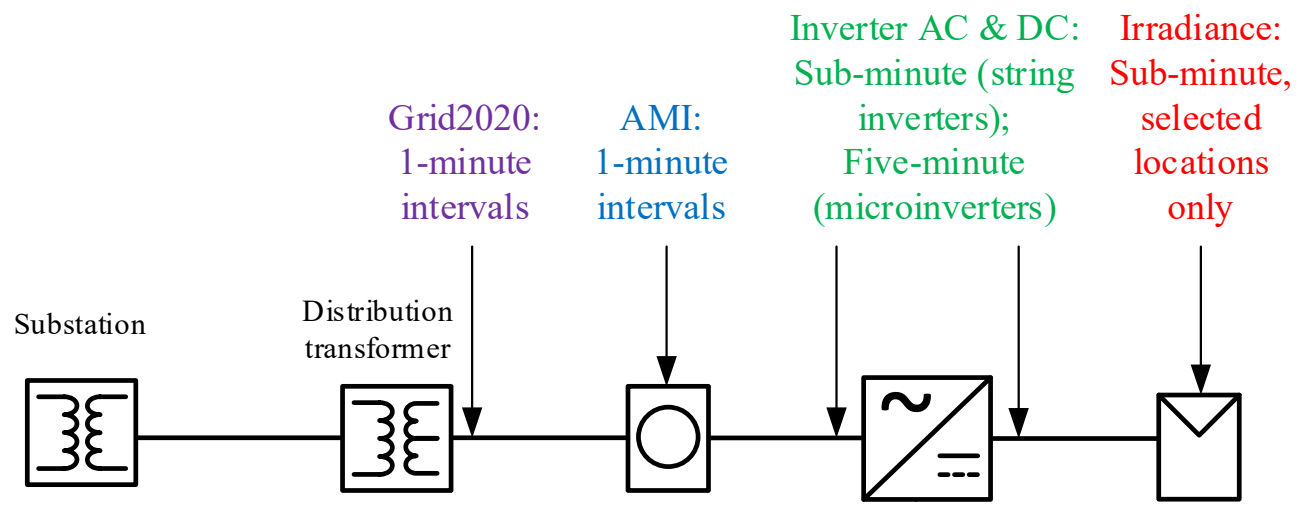

Figure 2. Field data collection points

In the cluster locations, some customers whose PV systems were not controlled as part of the pilot also provided AMI data; however, most Hawaiian Electric customers do not have AMI meters, so availability of this valuable data was limited.

\subsubsection{Communications}

The AMI and Grid2020 data were collected by Hawaiian Electric and transferred weekly to NREL. The microinverter data were collected by the manufacturer and transferred on-demand to NREL. String inverter and irradiance data were collected via a custom-designed communications system consisting of a cellular router connected via local area network (LAN) to the inverter, allowing SunSpec MODBUS TCP commands to be issued over the Internet directly from scripts running at NREL to monitor the inverters and remotely adjust inverter settings. The cellular routers were configured to ensure security, for example by allowing communications only from NREL Internet Protocol (IP) addresses. Hardware used for inverter and irradiance data collection is pictured in Figure 3. At cluster locations, the rooftop irradiance sensors were polled via a remote terminal unit (RTU) connected to the cellular router via LAN. 


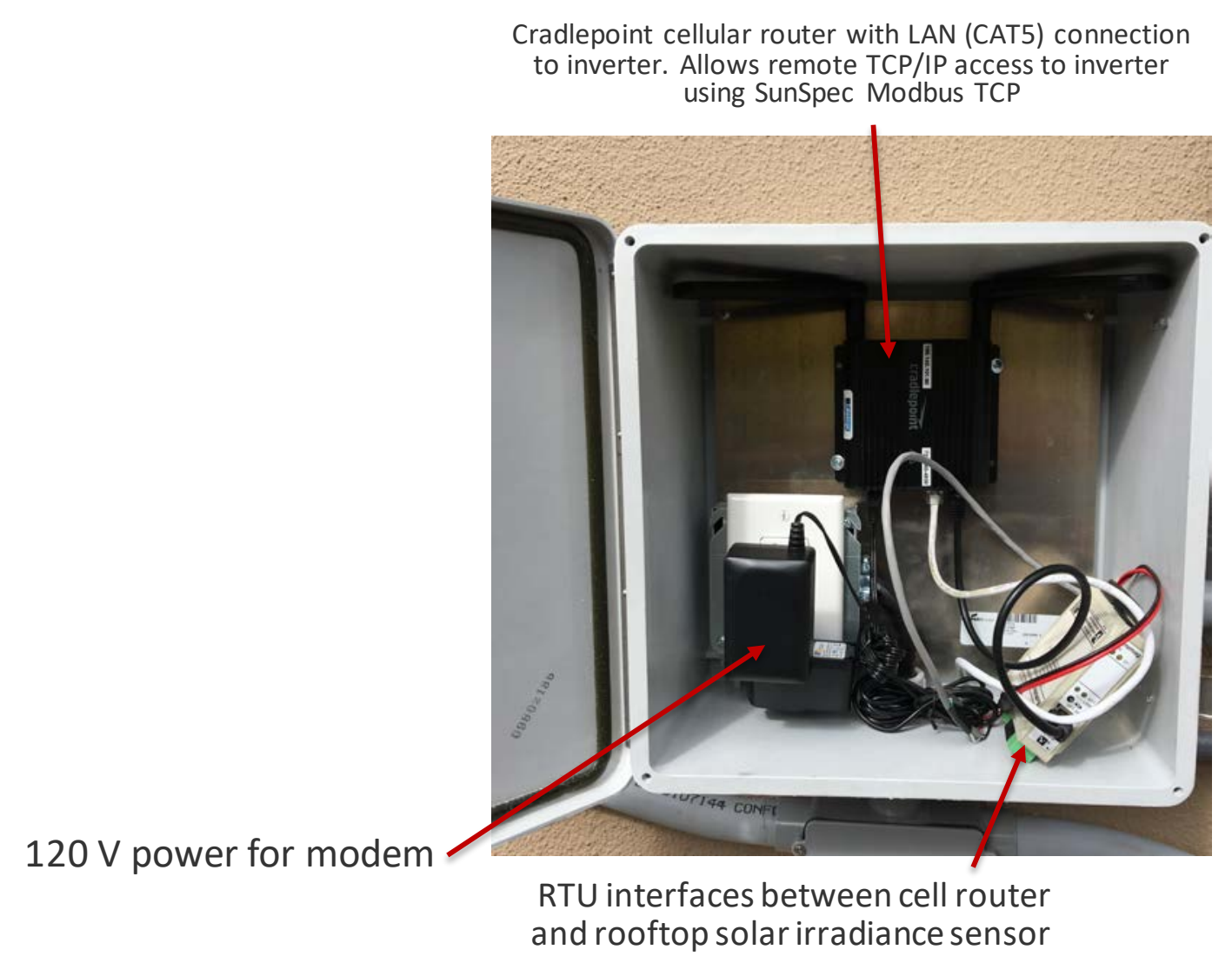

Figure 3. Hardware located at customer sites to provide inverter communications

Although this data collection system worked reasonably well for the purposes of this pilot project, it would be time-consuming and costly to scale such an approach up to thousands of PV systems.

All data were ingested into the Time-Series Cluster database in NREL's High Performance Computing (HPC) Center. This allowed data from multiple sources to be synchronized for visualization and analysis using the architecture shown in Figure 4. 


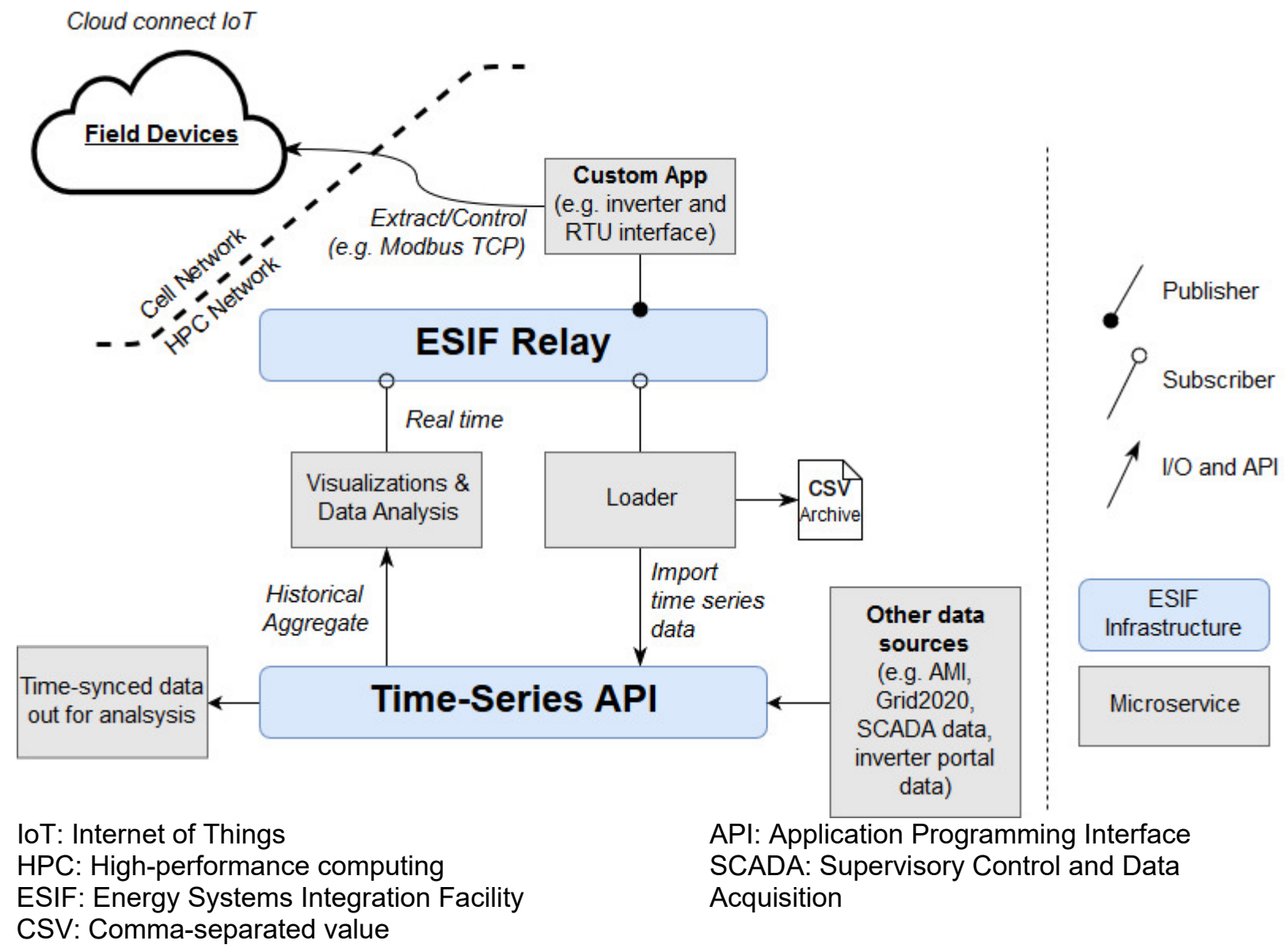

Figure 4. Data collection, storage, and visualization platform. ESIF is the Energy Systems Integration Facility, the laboratory housing NREL's High Performance Computing Center.

The data collected in the pilot were analyzed to evaluate the effectiveness of the advanced inverter functionalities as well as the impact of those functionalities on PV energy production, as described in Section 3. The data were also used to validate, tune, and drive simulation studies described in Section 3.4. 


\section{VROS Updated Simulations}

In this section, we describe the changes made to the simulation platform as well as the results of different high-penetration PV scenarios run on an Oahu $12 \mathrm{kV}$ feeder with different advanced inverter grid-support functions and combinations of exporting versus non-exporting tariffs.

\subsection{PyDSS}

PyDSS is used to run the QSTS simulations on an Oahu $12 \mathrm{kV}$ feeder. PyDSS is a high-level Python interface for OpenDSS built using OpenDSSdirect.py, which is an open-source Python wrapper for the OpenDSS direct DLL interface. PyDSS wraps each element in OpenDSS as an object in Python. Each object has functions that facilitate read-write operations.

Although OpenDSS has numerous control implementations in its internal equipment library (e.g., inverter controller, storage controller), these controller implementations are limited to a few control modes and do not necessarily mimic the behavior of the actual system we are modeling. The OpenDSS storage controller implementation, for example, is not capable of operating in the capacity-firming or base-loading mode that many utility-scale storage systems operate in. The three inverter control algorithms implemented in PyDSS are (1) volt/VAR, (2) volt/Watt and (3) non-exporting controls. The pseudo code for these algorithms is included in Appendix A.

To be able to implement new control modes and ensure that these controls converge to a steadystate solution at each time step, an iterative convergence algorithm has been implemented within the PyDSS architecture. The convergence loop uses the Heavy Ball optimization method to efficiently converge to a steady-state solution. Heavy Ball optimization is a two-step iterative method that uses the state of the previous iteration to maintain momentum in the same direction.

Each new controller implementation is a "pyController" object within PyDSS and controls one or more OpenDSS elements. The architecture implemented allows users to develop their own controllers and add them to the simulation environment using minimal coding effort.

PyDSS converges the controllers of all elements at once using an inner-loop technique, as shown in Figure 5. The convergence of all the PV system controllers at once was an important improvement in the simulation code. Previously for the 2017 VROS study, the inverter controllers programmed externally to OpenDSS were converged one PV system at a time, which greatly penalized (overcurtailed) PV systems that were converged first because they would overcompensate for the rest of the PV systems not providing any voltage support when they entered the control loop. This resulted in a higher curtailment estimate of the "outlier" PV systems which has been updated in this Heavy Ball optimization algorithm. 


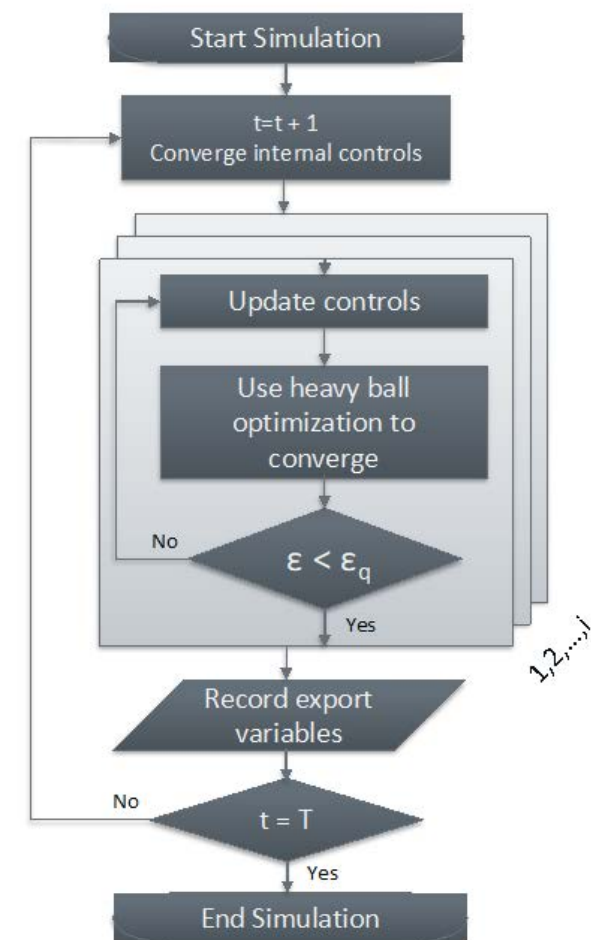

Figure 5. PyDSS simulation flow

The other upgrade that was easily implementable in PyDSS was the disconnection of PV systems (both legacy and advanced) when the voltage at the point of common coupling with the utility grid exceeds 1.1 p.u. Results of this modeling update are shown later in this section.

\subsection{High-Penetration PV Scenarios on a 12 kV Oahu Feeder}

Feeder M34 was selected because of the diversity of the different types of PV installations already existing on a circuit - residential, commercial, and large feed-in-tariff (FIT) projects that are approximately $500 \mathrm{~kW}$ each. For more information on the feeder model preparation for QSTS simulation see (Giraldez, et al., 2017).

\subsubsection{M34 Feeder High-Penetration PV Case and Scenarios}

To create a very high PV penetration case study, all the pending residential (1.8 MW) and FIT (5.2 MW) projects were added to the 2016 baseline as well as an additional 2.3 MW of residential PV customers, totaling 7.1 MW of rooftop PV and $7 \mathrm{MW}$ of FIT PV systems. On this high-penetration case, the scenarios shown in Table 1 were run for a high-voltage week in June and a low-voltage week in April. 
Table 1. Scenario Description for M34 Feeder High-PV Penetration Case

\begin{tabular}{|c|c|c|c|c|c|c|}
\hline $\begin{array}{l}\text { Scenario } \\
\#\end{array}$ & Scenario Name & $\begin{array}{l}\text { Legacy } \\
\text { Exporting }\end{array}$ & $\begin{array}{l}\text { New PV } \\
\text { Exporting }\end{array}$ & $\begin{array}{l}\text { New PV } \\
\text { Non- } \\
\text { Exporting }\end{array}$ & Network & $\begin{array}{l}\text { Inverters } \\
\text { Disconnect } \\
\text { if } V>1.1 \\
\text { p.u. }\end{array}$ \\
\hline 1.a & $\begin{array}{l}100 \% \text { New PV } \\
\text { Exporting-No } \\
\text { Grid-Support } \\
\text { Functions-No } \\
\text { Disconnect }> \\
1.1\end{array}$ & $\begin{array}{l}1.6 \mathrm{MW} \\
\text { rooftop } \\
5.2 \mathrm{MW} \\
\text { FITs }\end{array}$ & $\begin{array}{l}4.1 \mathrm{MW} \text { rooftop } \\
@ \text { power factor }=\end{array}$ & $\mathrm{N} / \mathrm{A}$ & Existing & No \\
\hline 1.b & $\begin{array}{l}100 \% \text { New PV } \\
\text { Exporting-No } \\
\text { Grid-Support } \\
\text { Functions }\end{array}$ & $\begin{array}{l}1.6 \mathrm{MW} \\
\text { rooftop } \\
5.2 \mathrm{MW} \\
\text { FITs }\end{array}$ & $\begin{array}{l}\text { 4.1 MW rooftop } \\
@ \text { power factor }=\end{array}$ & $\mathrm{N} / \mathrm{A}$ & Existing & Yes \\
\hline 2.a & $\begin{array}{l}100 \% \text { New PV } \\
\text { Exporting- } \\
\text { Volt/VAR }\end{array}$ & $\begin{array}{l}1.6 \mathrm{MW} \\
\text { rooftop } \\
5.2 \mathrm{MW} \\
\text { FITs }\end{array}$ & $\begin{array}{l}\text { 4.1 MW rooftop in } \\
\text { volt/VAR }\end{array}$ & $\mathrm{N} / \mathrm{A}$ & Existing & Yes \\
\hline 2.b & $\begin{array}{l}100 \% \text { New PV } \\
\text { Exporting- } \\
\text { Volt/VAR- } \\
\text { Volt/Watt }\end{array}$ & $\begin{array}{l}1.6 \mathrm{MW} \\
\text { rooftop } \\
5.2 \mathrm{MW} \\
\text { FITs }\end{array}$ & $\begin{array}{l}\text { 4.1 MW rooftop in } \\
\text { volt/VAR- } \\
\text { volt/Watt }\end{array}$ & $\mathrm{N} / \mathrm{A}$ & Existing & Yes \\
\hline 3.a & $\begin{array}{l}100 \% \text { New PV } \\
\text { Exporting- } \\
\text { Volt/VAR-With } \\
\text { Secondary } \\
\text { Upgrades }\end{array}$ & $\begin{array}{l}1.6 \mathrm{MW} \\
\text { rooftop } \\
5.2 \mathrm{MW} \\
\text { FITs }\end{array}$ & $\begin{array}{l}4.1 \mathrm{MW} \text { rooftop in } \\
\text { volt/VAR }\end{array}$ & $\mathrm{N} / \mathrm{A}$ & $\begin{array}{l}\text { x31 } \\
\text { secondary } \\
\text { upgrades }\end{array}$ & Yes \\
\hline 3.b & $\begin{array}{l}100 \% \text { New PV } \\
\text { Exporting- } \\
\text { Volt/VAR- } \\
\text { Volt/Watt-With } \\
\text { Secondary } \\
\text { Upgrades }\end{array}$ & $\begin{array}{l}1.6 \mathrm{MW} \\
\text { rooftop } \\
5.2 \mathrm{MW} \\
\text { FITs }\end{array}$ & $\begin{array}{l}\text { 4.1 MW rooftop in } \\
\text { volt/VAR- } \\
\text { volt/Watt }\end{array}$ & $\mathrm{N} / \mathrm{A}$ & $\begin{array}{l}\text { x31 } \\
\text { secondary } \\
\text { upgrades }\end{array}$ & Yes \\
\hline 4 & $\begin{array}{l}70 \% \text { New PV } \\
\text { Exporting- } \\
\text { Volt/VAR and } \\
30 \% \text { New PV } \\
\text { Non-exporting }\end{array}$ & $\begin{array}{l}1.6 \mathrm{MW} \\
\text { rooftop } \\
5.2 \mathrm{MW} \\
\text { FITs }\end{array}$ & $\begin{array}{l}2.5 \mathrm{MW} \text { rooftop in } \\
\text { volt/VAR }\end{array}$ & $\begin{array}{l}1.6 \mathrm{MW} \\
@ \text { power } \\
\text { factor = 1 }\end{array}$ & Existing & Yes \\
\hline
\end{tabular}

Scenarios 1.a and 1.b are not expected to occur in the future since volt/VAR is a requirement for interconnection of any new PV system in Hawai'i since October 2017, but they are run to establish a baseline for PV production without advanced inverter functions. By estimating the production of individual PV systems without advanced inverter functionality, the curtailment metrics can be calculated. 
Scenarios 2.a is run to show the effectiveness and impact to energy production of enabling volt/VAR in all new residential PV systems added to create the high-penetration PV case, and can be compared to scenario 2.b which models blanket activation of volt/VAR-volt/Watt in all new residential PV systems. Comparing scenarios 2.a and 2.b will provide insight into how much the volt/Watt function is activated when implemented in combination with volt/VAR.

The difference between scenarios 3.a and 3.b and scenarios 2.a and 2.b is that in the former there are upgrades to the distribution feeder infrastructure. The upgrades are identified by a thermal violation of the aggregated PV connected to a distribution service tranformer exceeding $200 \%$ of the kVA size of the transformer ${ }^{7}$. Comparing scenarios 3.a and 3.b with scenarios 2.a and 2.b respectively will show how infrastructure upgrades can mitigate high volatge issues.

Finally, in scenario 4 we explore the impact of having $30 \%$ of new residential PV systems configured as non-exporting systems to create the high-penetration PV, and the remaining $70 \%$ of new PV systems are exporting with volt/VAR enabled. The 30 to 70 ratio split between nonexporting and exporting systems was selected by NREL to represent one possible future scenario including a significant number of non-exporting systems. Scenario 4 can be compared to scenario 2.a, in which all new PV systems are exporting and in volt/VAR mode.

\subsection{Metrics}

The metrics computed are related to the impact of a given grid-support function control on residential customers:

- Max grid-support function curtailment: maximum customer energy curtailed for a given time period

- Average grid-support function curtailment: average customer energy curtailed for a given time period

- Average increased generation: average customer increased energy generation for a given time period because of reduced PV inverter disconnections for voltages above 1.1 p.u. (With volt/Watt activated, some PV systems continue to produce when they otherwise would have been disconnected at 1.1 p.u.)

- Average net generation change: Average customer increased generation minus average grid-support function curtailment for a given time period. A positive value represents a net increase in PV generation.

The voltage profiles for all customers are plotted across time for these scenarios using the following convention:

- The dotted line shows the maximum and minimum customer voltage profile.

- The solid line shows the $90^{\text {th }}$ percentile customer voltage.

- The dashed line shows the median customer voltage.

\footnotetext{
${ }^{7}$ The $200 \%$ percentage ratio of aggregated PV to kVA size of the transformer was chosen by NREL for identifying upgrades. Hawaiian Electric currently uses 166\% in the technical subcreens.
} 


\subsection{VROS Updated Simulation Results}

In this section, we present the metrics and voltage profiles for the scenarios described in Table 1 for the M34 feeder high-PV penetration case.

\subsubsection{Disconnect Versus Nondisconnect Above 1.1 p.u. Voltage}

In the VROS 2017 report, PV systems did not disconnect in the QSTS simulations when voltages were above 1.1 p.u. Inverters in the field disconnect if they sense voltage above 1.1 p.u., per the IEEE 1547 standard. Implementing this in the simulation is important to more accurately characterize the curtailment to customers with grid-support functions as well as to quantify the increased generation benefit due to inverters no longer tripping offline above 1.1 p.u. voltage.

Figure 6 and Figure 7 show the voltage envelops for customers in the M34 feeder for scenarios 1.a with disconnection (right plot) and 1.b without disconnection (left plot) of inverters above 1.1 p.u. voltage for a high-voltage week in June and a low-voltage week in April, respectively. Most loads in the M34 feeder in the baseline high-PV penetration scenarios with all exporting PV connected at unity power factor are within the no voltage control region ( 0.97 p.u. to 1.03 p.u.) and the volt/VAR voltage control region (1.03 p.u. to 1.06 p.u.). A subset of customers is between the $90^{\text {th }}$ percentile and the maximum customer voltage that are in the volt/Watt region (>1.06 p.u.), and this subset would have been disconnected in the field because customer voltages would have been above 1.1 p.u.

\subsubsection{Volt/VAR and Volt/VAR-Volt/Watt on New PV and Current Network}

Figure 8 and Figure 9 show customer voltage envelops for scenarios 2.a "100\% New PV Exporting —Volt/VAR" and 2.b "100\% New PV Exporting—Volt/VAR-Volt/Watt" for a highvoltage week in June and a low-voltage week in April, respectively ${ }^{8}$. The left plots show that volt/VAR is very effective at reducing overall customer voltages when compared to the plots in Figure 6 and Figure 7, and the right plots show that volt/Watt is more significantly activated only in a small subset of customer outliers. Note that volt/VAR in combination with volt/Watt does not always converge into lower voltages for the highest voltage customer (dotted line).

The curtailment histograms shown in Figure 10 for the April (left) and June (right) weeks, respectively, compare customer weekly curtailment percentages between 2.a (volt/VAR on the new PV) versus 2.b (volt/VAR-volt/Watt on the new PV). The number of customers that would experience significant activation of volt/Watt in the very high PV penetration case simulated is very low (less than 10 out of a total 531 systems), and the average curtailment, represented by the dashed vertical lines, is less than $0.5 \%$ per customer for both volt/VAR and the volt/VARvolt/Watt scenarios.

\footnotetext{
${ }^{8}$ Note that the voltage profile plots show voltages for all loads (with and without PV, and legacy and advanced PV systems), and as such, the customer experiencing the highest voltage profile (dotted line) may not be an advanced PV system.
} 

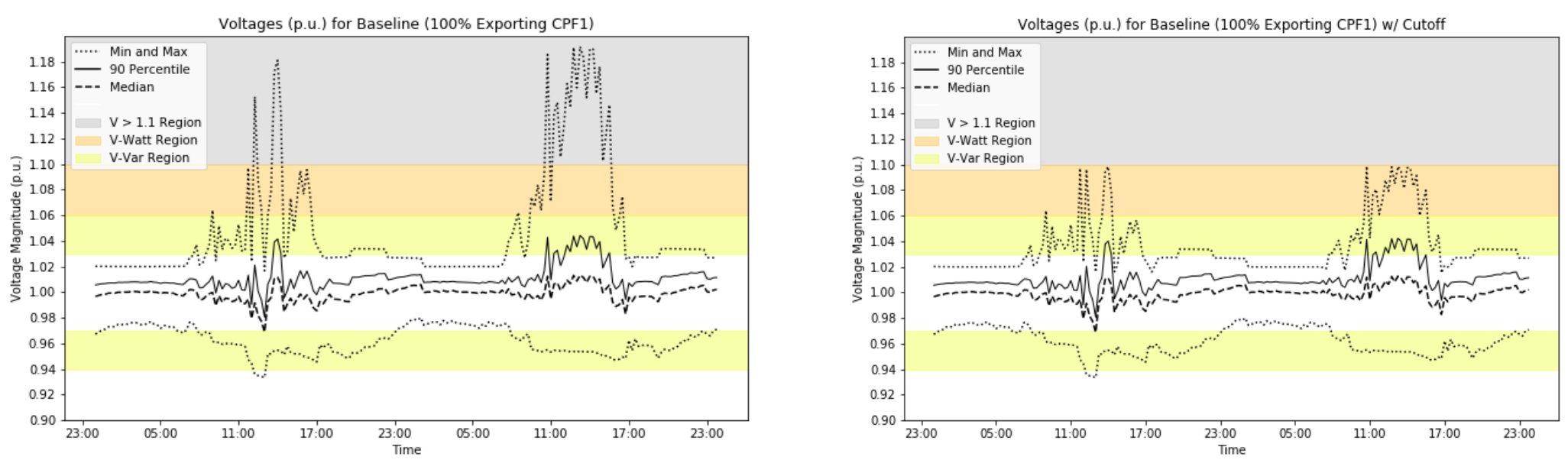

Figure 6. Voltage envelops for all loads in the M34 feeder for scenarios 1.a without disconnection (left plot) and 1.b with disconnection (right plot) of inverters above 1.1 p.u. voltage for a high-voltage week in June. "CPF1" indicates that inverters are operating without volt/VAR-volt/Watt enabled.
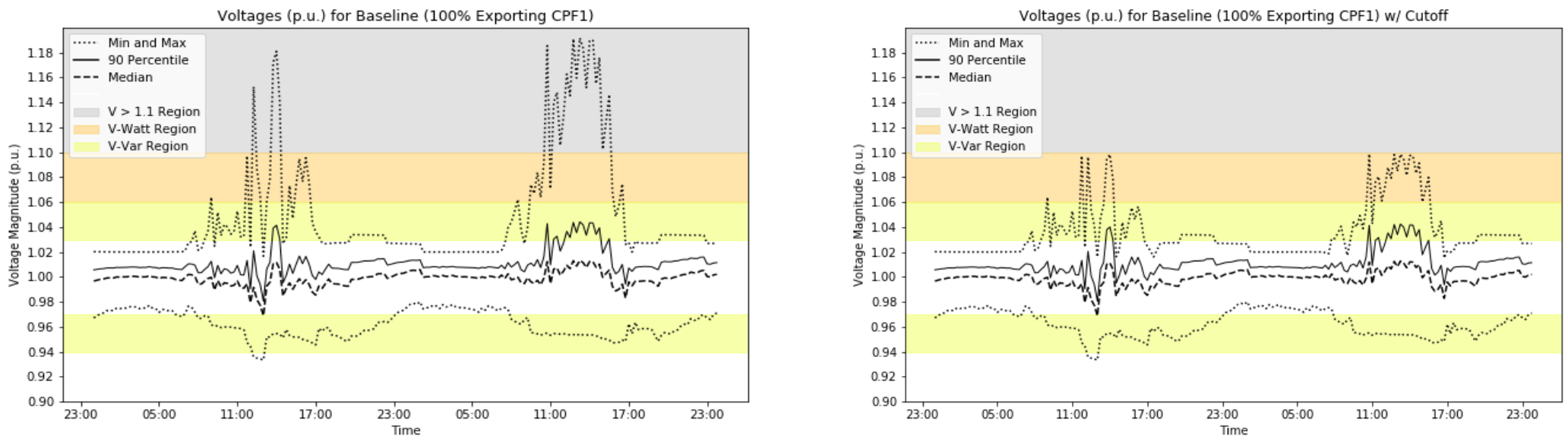

Figure 7. Voltage envelops for all loads in the M34 feeder for scenarios 1.a without disconnection (left plot) and 1.b with disconnection (right plot) of inverters above 1.1 p.u. voltage for a low-voltage week in April 

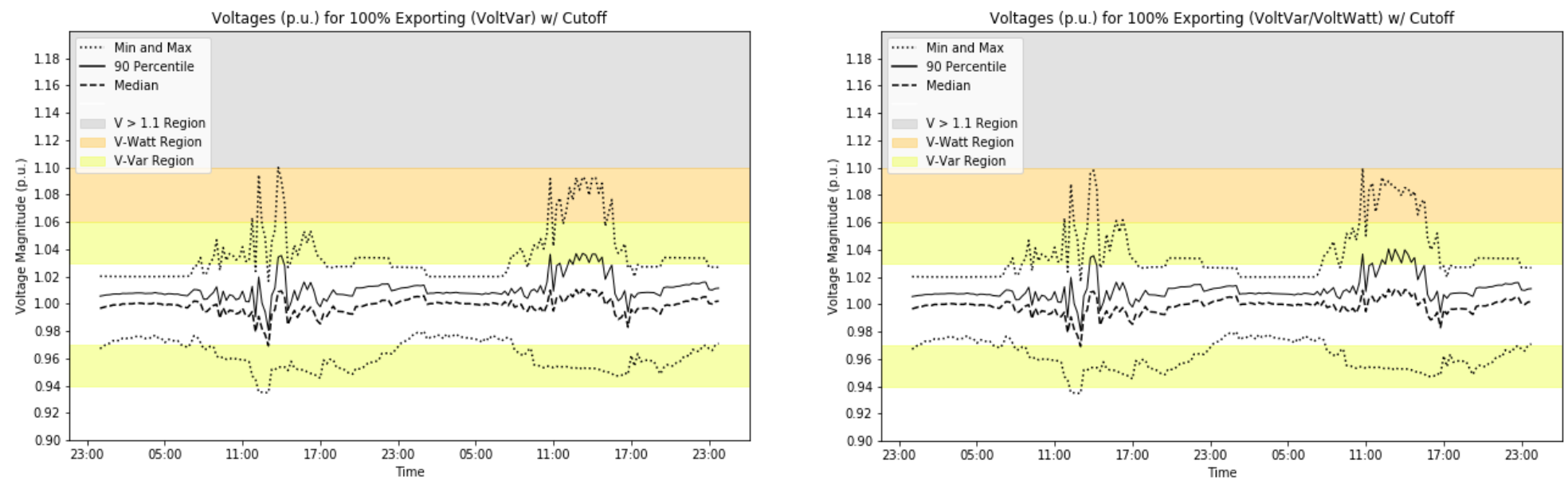

Figure 8. Voltage envelops for all loads in the M34 feeder for scenarios 2.a "100\% New PV Exporting-Volt/VAR" (left) and 2.b "100\% New PV Exporting-Volt/VAR-Volt/Watt" (right) for a high-voltage week in June
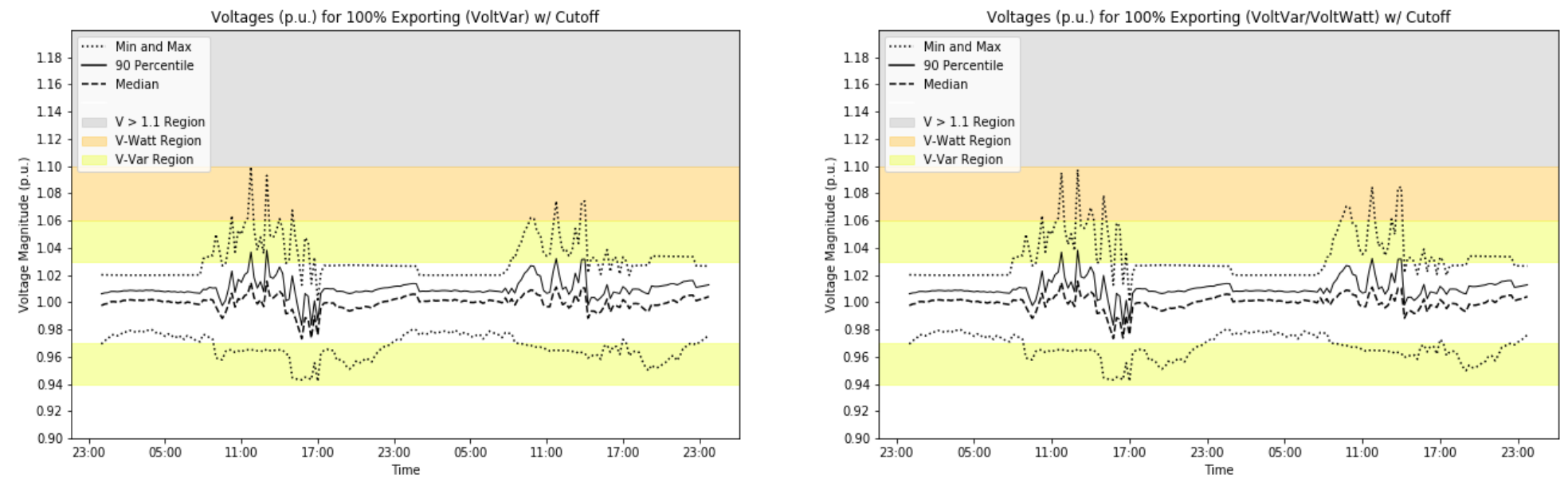

Figure 9. Voltage envelops for all loads in the M34 feeder for scenarios 2.a "100\% New PV Exporting-Volt/VAR" (left) and 2.b "100\% New PV Exporting-Volt/VAR-Volt/Watt" (right) for a low-voltage week in April 

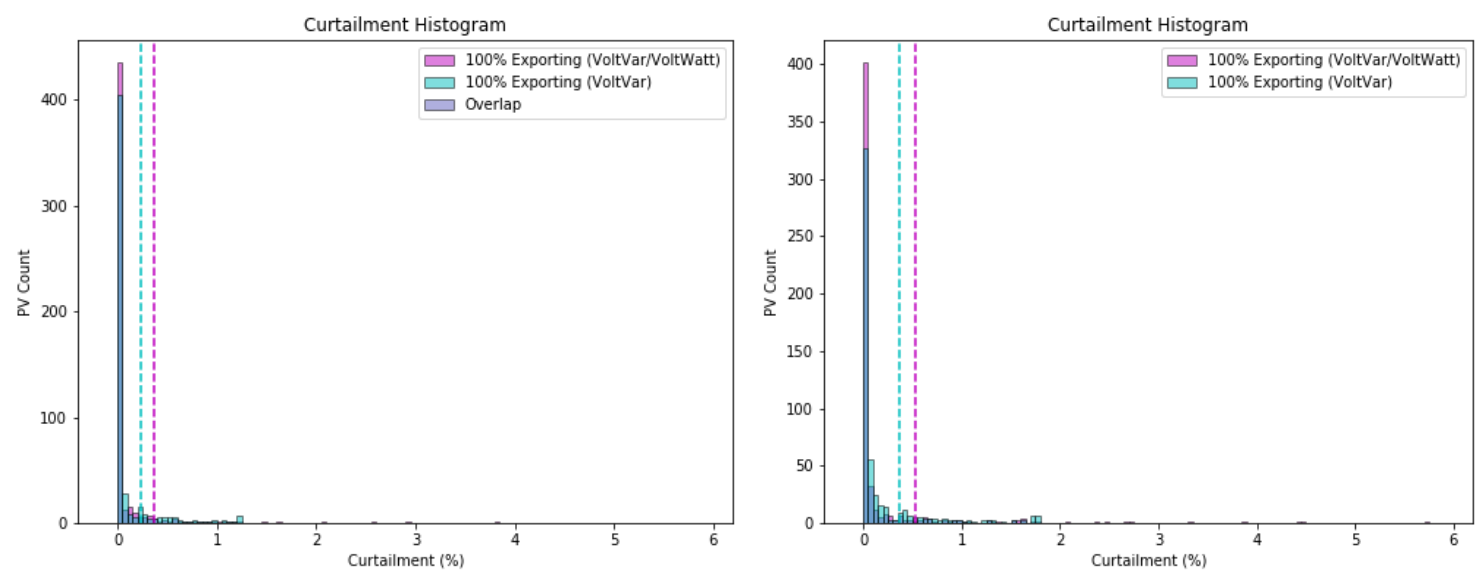

Figure 10. Customer energy percentage curtailment histograms for a low-voltage week in April (left) and a high-voltage week in June (right). Each plot compares customer weekly curtailment percentages between scenarios 2.a (volt/VAR on the new PV in blue) versus 2.b (Volt/VARVolt/Watt on the new PV in pink). The dashed vertical lines represent the average customer curtailment for each scenario.

More than $99 \%$ of the customers in this high-penetration PV case with all PV customers exporting experience energy curtailment of less than $2 \%$ for a high-voltage week. The remaining $1 \%$ of customer outliers for the high-voltage week in June have the following characteristics:

- Overhead secondary

- Total PV kW/transformer kVA > 150\%

- Customer electrical distance from service transformer $>0.09 \mathrm{Ohms}$

- Larger PV systems (average $15 \mathrm{~kW}$ )

- $35 \mathrm{~kW}$ of other PV connected upstream between the customer and the service transformer on the same branch.

The other very important factor of these outlier customers is that they are all connected to supposed secondary circuits that were approximated by NREL (versus secondary circuits provided by Hawaiian Electric) using the following assumption: up to six customers per branch connected 200 feet apart via $1 / 0$ cable (Figure 11). This assumed secondary design for rural customers represents a very high-impedance scenario (customers up to $1200 \mathrm{ft}$ away from the service transformer on $1 / 0$ cable) and does not correspond to the real secondary circuits that may be found in the rural area of the M34 feeder. 


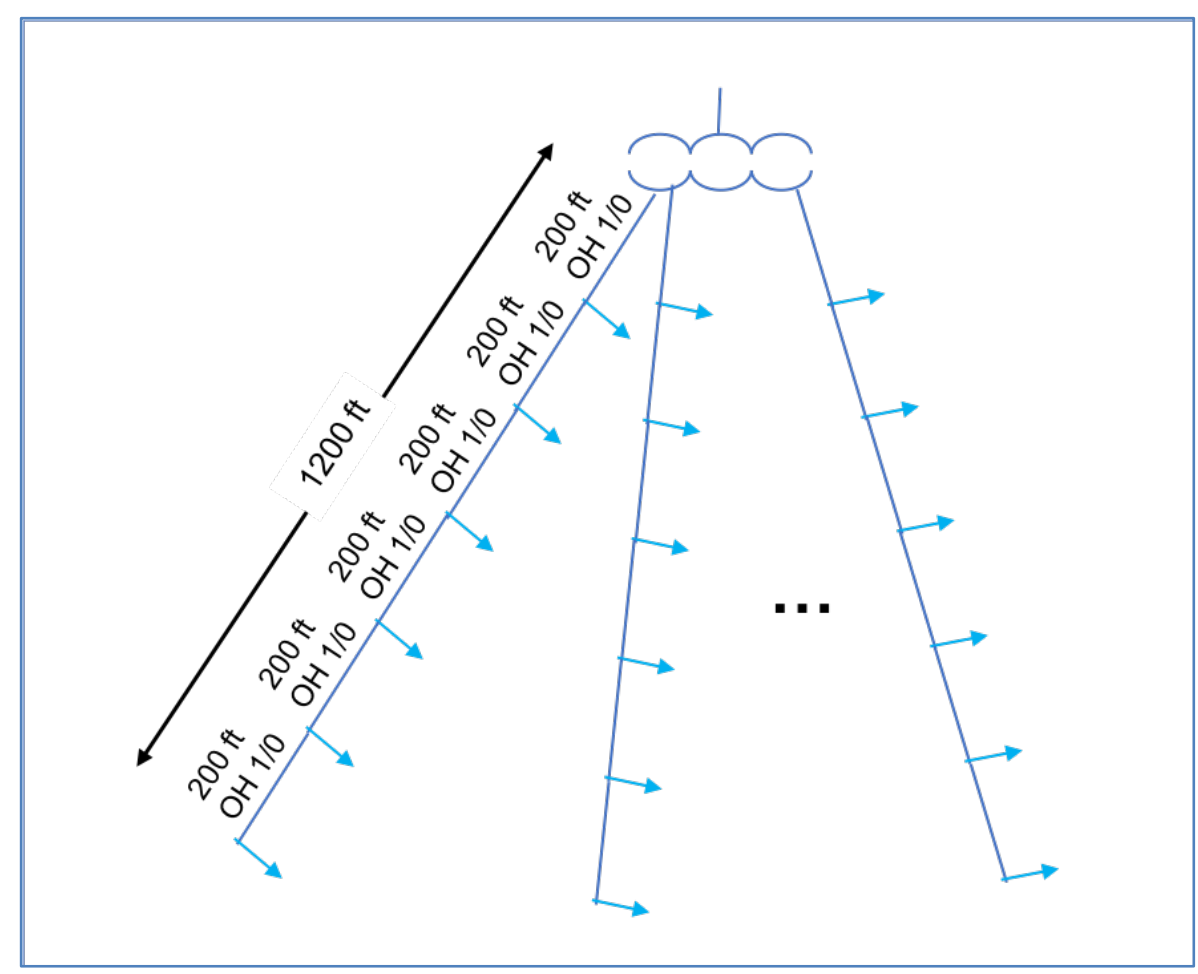

Figure 11. Assumed worst-case secondary design for rural customers in the M34 feeder

The overhead residential suburban customer that experienced the highest weekly energy curtailment of $2 \%$ for the high representative voltage week had the following characteristics:

- $\quad$ Total PV kW/transformer $\mathrm{kVA}>400 \%$

- More than $50 \mathrm{~kW}$ PV connected upstream between the customer and transformer on the same branch

- Customer electrical distance from transformer $>0.16$ Ohms.

The secondary circuit design that the highest overhead residential customer is connected to is shown in Figure 12, and the customer is the one that has highest impedance $(>0.16 \mathrm{Ohms}$, shown in dark red). The secondary circuit was provided by Hawaiian Electric as part of the pool of secondary designs that were used to approximate secondary circuits for feeder M34. For more information on how secondaries were approximated for the M34 feeder, see (Giraldez, et al., 2017). 

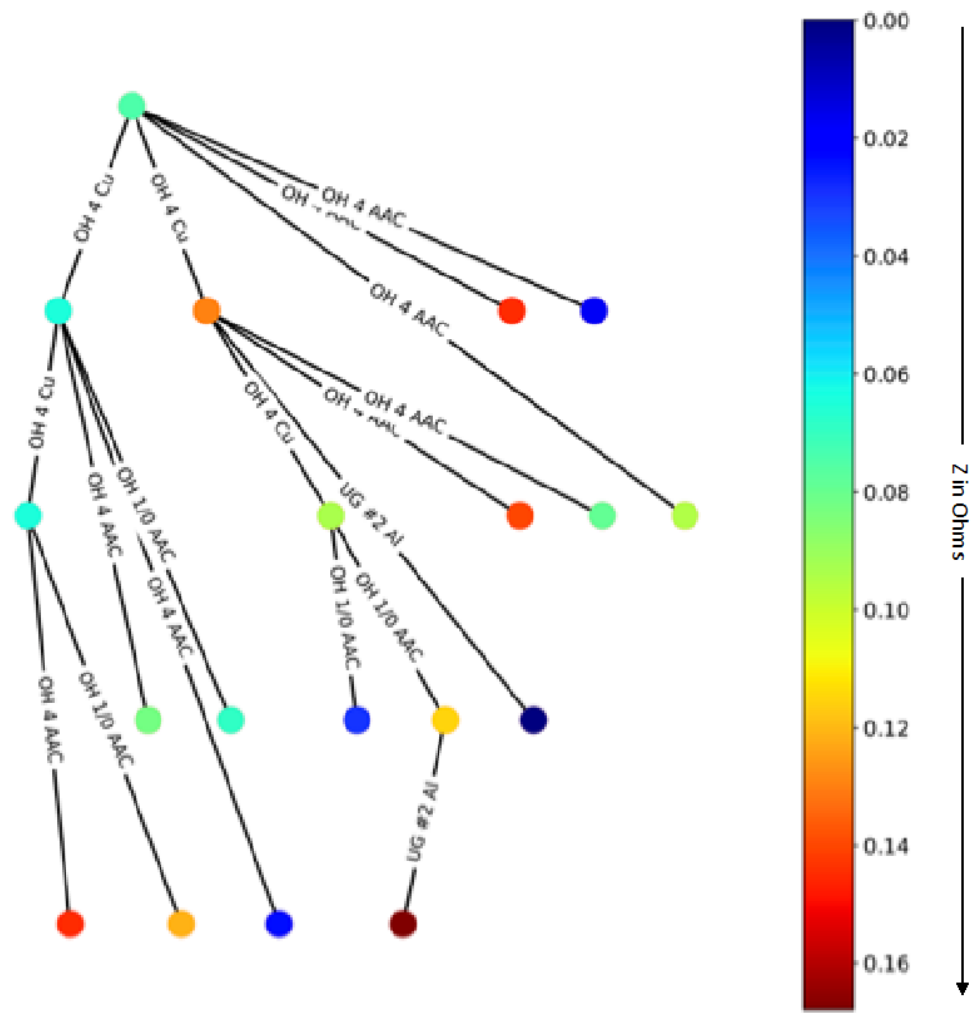

Figure 12. Secondary design for highest curtailed customer (dark red dot) in the M34 feeder

The curtailment metrics for the high- and low-voltage weeks for the M34 feeder are shown in Table 2 . The volt/VAR weekly maximum customer curtailment is $1.79 \%$ for the high-voltage week (June) and $1.24 \%$ or the low-voltage week (April), whereas the average customer curtailment is $0.24 \%$ and $0.14 \%$ for the high- and low-voltage weeks. The increased PV generation during the same time periods from PV production that otherwise would have been lost because of PV systems being disconnected above 1.1 p.u. is $2.68 \%$ and $2.54 \%$, which in both the June and the April high- and low-voltage weeks is higher than the experienced curtailment. As such, more PV generation is enabled than curtailed, which is reflected by the positive average net generation values of $+2.44 \%$ for the week in June and $+2.40 \%$ for the week in April.

The average customer curtailment numbers are very similar in the volt/VAR scenario to the volt/VAR-volt/Watt case. The maximum customer curtailment is higher due to the customer outliers having volt/Watt activated (5.68\% and 3.84\% for the high- and low-voltage weeks, respectively). However, without volt/Watt activated, more generation would have been lost from being disconnected above 1.1 p.u. With volt/Watt active, the average net generation weekly values are greater $(+2.74 \%$ and $+3.03 \%$ for the high- and low-voltage weeks, respectively). 
Table 2. Energy Curtailment and Increased Generation Metrics for Scenarios 2.a " $100 \%$ New PV Exporting-Volt/VAR" and 2.b " $100 \%$ New PV Exporting-Volt/VAR-Volt/Watt" for a high-voltage week in June and a low-voltage week in April

\begin{tabular}{l|lc|lc}
\hline \multirow{2}{*}{ Metrics } & \multicolumn{2}{|l|}{$\begin{array}{l}\text { High-Penetration New } \\
\text { All Exporting } \\
\text { No Upgrades_June }\end{array}$} & \multicolumn{2}{l}{$\begin{array}{l}\text { High-Penetration New } \\
\text { All Exporting } \\
\text { No Upgrades_April }\end{array}$} \\
\cline { 2 - 5 } & Volt/VAR & $\begin{array}{l}\text { Volt/VAR- } \\
\text { Volt/Watt }\end{array}$ & Volt/VAR & \multicolumn{1}{|l}{$\begin{array}{c}\text { Volt/VAR- } \\
\text { Volt/Watt }\end{array}$} \\
\hline $\begin{array}{l}\text { Max Grid-Support } \\
\text { Function Curtailment A }\end{array}$ & $1.79 \%$ & $5.68 \%$ & $1.24 \%$ & $3.84 \%$ \\
$\begin{array}{l}\text { Average Grid-Support } \\
\text { Function Curtailment A }\end{array}$ & $0.24 \%$ & $0.23 \%$ & $0.14 \%$ & $0.13 \%$ \\
$\begin{array}{l}\text { Average Increased } \\
\text { Generation }{ }^{B}\end{array}$ & $2.68 \%$ & $2.97 \%$ & $2.54 \%$ & $3.16 \%$ \\
\hline $\begin{array}{l}\text { Average Net } \\
\text { Generation Change }\end{array}$ & $\mathbf{+ 2 . 4 4 \%}$ & $\mathbf{+ 2 . 7 4 \%}$ & $\mathbf{+ 2 . 4 0 \%}$ & $\mathbf{+ 3 . 0 3 \%}$ \\
\hline
\end{tabular}

Note A: Curtailment values represent PV energy reduction due to the activation of grid support functions,

Note B: Increased PV generation that would have otherwise been disconnected due to systems tripping above 1.1 p.u. per IEEE 1547.

Note C: Positive values represent a net increase in PV generation.

\subsubsection{Volt/VAR and Volt/VAR-Volt/Watt on New PV with Secondary Upgrades}

In this scenario, we identified 31 secondary service transformers (out of a total of 340 distribution transformers) that violated the thermal screening limit of the Total PV kW/Xfmr $\mathrm{kVA}>200 \%$ rule for these 31 locations, and we modeled secondary upgrades. For locations with more than 10 customers, a new transformer was added, and customers were split between the existing and the new transformer. For locations with less than 10 customers, the service transformer capacity only was upgraded.

Figure 13 shows the voltage envelopes for scenarios 2.a "100\% New PV Exporting-Volt/VAR" and 3.a "100\% New PV Exporting-Volt/VAR — With Upgrades". Figure 14 shows the voltage envelopes for scenarios 2.b "100\% New PV Exporting_Volt/VAR-Volt/Watt" and 3.b "100\% New PV Exporting — Volt/VAR-Volt/Watt—With Upgrades”. Both confirm that secondary upgrades solve the high-voltage issues in the nonallowable ANSI Range B region and that all customers are within the volt/VAR voltage control region. 

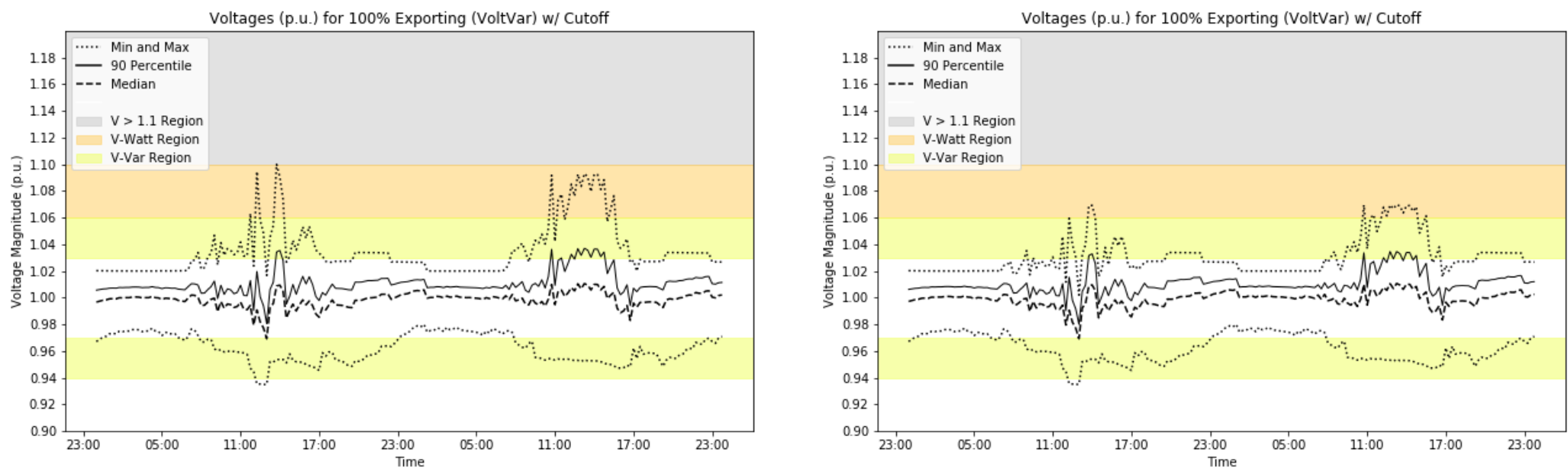

Figure 13. Voltage envelops for all loads in the M34 feeder for scenarios 2.a "100\% New PV Exporting-Volt/VAR" (left) and 3.a "100\% New PV Exporting—Volt/VAR with Secondary Upgrades" (right) for a high-voltage week in June
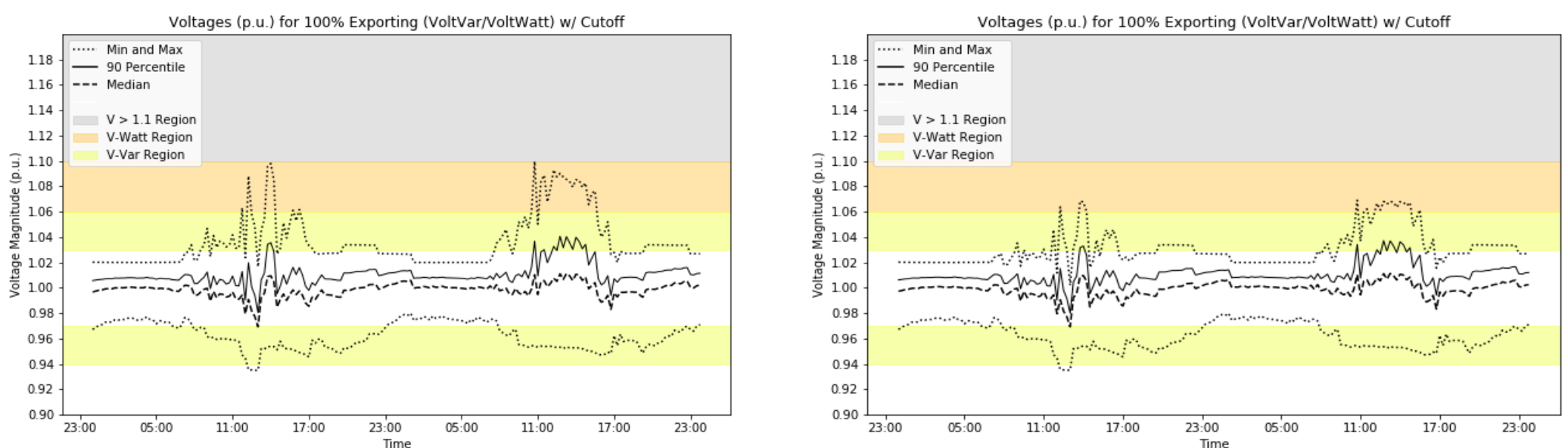

Figure 14. Voltage envelops for all loads in the M34 feeder for scenarios $2 . b$ " $100 \%$ New PV Exporting-Volt/VAR-Volt/Watt" (left) and 3.b " $100 \%$ New PV Exporting-Volt/VAR-Volt/Watt with Secondary Upgrades" (right) for a high-voltage week in June 
Figure 15 shows the customer curtailment histograms with secondary upgrades (right) and without secondary upgrades (left) and shows how the hypothetical customer outliers experiencing increased curtailment from volt/Watt are resolved. Table 3 compares the curtailment metrics for the high-voltage week in June with and without secondary upgrades. Maximum customer curtailment from advanced inverter functions is in the $2.5 \%$ range for the high-voltage week, and there is very little PV generation being disconnected above 1.1 p.u. with secondary upgrades. Note that the baseline with secondary upgrades and no grid support functions has very few voltages above 1.1 p.u., and that is why the average increased generation and net curtailment change values are lower than in the scenarios without upgrades. It may seem counter intuitive that net generation change is lower with secondary upgrades, but since such upgrades maintain voltages within ANSI Range A, there is no increased generation to report because PV systems would have not tripped above 1.1 p.u. in the baseline case with upgrades and no volt/VAR-volt/Watt used to determine the curtailment and increased generation values.
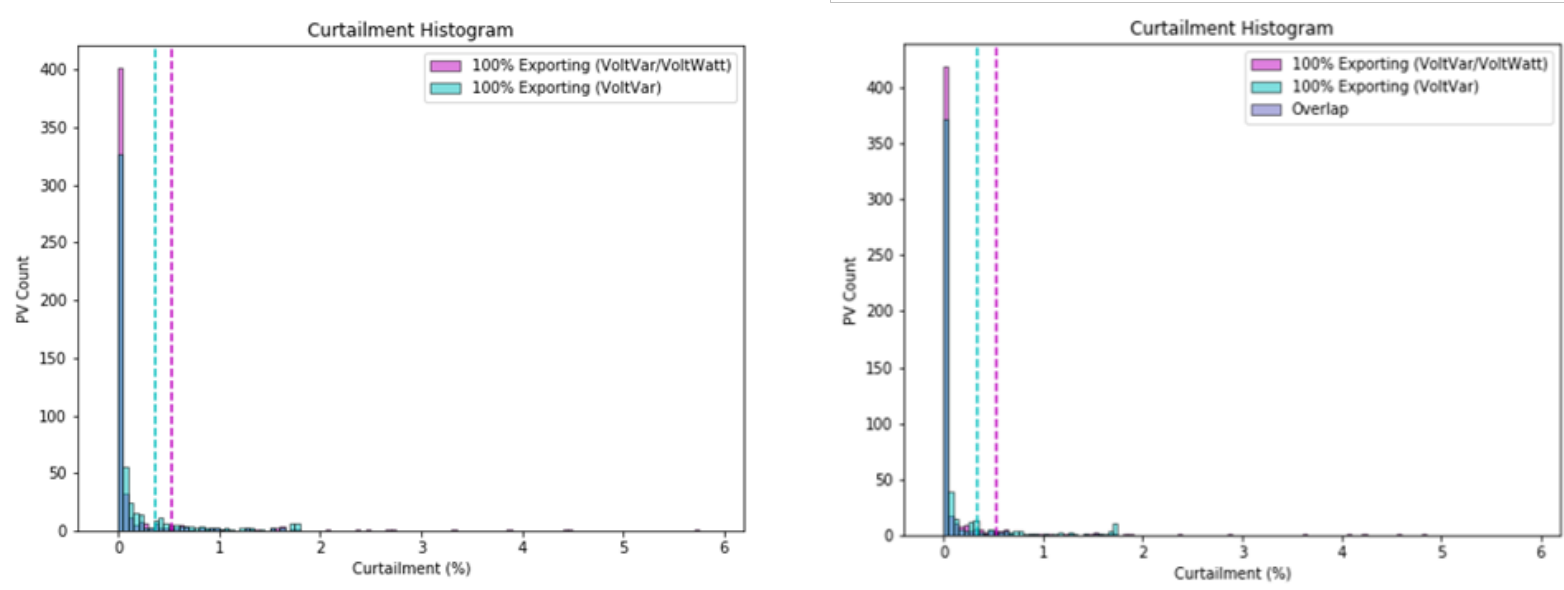

Figure 15. Customer energy percentage curtailment histograms without upgrades (left) and with secondary upgrades (right) for a high-voltage week in June. Each plot compares customer weekly curtailment percentages of volt/VAR on the new PV (in blue) to Volt/VAR-Volt/Watt on new PV (in pink). The dashed vertical lines represent the average customer curtailment for each scenario. 
Table 3: Energy Curtailment and Increased Generation Metrics for Scenario 2.a and Scenario 2.b (No Upgrades) and 3.a and 3.b (with Secondary Upgrades) for a High-Voltage Week in June

\begin{tabular}{|c|c|c|c|c|}
\hline \multirow[t]{2}{*}{ Metrics } & \multicolumn{2}{|c|}{$\begin{array}{l}\text { High-Penetration New } \\
\text { All Exporting } \\
\text { No Secondary Upgrades } \\
\text { High-Voltage Week (June) }\end{array}$} & \multicolumn{2}{|c|}{$\begin{array}{l}\text { High-Penetration New } \\
\text { All Exporting } \\
\text { With Secondary Upgrades } \\
\text { High-Voltage Week (June) }\end{array}$} \\
\hline & Volt/VAR & $\begin{array}{l}\text { Volt/WAR+ } \\
\text { Volt/Watt }\end{array}$ & Volt/VAR & $\begin{array}{l}\text { Volt/WAR+ } \\
\text { Volt/Watt }\end{array}$ \\
\hline $\begin{array}{l}\text { Max Grid-Support } \\
\text { Function Curtailment A }\end{array}$ & $1.79 \%$ & $5.68 \%$ & $1.74 \%$ & $2.57 \%$ \\
\hline $\begin{array}{l}\text { Average Grid-Support } \\
\text { Function Curtailment }{ }^{A}\end{array}$ & $0.24 \%$ & $0.23 \%$ & $0.17 \%$ & $0.13 \%$ \\
\hline $\begin{array}{l}\text { Average Increased } \\
\text { Generation }{ }^{B}\end{array}$ & $2.68 \%$ & $2.97 \%$ & $0.17 \%$ & $0.16 \%$ \\
\hline $\begin{array}{l}\text { Average Net } \\
\text { Generation Change }{ }^{C}\end{array}$ & $+2.44 \%$ & $+2.74 \%$ & $+0.00 \%$ & $+0.04 \%$ \\
\hline
\end{tabular}

Note A: Curtailment values represent PV energy reduction due to the activation of grid support functions,

Note B: Increased PV generation that would have otherwise been disconnected due to systems tripping above 1.1 p.u. per IEEE 1547.

Note C: Positive values represent a net increase in PV generation.

\subsubsection{0\% New PV Exporting with Volt/VAR and 30\% New PV Non-exporting}

In this section, we compare voltages and voltage histograms for Scenario 2.a " $100 \%$ New PV Exporting_Volt/VAR" and Scenario 4 "70\% New PV Exporting_Volt/VAR and 30\% New PV Non-Exporting," which illustrate the impact non-exporting tariffs such as Customer Self-Supply (CSS) and Smart Export have on voltages.

When comparing having 30\% of the new PV being non-exporting systems versus $100 \%$ of the new PV being exporting systems in volt/VAR, overall voltages are lower (Figure 16). This means that voltages are lower for the exporting systems too in Scenario 4 when compared to the same exporting systems in the all-exporting Scenario 2.a. This also results in slight reduction in curtailment to the exporting systems in volt/VAR (Figure 17).

In summary, we know that the current future is a combination of exporting and non-exporting tariffs; as such, energy curtailment from advanced inverters would be expected to be less than in the all-exporting scenarios previously discussed. 


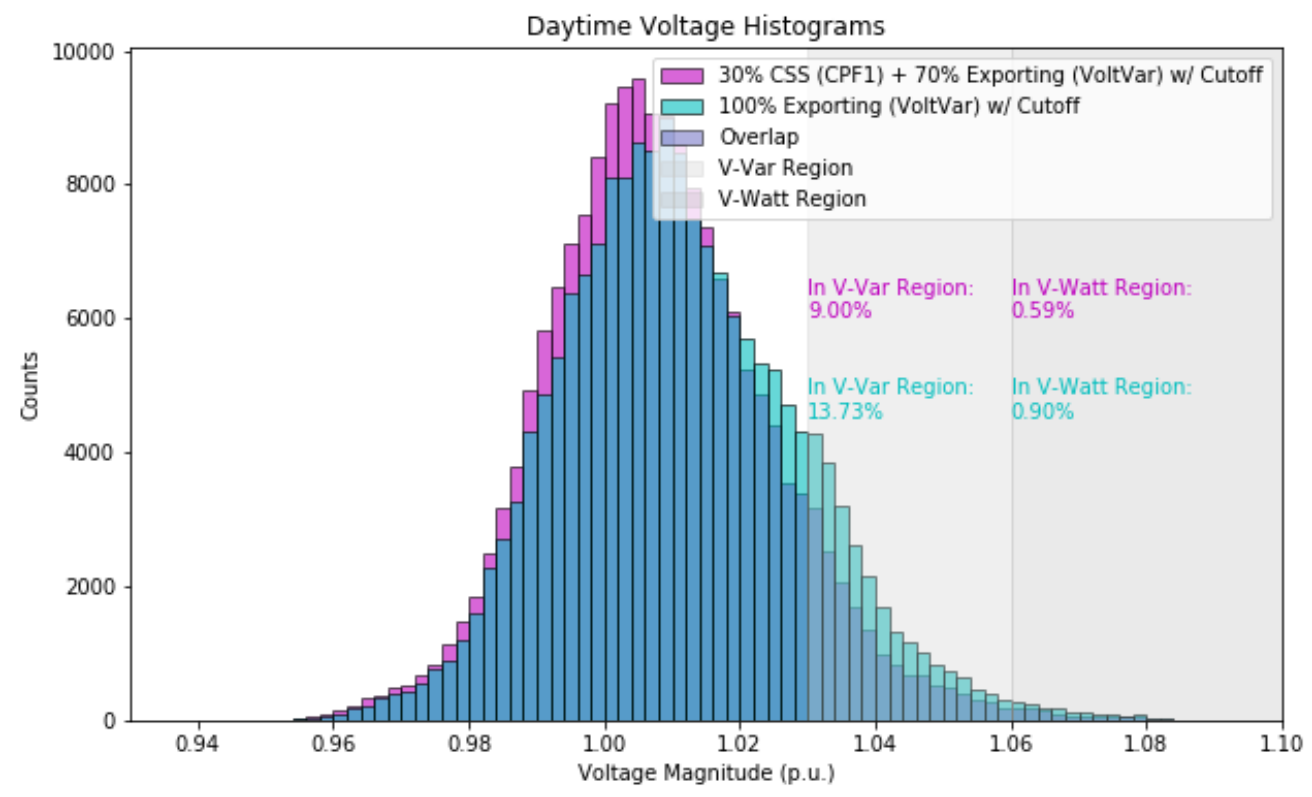

Figure 16. Histogram of voltages for Scenario 2.a "100\% New PV Exporting-Volt/VAR" (in light blue) and Scenario 4 "70\% New PV Exporting—Volt/VAR and 30\% New PV Non-exporting" (in pink)

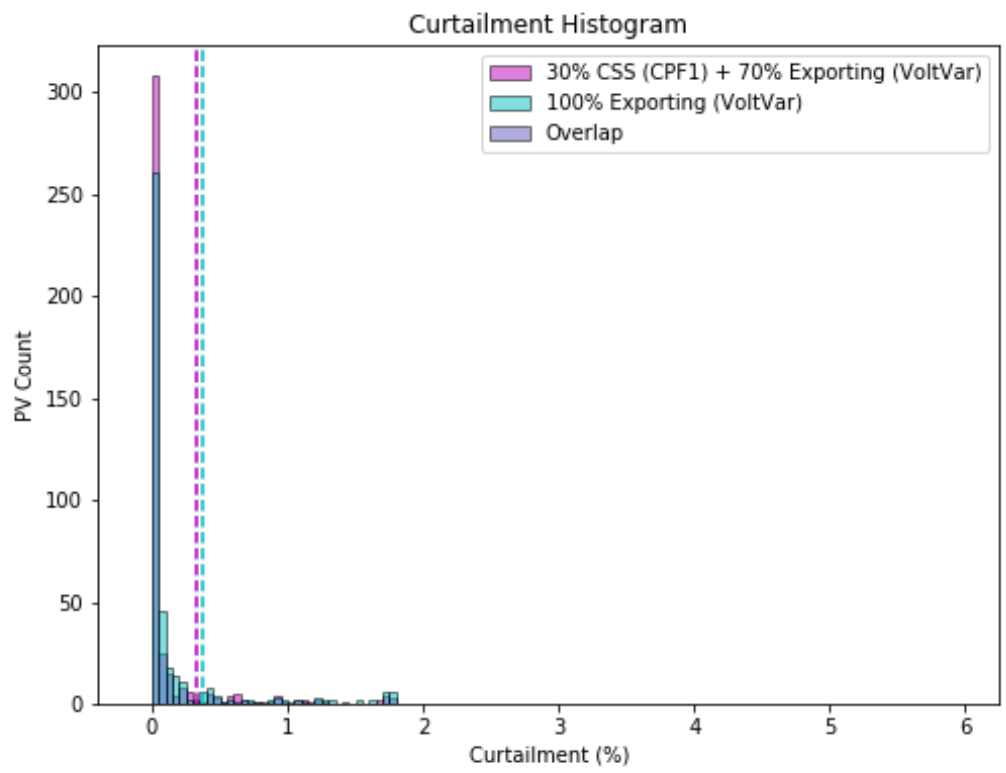

Figure 17. Customer energy curtailment percentages for Scenario 2.a "100\% New PV ExportingVolt/VAR" (in light blue) and Scenario 4 " $70 \%$ New PV Exporting-Volt/VAR and $30 \%$ New PV Nonexporting" (in pink) for a high-voltage week in June. The dashed lines show the average customer energy curtailment. 


\subsubsection{Current Hawaiian Electric Technical Sub-Screens and Recommended NREL Sub-Screens}

Current Hawaiian Electric technical sub-screens for technical review are shown in Table 4 and are the results of a single-fail process based on the following factors depending on the primary feeder voltage level:

- Total number of customers connected to a transformer

- Ratio of total PV in $\mathrm{kW}$ to transformer $\mathrm{kVA}$

- Total exporting PV connected to the transformer

- Customer distance to transformer.

Table 4. Hawaiian Electric Technical Review Sub-screens for PV Interconnection Applications

\begin{tabular}{lllll}
\hline $\begin{array}{l}\text { Hawaiian Electric } \\
\text { Sub-screen }\end{array}$ & $\begin{array}{l}\text { Total \# of } \\
\text { Customers } \\
\text { Connected to a } \\
\text { Xfmr }\end{array}$ & $\begin{array}{l}\text { Total PV } \\
\text { kW/Xfmr kVA }\end{array}$ & Total PV [kW] & $\begin{array}{l}\text { Customer } \\
\text { Distance } \\
\text { to Xfmr [ft] }\end{array}$ \\
\hline $\begin{array}{l}\text { 1. Underground and } \\
12 \mathrm{kV}\end{array}$ & 15 & $>166 \%$ & $\begin{array}{l}>3^{*} \# \text { Cust. or } \\
>45 \mathrm{~kW}\end{array}$ & $\mathrm{NA}$ \\
$\begin{array}{l}2 . \text { Overhead } 12 \mathrm{kV} \text { and } \\
\begin{array}{l}\text { Overhead/Underground } \\
4 \mathrm{kV}\end{array}\end{array}$ & 15 & $>166 \%$ & $>3^{*} \#$ Cust. or & $150 \mathrm{ft}$. \\
\hline
\end{tabular}

Current Hawaiian Electric sub-screens would have identified the hypothetical outlier customers for both thermal and overvoltage violations in the M34 feeder.

Based on the simulation results produced for the hypothetical very high PV penetration case on the 12-kV Oahu feeder, the following technical review sub-screens are proposed and shown in Table 5. The main recommendations compared to current Hawaiian Electric sub-screens are:

- For overhead customers, the total PV connected to the transformer can be relaxed if there is no thermal violation of total PV to transformer size above $150 \%$.

- Include a more detailed sub-screen looking at the amount of PV from other customers directly connected between the customer applicant and the transformer on the same branch.

- The size of the PV system can be important if larger than $9 \mathrm{~kW}$. 
Table 5. VROS Study Sub-screens

\begin{tabular}{lllllll}
\hline $\begin{array}{l}\text { VROS Results } \\
\text { Sub-screen }\end{array}$ & $\begin{array}{l}\text { Total \# of } \\
\text { Customers } \\
\text { Connected } \\
\text { to a Xfmr }\end{array}$ & $\begin{array}{l}\text { Total PV } \\
\mathbf{k W} / \mathbf{X f m r} \mathbf{k V A}\end{array}$ & $\begin{array}{l}\text { Total PV } \\
{[\mathbf{k W}]}\end{array}$ & $\begin{array}{l}\text { Total PV between } \\
\text { Customer and } \\
\text { Xfmr }\end{array}$ & $\begin{array}{l}\text { Electrical } \\
\text { Distance Z } \\
\text { [Ohms] }\end{array}$ & $\begin{array}{l}\text { PV } \\
\text { Size } \\
\text { [kW] }\end{array}$ \\
\hline $\begin{array}{l}\text { 1. Underground } \\
\text { and } 12 \mathrm{kV}\end{array}$ & Up to 16 & NA & NA & NA & NA & NA \\
$\begin{array}{l}\text { 2. Overhead 12 } \\
\text { kV }\end{array}$ & Up to 25 & $>150 \%$ & $>5^{*}$ \#Cust. & $35 \mathrm{~kW}$ & 0.09 Ohms & $>9 \mathrm{~kW}$ \\
\hline
\end{tabular}

In the short term, Hawaiian Electric is working on a business process initiative (BPI) to streamline distributed energy resource interconnections to ensure that customers are not experiencing high-voltage conditions that could impact the performances of their PV systems. The business process will leverage the finding that curtailment is negligible in cases where voltage in inside ANSI C84.1 specification, as shown in Figure 18. Each data point represents a single customer's weekly energy curtailment for a high-voltage week in June, plotted as a function of that customer's maximum voltage for the week. The Volt/VAR curtailment function increases with the maximum voltage for voltages in the volt/VAR region (1.03 to 1.06 p.u.), and then plateaus at higher voltages since the 0.44 p.u. reactive power limit of the volt/VAR curve is reached. Curtailment due to volt/VAR-volt/Watt however is overall lower for the majority of the customers, and the trend is more asymptotic than linear in the voltage control region. Note that there are customers that do not fall on the curves (low right portion) since they were not producing power during a significant amount of time in the baseline scenario with no advanced inverter functions because of voltages being higher than 1.1 p.u.; there is no curtailment associated to time-steps that were disconnected in the baseline case. 


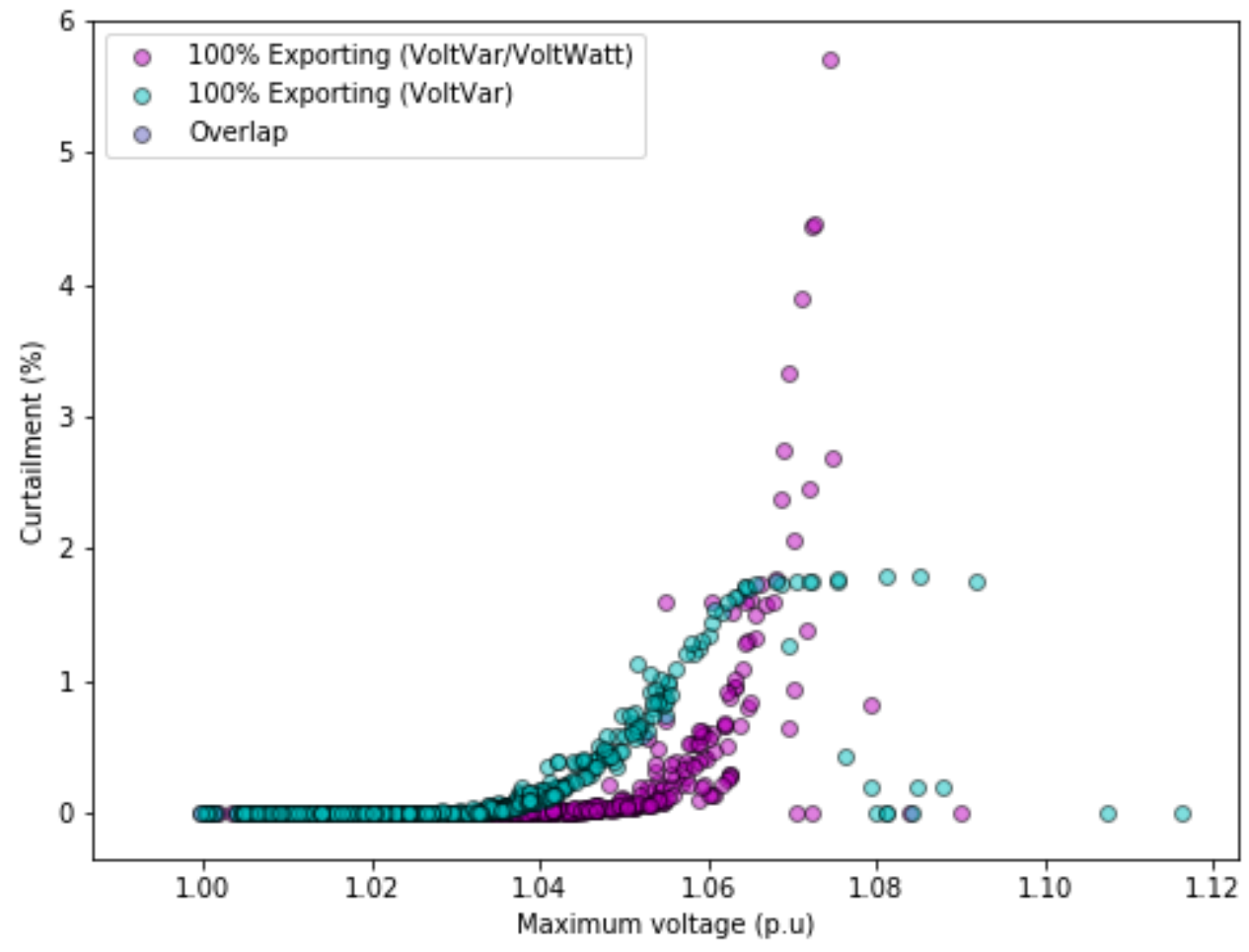

Figure 18. Customer energy curtailment percentages as a function of weekly maximum customer voltage for a high-voltage week in June. 


\section{Advanced Inverter Pilot Results}

\subsection{Behind-the-Meter Voltage Rise}

Because inverters typically respond to the voltage at their terminals when performing functions such as volt/VAR and volt/Watt control, any voltage change between the utility meter and the inverter can have a significant impact on inverter output. (Inverters are permitted by IEEE 15472018 to use the meter voltage for volt/Watt control (IEEE, 2018), and in some circumstances also for volt/VAR control, but most manufacturers have not yet widely deployed this capability. This capability may be considered as technology and test standards mature. ${ }^{9}$ ) The field data from this pilot project were used to quantify and analyze behind-the-meter voltage rise, shown as $\Delta V_{b t m}$ in Figure 19.

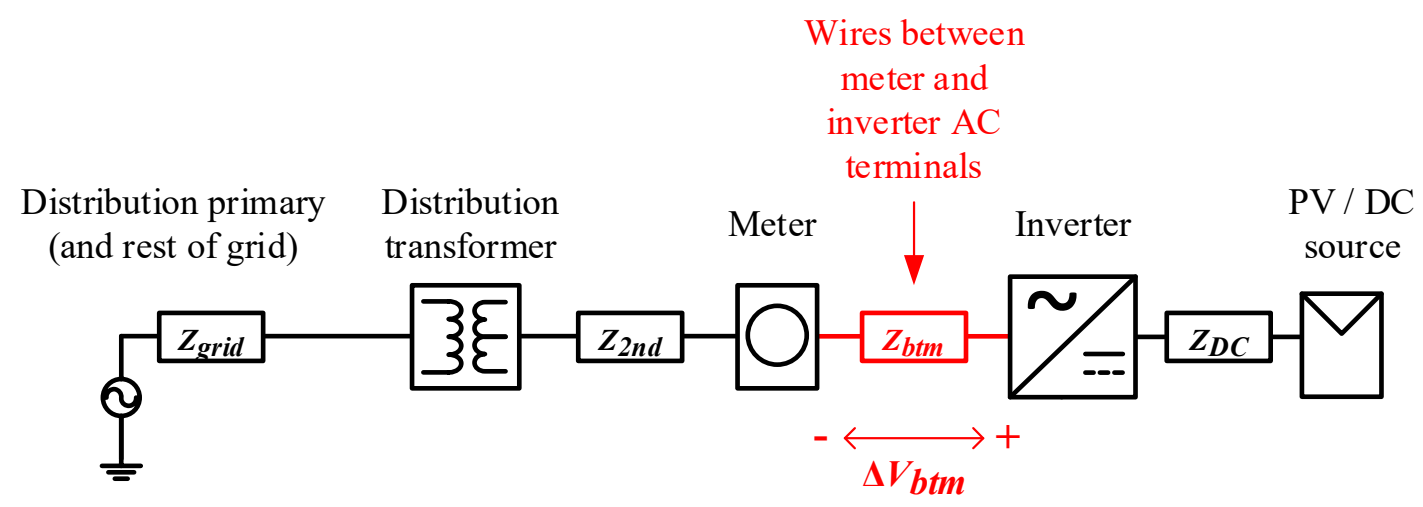

Figure 19. Behind-the-meter voltage rise is one of several factors affecting inverter terminal voltage and system losses.

It is good PV installation practice to limit behind-the-meter voltage rise because it directly results in lost energy production (even in the absence of grid-support functions). This can be achieved by taking into account voltage drop when sizing conductors and using larger conductors, if necessary. However, even a relatively small amount of behind-the-meter voltage rise can have an impact because volt/VAR and volt/Watt operate over narrow voltage bands, as illustrated in Figure 20.

\footnotetext{
${ }^{9}$ Performing volt/VAR or volt/Watt control using a voltage reference point remote from the inverter can be done using a remote voltage sensor, similar to the way compliance with non-export tariffs is done using a remote power (or current) sensor. In many cases it could also be done using an estimate of impedance between the inverter location and the remote reference point, assuming other local loads or generation are not connected in a way that would significantly affect voltage rise along the conductors interconnecting the inverter to the remote reference point. Other methods may also be possible.
} 

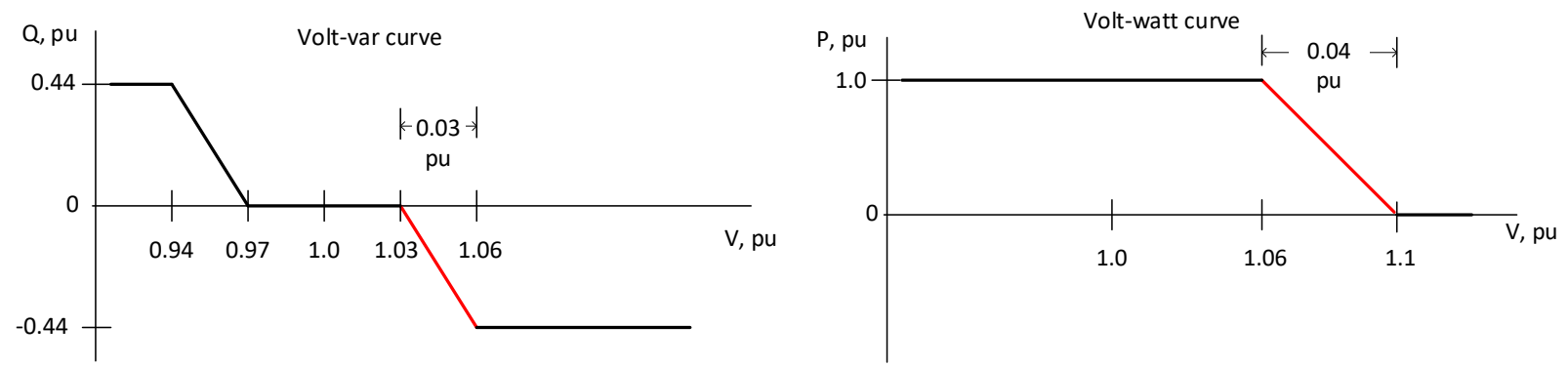

Figure 20 . Voltage differences as small as $2 \%$ can have a significant impact on volt/VAR and volt/Watt performance because the entire sloping regions of the curves cover $3 \%$ or $4 \%$ of nominal voltage. Pictured here are Hawaiian Electric's approved volt/VAR curve and optional volt/Watt curve.

Figure 21 compares meter voltage (orange) and inverter voltage (blue) for a string inverter pilot customer during 2 mostly sunny days. There is approximately $1 \mathrm{~V}$ of behind-the-meter voltage rise, or $0.4 \%$ of the nominal voltage of $240 \mathrm{~V}$.

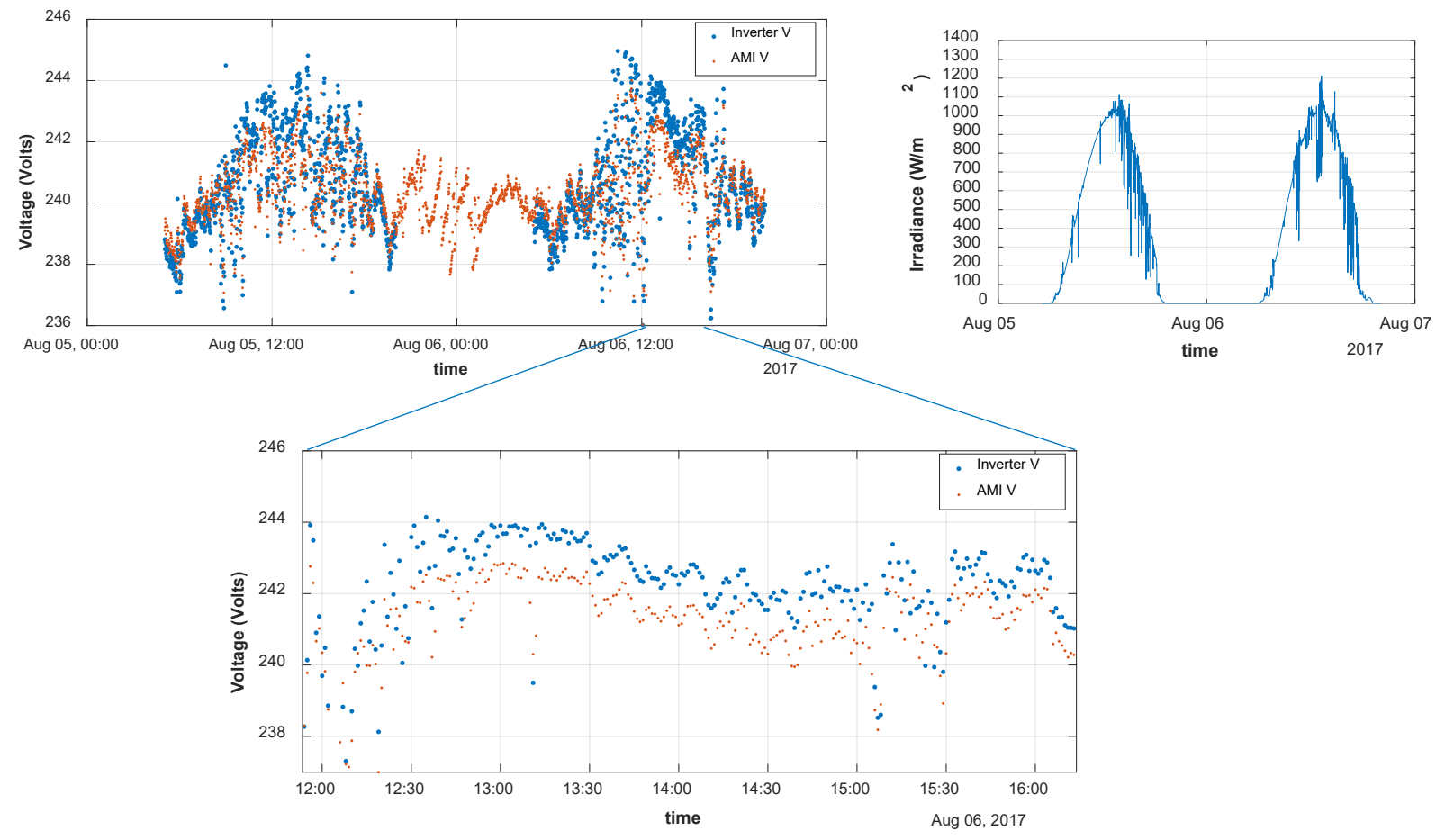

Figure 21. Voltage differences as small as $2 \%$ can have a significant impact on volt/VAR and volt/Watt performance.

Figure 22 plots behind-the-meter voltage rise for all string inverter systems in the pilot as a function of measured inverter power. Data from each system are shown in a different color. A significant amount of noise is visible in the data. As expected, voltage rise is near zero when inverter power is near zero: when there is little current flowing between the inverter and the meter, there should be little voltage difference. This also confirms that inverter voltage measurements are typically reasonably accurate relative to utility meter measurements, even 
though there is no accuracy requirement for inverter voltage measurements prior to IEEE 15472018 adoption. ${ }^{10}$

For most PV systems in Figure 22, a vertical band is visible in the data near the inverter's power rating because of significant time spent operating near maximum power; most of these PV systems have DC:AC power ratios around 1.1 to 1.3, so the inverter is the limiting factor on energy production during peak solar production hours. Behind-the-meter voltage rise typically peaks around 1 to $1.5 \mathrm{~V}$, or $0.4 \%$ to $0.6 \%$. This is a reasonable amount of voltage rise indicative of properly sized AC conductors.

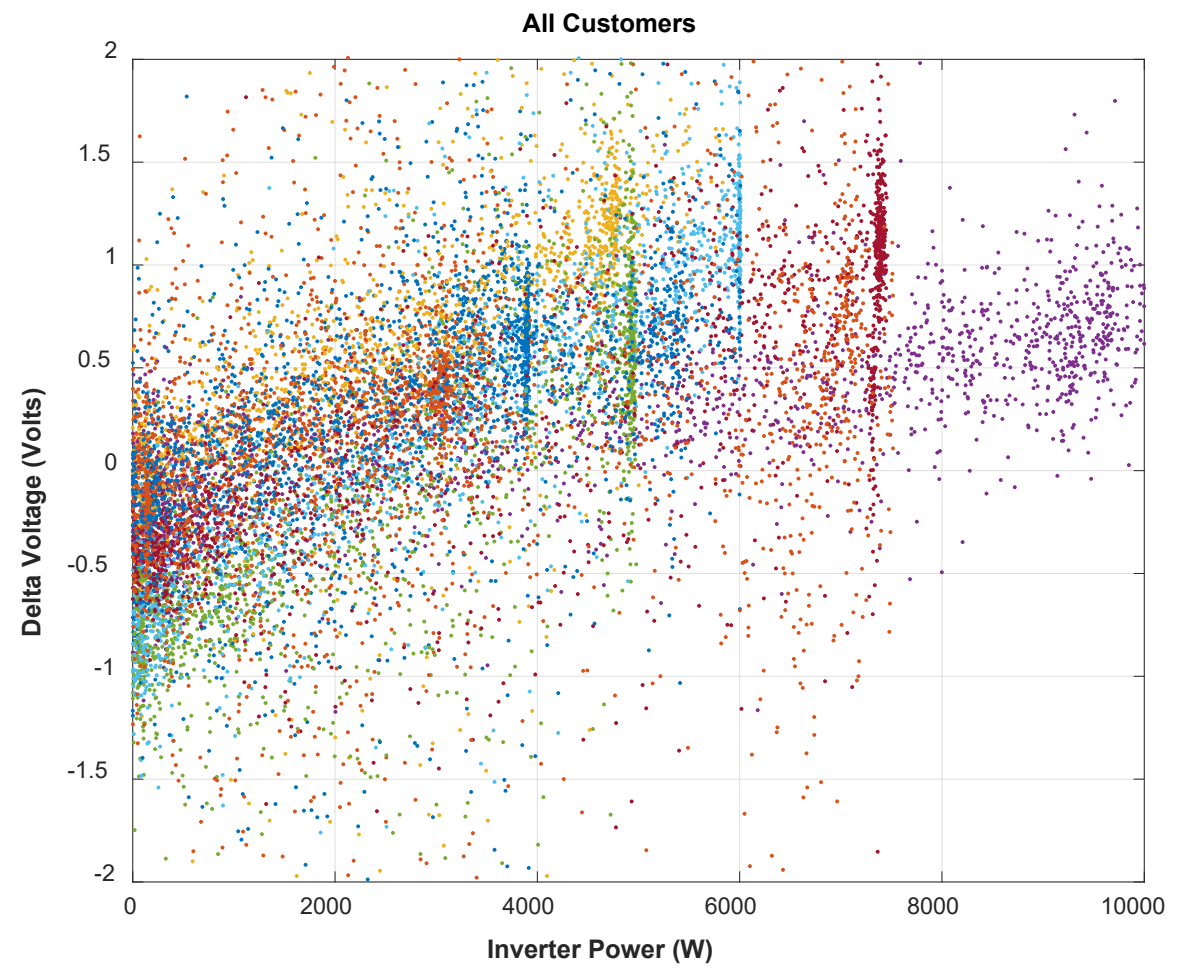

Figure 22. Behind-the-meter voltage rise for all string inverter customers as a function of inverter output power

Behind-the-meter voltage rise for the string inverter system with the greatest voltage rise is shown in Figure 23. Note that when inverter current is zero, voltage rise is reported as $-0.8 \mathrm{~V}$, meaning that the reported inverter voltage is less than the meter voltage. Occasional instances of inverter voltage being less than meter voltage could be explained by load current draw (depending on the house wiring configuration). However, because the inverter voltage is systematically low, and because the plot of voltage rise versus current is relatively linear, loads are likely playing little to no part (as would be expected if the inverter is directly connected to a main load panel that is close to the meter, which is often the case). Therefore, it appears that this

${ }^{10}$ IEEE 1547-2018 requires voltage measurement accuracy for DERs be $1 \%$ or better. 
inverter tends to measure voltage about $0.8 \mathrm{~V}$ low compared to the meter. Accounting for this, the peak voltage rise at this location is about $2 \mathrm{~V}(0.8 \%)$ when the inverter is at full output.

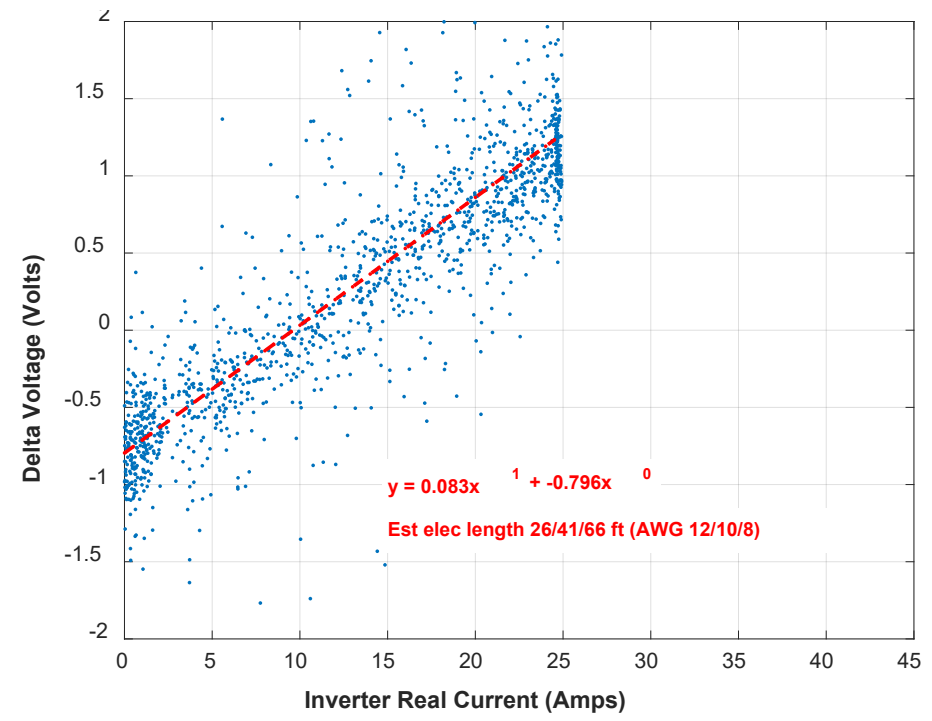

Figure 23. Behind-the-meter voltage rise as a function of inverter current for the string inverter system with the highest behind-the-meter voltage rise

In the case of microinverters (as typically operated today), each microinverter responds to its own local voltage, which differs slightly from the local voltages of other microinverters in the system due to small mismatches between sensors and small impedances between inverters (Nelson, et al., 2016). In addition, microinverters are located directly underneath each PV module (i.e., on the roof), so wire lengths between the inverters and the meter tend to be longer than for string inverters. (In a string inverter system with the inverter near the meter, this wire length conducts DC current, so any voltage rise contributes to losses but does not affect AC inverter terminal voltage.)

Behind-the-meter voltage rise for an example microinverter system is pictured in Figure 24. AMI meter voltage is shown in green, and each microinverter's voltage is separately shown in other colors. There is an approximate $2 \mathrm{~V}$ rise to the first inverter and an additional $4 \mathrm{~V}$ rise to the last inverter. The effect of behind-the-meter voltage rise is best quantified by using the average of all inverters at $4 \mathrm{~V}$ or $1.7 \%$. 

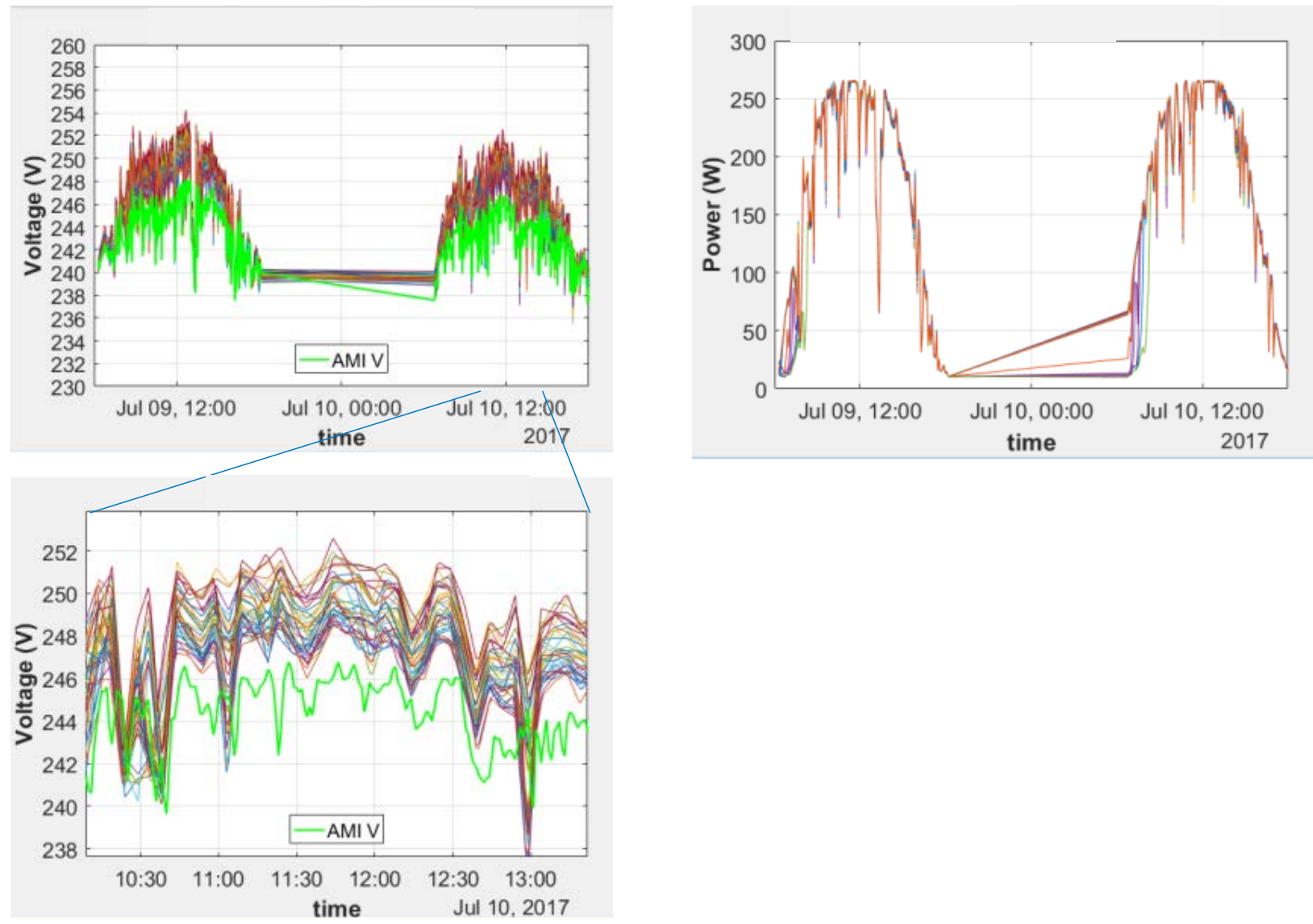

Figure 24. Behind-the-meter voltage rise during 2 mostly sunny days for an example microinverter system. Meter voltage is shown in green, and each inverter's reported voltage is plotted separately in other colors.

Behind-the-meter voltage rise as a function of inverter current for the microinverter system with the highest voltage rise is pictured in Figure 25. Dots represent individual data points, and turquoise lines are linear regression fits for each individual microinverter. The regression lines clearly fall into two groups with similar slopes. Each group represents a separate subarray in a separate roof location. The group with the lower slope peaks at about $2 \mathrm{~V}$ of rise $(0.8 \%)$ when averaged across all inverters in the group. The group with the higher slope peaks at about $5 \mathrm{~V}$ of rise $(2.1 \%)$ averaged across the group, likely because of a longer AC wire run. It appears that the $\mathrm{AC}$ conductors connecting the later group to the main panel are undersized from a voltage drop/loss perspective. This will increase resistive losses and will cause the inverters' volt/VAR and volt/Watt responses to be amplified. 


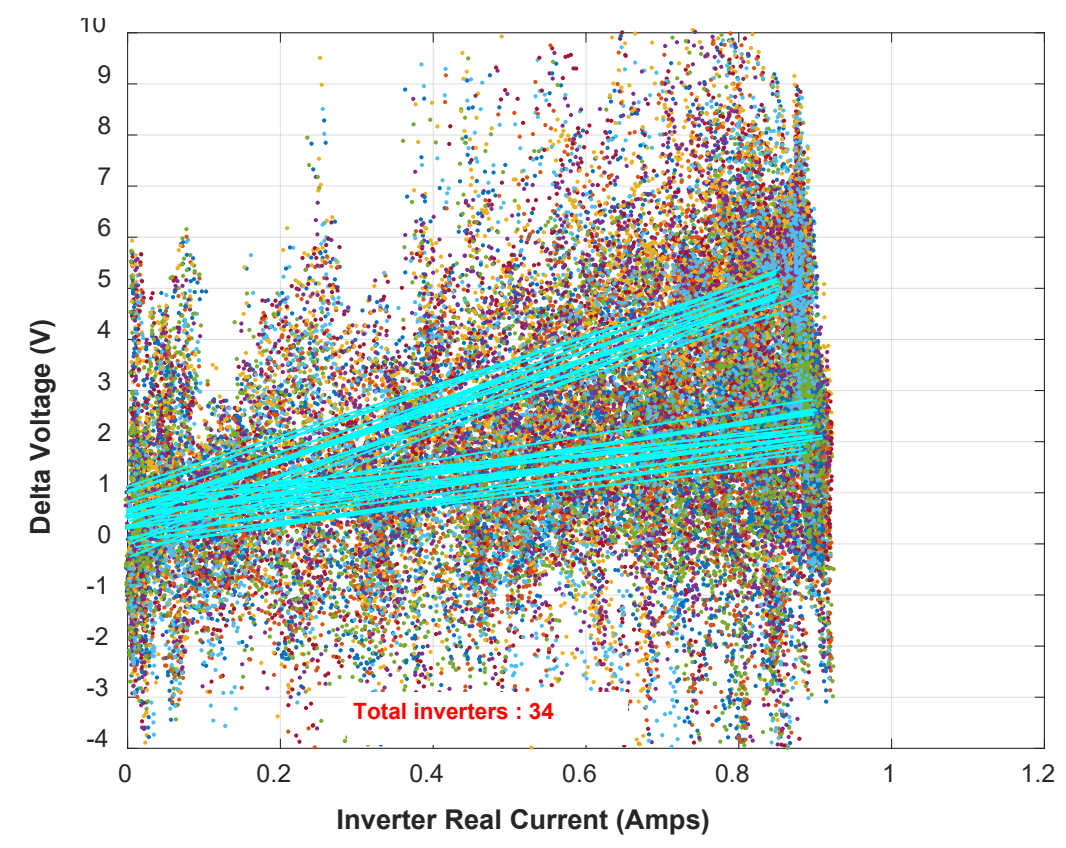

Figure 25. Behind-the-meter voltage rise for the microinverter system with the highest voltage rise. A linear regression fit of voltage rise versus inverter current for each individual inverter is shown in turquoise. The regression fit lines are clearly clustered into two groups with similar slopes; the two groups represent two PV subarrays on different roof pitches.

Results are summarized in Table 6. Behind-the-meter voltage rise during peak PV production hours was found to vary from about $0.3 \%$ to about $2.1 \%$ among the 15 PV systems in the pilot. For microinverter systems, the data in Table 6 are based on the average behind-the-meter voltage rise across all inverters at each location.

Table 6. Behind-the-Meter Voltage Rise During Peak PV Production Hours

\begin{tabular}{ccccc}
\hline & $\begin{array}{c}\text { Number of } \\
\text { Systems } \\
\text { Assessed }\end{array}$ & $\begin{array}{c}\text { Minimum } \\
\Delta \boldsymbol{V}_{b t m}\end{array}$ & Mean $\Delta \boldsymbol{V}_{b t m}$ & $\begin{array}{c}\text { Maximum } \\
\Delta \boldsymbol{V}_{b t m}\end{array}$ \\
\hline String inverters & 9 & $0.3 \%$ & $0.5 \%$ & $0.8 \%$ \\
Microinverters & 6 & $0.6 \%$ & $1.1 \%$ & $2.1 \%$ \\
\hline
\end{tabular}

The difference between the ANSI C84.1 standard (1.05 p.u.) and the volt/Watt starting point (1.06 p.u., as measured at the inverter terminals in the field) provides a $0.01 \mathrm{p}$.u. allowance to compensate for behind the meter voltage drop. Therefore, where behind-the-meter voltage rise is greater than the $1 \%$ design criteria target, there is an increased potential for curtailment. 


\subsection{Customer Measured Voltages}

The location referred to as Cluster 1 features a long, shared overhead secondary circuit serving five PV systems and several non-PV customers. This location was the second-highest voltage location in the pilot. As shown in the plot of inverter power, irradiance, and inverter voltage for one of the Cluster 1 systems during a partially sunny day in Figure 26, PV output is clearly driving high voltages. The two controllable inverters at this location both had Hawaiian Electric's volt/VAR curve and proposed volt/Watt curve enabled on this day. As expected, the inverter absorbs reactive power when the voltage is above 1.03 p.u. Active power remains close to the inverter rating of $3.8 \mathrm{~kW}$, indicating curtailment is minimal; curtailment for this system is quantified later in this section. At the time of this plot, this PV system had a DC:AC ratio of 1.2, so the inverter is at maximum output during times of peak irradiance. Voltage peaked at slightly less than 1.06 p.u. on the timescale shown, so volt/Watt was not active to a significant degree. These findings are typical for this PV system as well as the other controllable PV system in Cluster 1 .

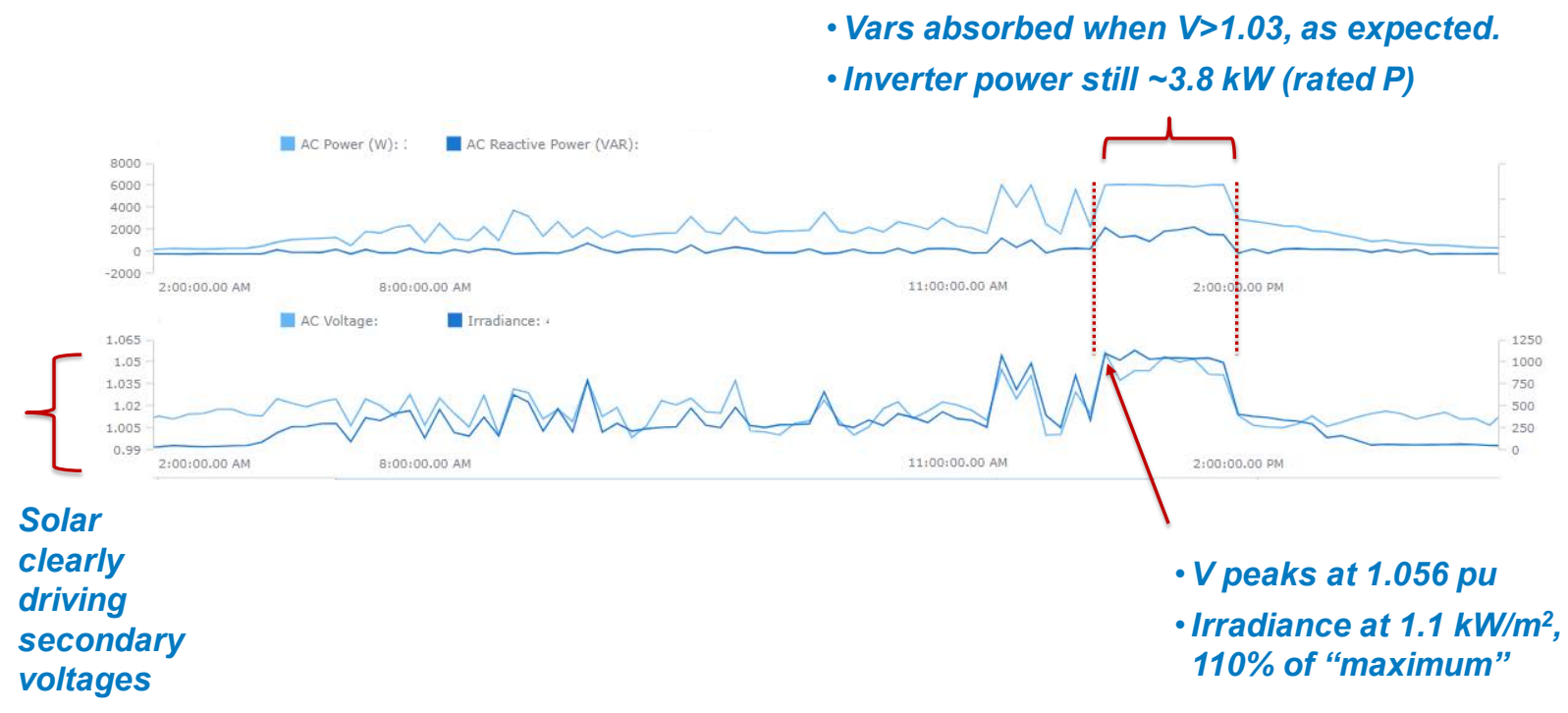

Figure 26. PV power and reactive power, irradiance, and inverter voltage for one of the two smart PV systems in Cluster 1 during a partially sunny day. Voltage is highly correlated with irradiance and inverter active power at this location. Reactive power absorption is defined as positive in this plot (opposite of the typical generator sign convention).

Cluster 2 featured a relatively strong underground secondary system. Voltages in this location were more typical of those in the other pilot locations: they tended to be well regulated, with voltages high enough to significantly activate volt/VAR occurring infrequently and voltages almost never high enough to activate volt/Watt. Figure 27 show inverter active power, reactive power, and voltage for one of the three smart PV systems in this location on a partially sunny day. All three controllable inverters at this location had Hawaiian Electric's volt/VAR curve and proposed volt/Watt curve enabled on this day. Irradiance is not shown but did go high enough that the $6 \mathrm{~kW}$ inverter was at maximum power for a couple of hours, yet voltage peaked at 1.033 p.u., barely into the volt/VAR active region. This day was fairly typical for this location. 


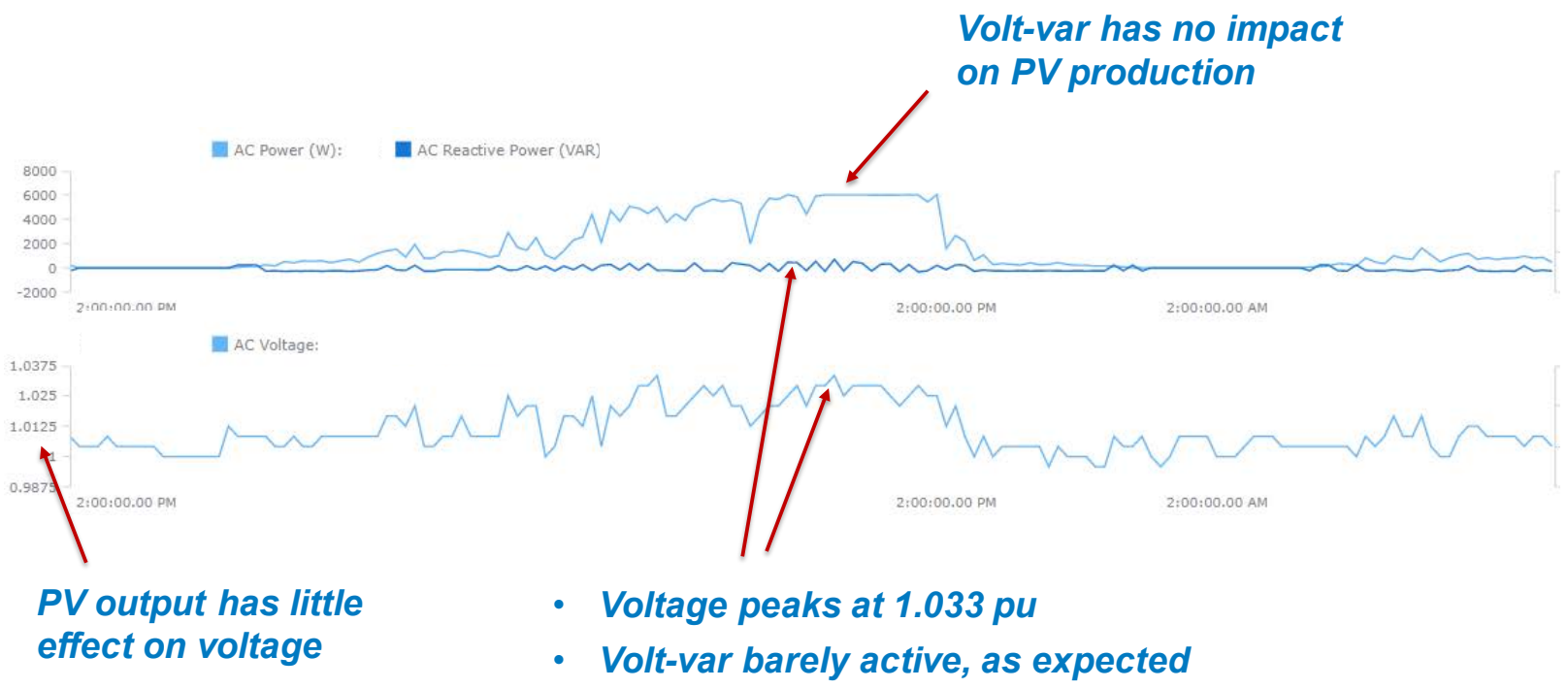

Figure 27. Inverter power, reactive power, and voltage for one of the three smart PV systems in Cluster 2 during a partially sunny day. Voltage is largely independent of irradiance and inverter active power at this location. Reactive power absorption is defined as positive in this plot (opposite of the typical generator sign convention).

Figure 28, Figure 29, and Figure 30 show histograms of inverter and AMI voltages during daytime and nighttime at three locations during multi-month periods. For the purposes of these figures, night is defined as 6 p.m. to 6 a.m. (the period when PV system output is zero or negligible). Day is defined as 9 a.m. to 3 p.m., the core period of PV production. The shoulder times of 6 a.m. to 9 a.m. and 3 p.m. to 6 p.m. when PV output is present but relatively low are not shown so that a clear distinction between PV production hours and nonproduction hours can be drawn. Each plot shows three separate overlapping histograms: nighttime AMI voltage (blue), daytime AMI voltage (orange), and daytime inverter voltage (yellow). The histograms are semitransparent so that all three can be seen even when they overlap.

Figure 28 focuses on the second-highest voltage location in the pilot, which was one of the PV systems in Cluster 1. In this location, daytime voltages tend to be significantly higher than nighttime voltages largely because of the effect of PV output, as shown in Figure 26. Voltage rise at this location is dominated by the relatively high-impedance distribution secondary lines (i.e. older circuit with smaller wires). Daytime AMI voltage and daytime inverter voltage are nearly overlapping because behind-the-meter voltage rise is small. Voltages in the volt/VAR active region (above 1.03 p.u.) are common (40\% of daytime voltages), and voltages above 1.06 p.u. (the volt/Watt active region) occur on rare occasions ( $0.5 \%$ of daytime voltages). This location included an irradiance sensor; curtailment due to volt/Var-in combination with volt/Watt was quantified at less than $0.1 \%$ of PV production, a negligible amount, despite the relatively high voltages at this location. A later plot will revisit voltages and curtailment at this site during a specific high-voltage event that occurred during the pilot. 


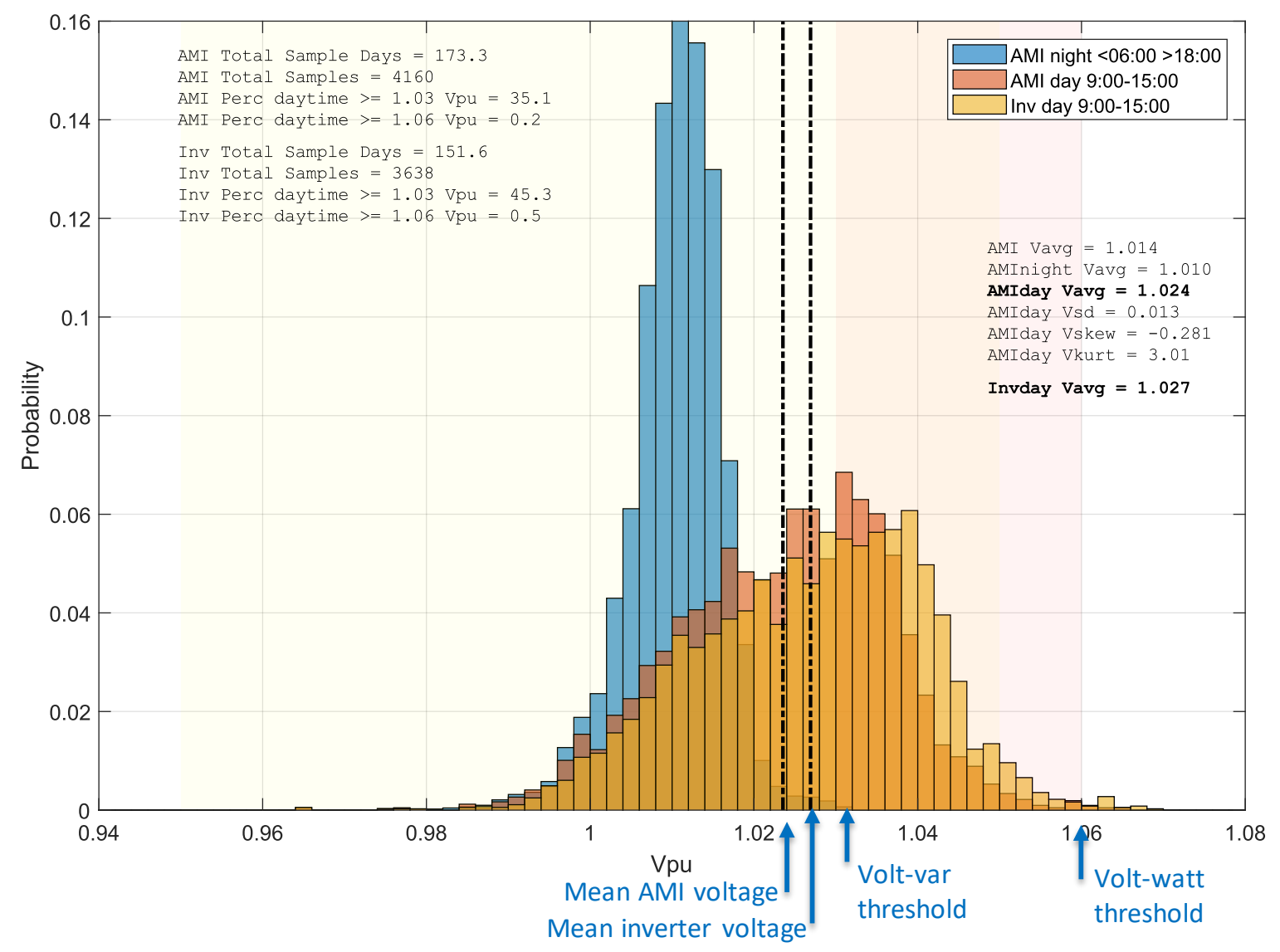

Figure 28. Histogram of inverter and AMI voltages for Cluster 1 (the second-highest voltage location in the pilot)

Figure 29 focuses on one of the PV systems in Cluster 2. In this location, nighttime and daytime voltages nearly overlap; nighttime voltages are slightly higher. This confirms the conclusion in Figure 27 that PV output is not a significant driver of voltage in this location. Inverter voltages are slightly higher than daytime AMI voltages, indicating a small amount of behind-the-meter voltage rise. Voltages are rarely high enough to activate volt/VAR or volt/Watt, and curtailment is negligible. Again, this location was qualitatively typical of most systems in the pilot in that voltages were rarely problematic. 


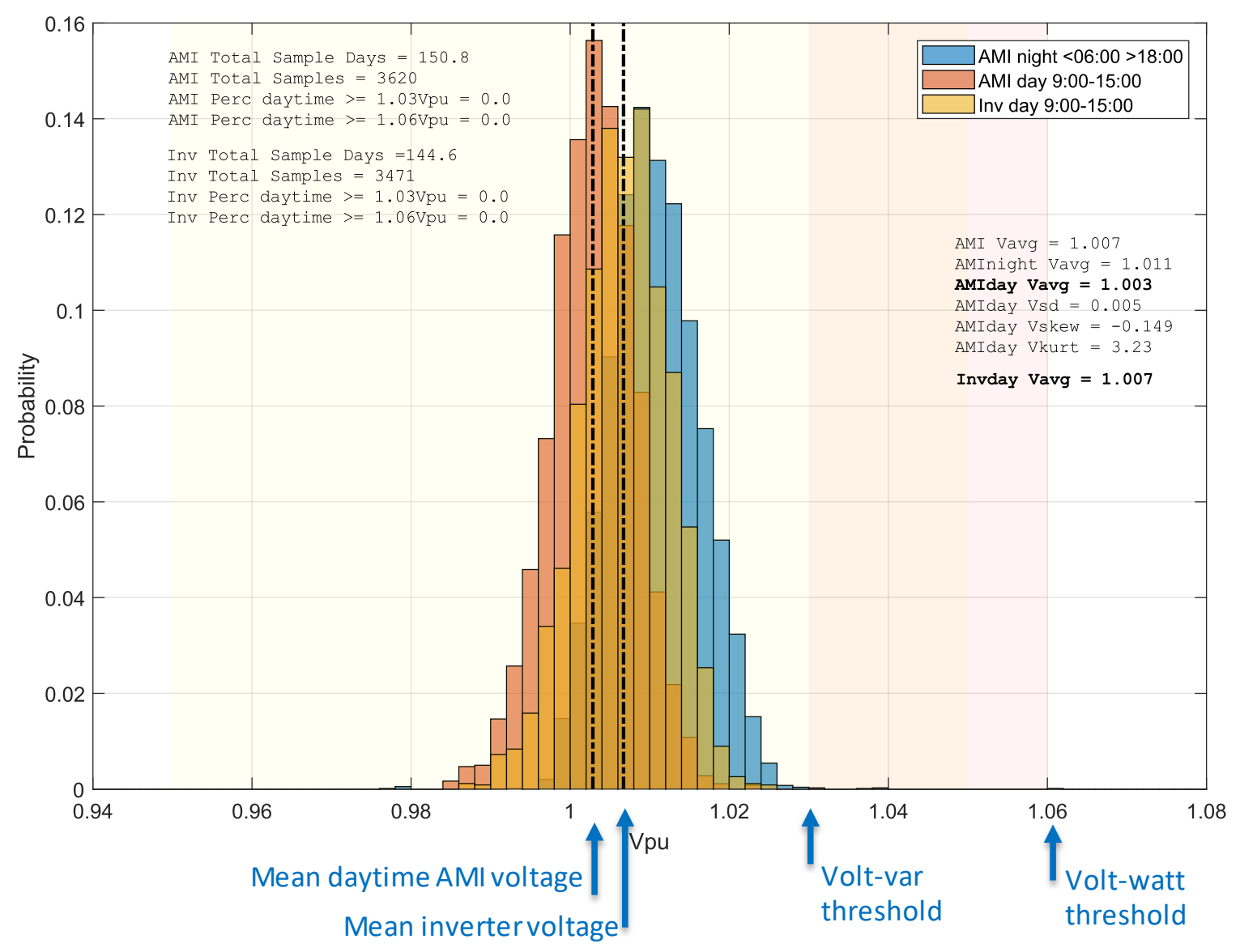

Figure 29. Histogram of inverter and AMI voltages for a typical location with well-regulated voltage

Figure 30 focuses on voltages at the highest voltage location in the pilot. As in Figure 28, daytime AMI voltages are significantly higher than nighttime AMI voltages because of PV output. However, inverter voltages are higher still, indicating significant behind-the-meter voltage rise. Inverter voltages are in the volt-VAR region $76 \%$ of the time and in the volt/Watt region $6 \%$ of the time. Despite the significant amount of time spent at high voltage, it is still expected that curtailment caused by volt/VAR in combination with volt/Watt (volt/VARvolt/Watt) is relatively low (but likely non-negligible). No irradiance sensor was installed at this location during the initial phase of the pilot; however, a sensor has now been installed, and curtailment will be quantified in a later report. Regardless of exact curtailment levels, voltages at this location are high enough that mitigation is likely needed, perhaps using some combination of:

- Increasing the size of wiring between the inverters and the meter

- Upgrading the distribution secondary to reduce secondary voltage rise

- Non-wire alternatives such as further inverter-based measures (possibly involving compensation) or utility-side devices.

This location is already scheduled to have the last leg of the distribution secondary reconductored with larger wire to mitigate the voltage issue based on a study done before the start of the pilot. 


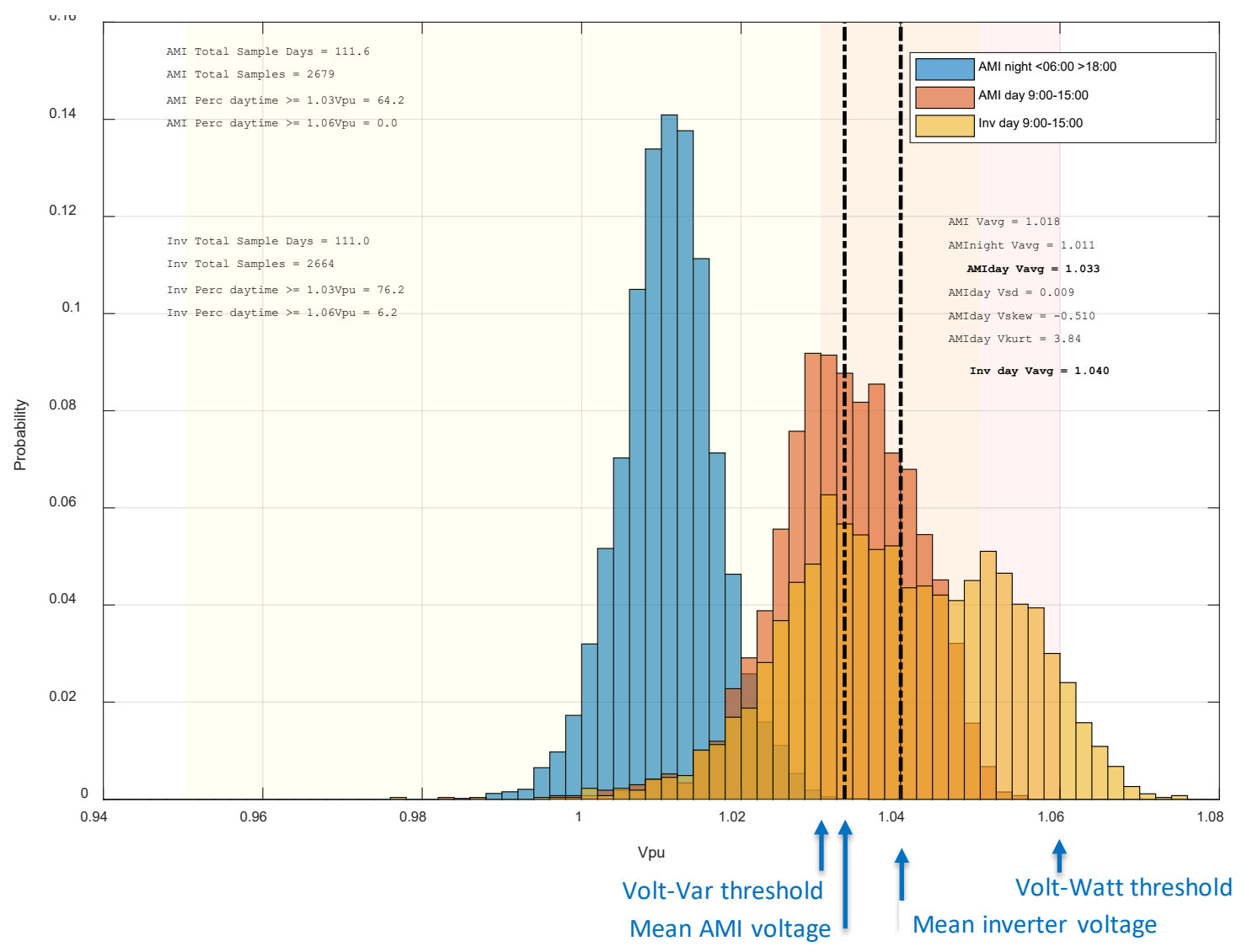

Figure 30. Histogram of inverter and AMI voltages for the highest voltage location in the pilot

During the pilot period, a temporary high-voltage condition lasting 6 days was observed at the Cluster 1 location because of a feeder primary reconfiguration. This late October 2017 event, clearly visible in Figure 31, provided an opportunity to see volt/Watt serve its intended purpose, which is to mitigate occasional voltage issues (as opposed to mitigating persistent issues, which is not the intended purpose of volt/Watt and should be addressed through other means).

Curtailment of PV production caused by volt/VAR-volt/Watt was analyzed during a 3-day portion of the high-voltage event during which the inverters were in volt/VAR-volt/Watt mode, and this curtailment was compared to a similar 3-day period of normal voltage conditions, as shown in Figure 32. Expected PV production was calculated based on plane-of-array irradiance measurements, and curtailment was calculated as the difference between expected production and measured production. During the typical 3-day period, curtailment was estimated at $0.04 \%$ of expected (69.22 kWh expected versus $69.19 \mathrm{kWh}$ produced, for $0.03 \mathrm{kWh}$ curtailed). During the high-voltage period, curtailment was estimated at $1.6 \%$ of energy expected $(75.69 \mathrm{kWh}$ expected vs $74.46 \mathrm{kWh}$ produced, for $1.23 \mathrm{kWh}$ curtailed). Although the curtailment during the high-voltage period is about 60 times higher than during the normal period, it is still relatively small in absolute terms, and given that the event only lasted 6 days, the impact on annual energy production is negligible. 


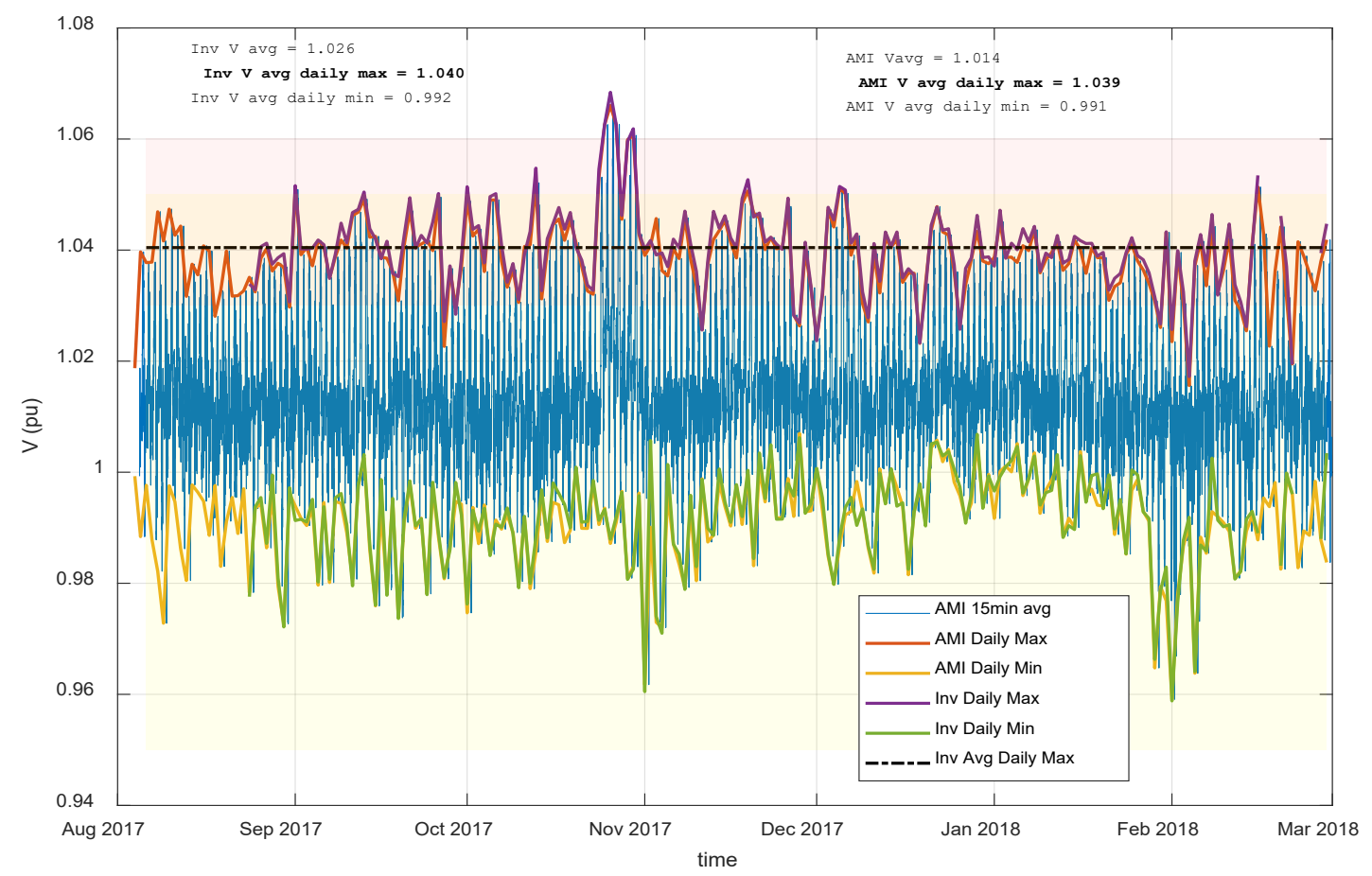

Figure 31. Inverter and AMI voltage profiles for the second-highest voltage location in the pilot. Note the period of unusually high voltages in late October.
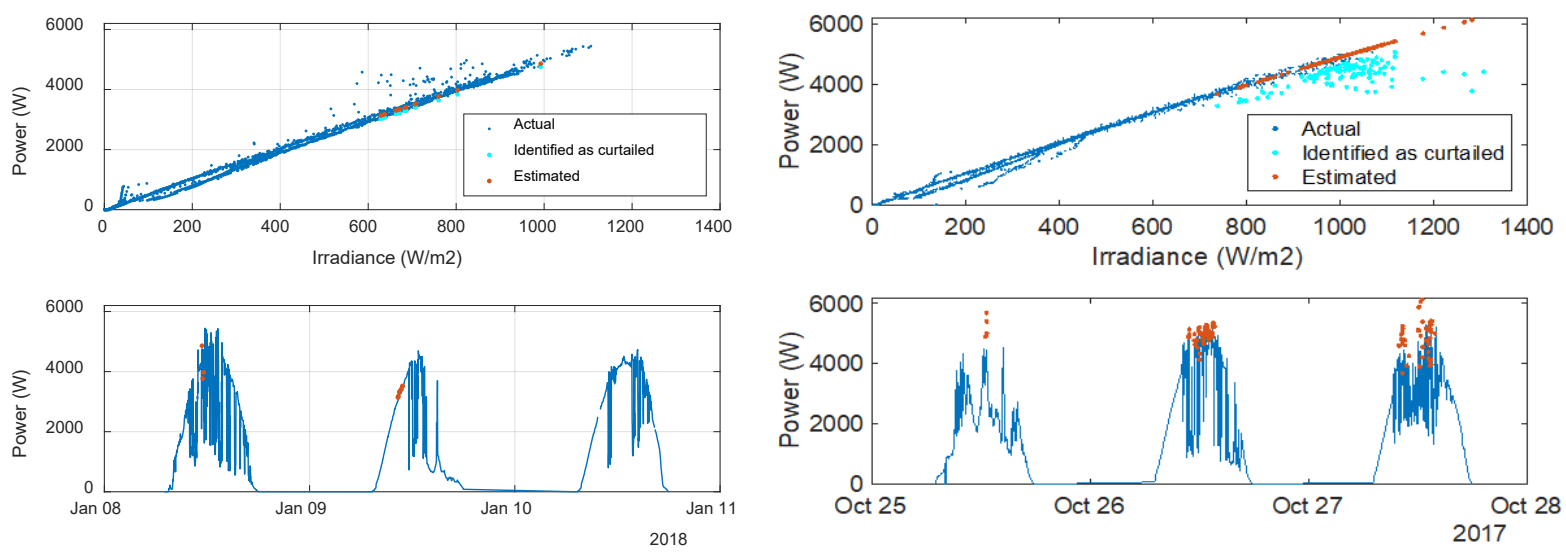

Figure 32. Comparison of curtailment due to volt/VAR-volt/Watt during two periods: on the left, a normal period, and on the right, the period of unusually high voltages in late October

Measured customer voltages were not as high as might have been expected given that pilot customers were preselected based on expected problem locations based on Hawaiian Electric's sub-screens (see prior discussion in Section 2.4.2). This is perhaps not surprising because utility planners typically do not have detailed load profiles, PV data, feeder voltage profiles, secondary circuit topologies and impedances, or other information needed for accurate voltage estimation, so the planners must make assumptions when conducting technical reviews. In the case of the pilot customers, Hawaiian Electric had commissioned a detailed secondary circuit field analysis, but that still left many other key parameters unknown, including customer load profile and transformer primary voltage profile. In the absence of primary voltage information, maximum 
allowed secondary voltage rise was set at 0.025 p.u. under minimum assumed load and maximum PV conditions to ensure that customer voltage would fall below the ANSI C84.1 Range A maximum (1.05 p.u.) (ANSI, 2016) even if primary voltage was as high as 1.025 p.u.

Table 7 compares the measured typical daily peak meter voltages at pilot locations to expected peak meter voltages based on the field analysis of the secondary and the assumption of worstcase primary voltage of 1.025 p.u. The list includes more than 15 customers because in some cases neighboring PV systems also provided AMI data for use in the pilot. In all cases, the measured peak voltage is less than the expected peak voltage by at least 0.003 p.u. and by up to 0.065 p.u., with an average difference of 0.036 p.u. This largely explains the finding that voltages at most locations were not very high despite the preselection of expected problem locations for the pilot.

Table 7. Comparison of Expected Maximum Voltages to Measured Maximum Voltages

\begin{tabular}{|c|c|c|c|c|}
\hline Location & $\begin{array}{c}\text { Expected } \\
\text { Secondary } \\
\text { Voltage Rise } \\
\text { (p.u.) }\end{array}$ & $\begin{array}{c}\text { Expected Meter } \\
\text { Voltage } \\
\text { Assuming } \\
1.025 \text { p.u. at } \\
\text { Transformer } \\
\text { Primary (p.u.) }\end{array}$ & $\begin{array}{c}\text { Typical } \\
\text { Measured } \\
\text { Daily } \\
\text { Maximum } \\
\text { Voltage (p.u.) }\end{array}$ & $\begin{array}{l}\text { Voltage } \\
\text { Difference } \\
\text { from } \\
\text { Expected } \\
\text { (p.u.) }\end{array}$ \\
\hline 1 & 0.0265 & 1.0515 & 1.0059 & -0.0456 \\
\hline 2 & 0.0255 & 1.0505 & 1.0391 & -0.0114 \\
\hline 3 & 0.0255 & 1.0505 & 1.0380 & -0.0125 \\
\hline 4 & 0.0531 & 1.0781 & 1.0131 & -0.0650 \\
\hline 5 & 0.0325 & 1.0575 & 1.0134 & -0.0441 \\
\hline 6 & 0.0224 & 1.0474 & 1.0182 & -0.0292 \\
\hline 7 & 0.0201 & 1.0451 & 1.0272 & -0.0179 \\
\hline 8 & 0.0251 & 1.0501 & 1.0475 & -0.0026 \\
\hline 9 & 0.0224 & 1.0474 & 1.0177 & -0.0298 \\
\hline 10 & 0.0422 & 1.0673 & 1.0072 & -0.0600 \\
\hline 11 & 0.0224 & 1.0474 & 1.0187 & -0.0288 \\
\hline 12 & 0.0539 & 1.0789 & 1.0261 & -0.0528 \\
\hline 13 & 0.0358 & 1.0608 & 1.0286 & -0.0322 \\
\hline 14 & 0.0418 & 1.0668 & 1.0127 & -0.0541 \\
\hline 15 & 0.0309 & 1.0559 & 1.0229 & -0.0330 \\
\hline 16 & 0.0297 & 1.0548 & 1.0121 & -0.0427 \\
\hline 17 & 0.0401 & 1.0651 & 1.0211 & -0.0440 \\
\hline
\end{tabular}

One key piece of missing information that would be valuable for identifying problem locations in advance of PV installation is AMI data. Absent a broad deployment of AMI or visibility, particularly in DER locations, it is very difficult to accurately predict customer voltages before 
PV is installed. ${ }^{11}$ As part of a new business process improvement intended to streamline the interconnection of DER, Hawaiian Electric is proposing to begin installing AMI meters as early as possible following a $\mathrm{PV}$ interconnection application rather than waiting until the installation is completed, as is typical in Hawaii and elsewhere. The early availability of AMI data will allow problem locations to be identified in advance and potentially mitigated before the PV is interconnected. As part of this proposed business process, NREL and Hawaiian Electric will develop analytics using AMI data to identify likely problem locations (those with high voltages and those where voltage is expected to become high when DERs are interconnected). For example, a linear regression fit of meter voltage versus meter active power can be used to estimate the dependence of voltage on power and extrapolate to estimate the voltage that will result when PV is exporting, as shown conceptually in Figure 33 for a customer with a $9 \mathrm{~kW} \mathrm{PV}$ system in the queue.

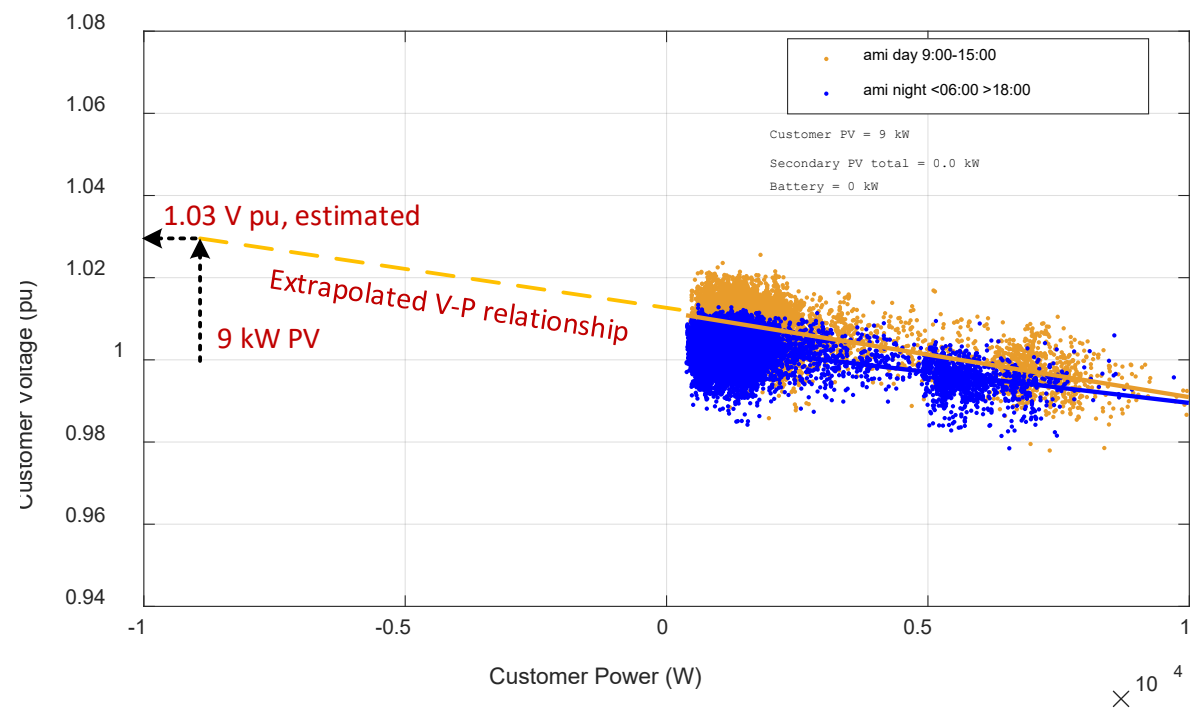

Figure 33. Using instantaneous AMI meter power and voltage data to estimate the impact of PV on voltage before the PV is installed

\subsection{Summary of Findings}

In summary, the initial phase of the field pilot confirmed the expectation from the VROS simulations that curtailment caused by volt/VAR-volt/Watt is typically low or negligible. This is largely because - at least for this sample of 15 customers - high voltages were rare in most cases. For one customer, nonnegligible curtailment is expected to be found once irradiance data are available; this location will likely require mitigation (and was already scheduled for mitigation prior to the pilot).

Behind-the meter voltage rise was found to be significant in some cases; however, all but one system had low enough meter voltages that even considering behind-the-meter voltage rise,

\footnotetext{
${ }^{11}$ In some cases, inverter data from neighboring locations may be available to inverter manufacturers, but this data is not typically available to the utility at present.
} 
inverter voltages were not high enough for volt/VAR-volt/Watt control to have a significant impact on PV energy production.

It was also observed that volt/Watt control can help mitigate occasional high-voltage conditions without significantly impacting annual PV energy production during temporary/abnormal grid conditions.

\subsection{Pilot Modeling of Cluster Participants}

In this section, we build a QSTS model of Cluster 1 based on the exact secondary circuit in the field and leveraging the time-series data from the field pilot, and then we create a series of extreme high PV penetration cases for scenario analysis.

The model was built using the secondary circuit of Cluster 1 customers provided by Hawaiian Electric (shown in Figure 34) and the following data from the field pilot from September 8 through September 15, 2017, at a 15-minute resolution:

- Replay transformer primary voltage.

- Replay four customer's AMI real and reactive power at the respective customer locations.

- Replay four inverter active power profiles at four customer locations.

- Estimate one load profile for the rest of the 10 customers connected to the service transformer by subtracting the active power consumption of the four customers with AMI from the active power measured at the service transformer.

- Assume a constant load power factor of 0.98 for the unmetered loads.

- Replay normalized inverter active power profile from a selected customer at customers without PV for increasing PV penetration levels. 


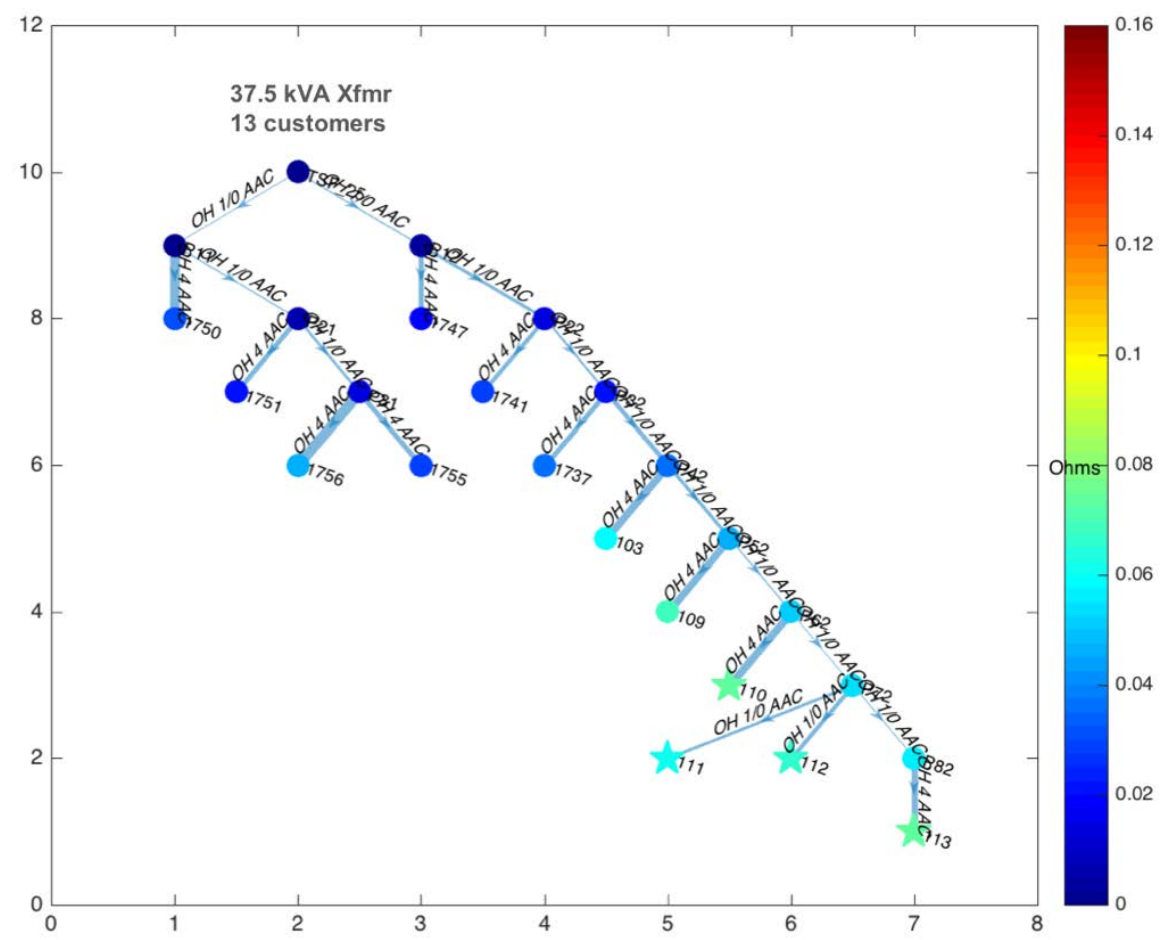

Figure 34. Secondary circuit for Cluster 1 of the pilot project. The last four customers in the second branch from the service transformer have PV systems (star shapes).

\subsubsection{Cluster 1: 210\% PV Penetration of Daytime Minimum Load}

In this scenario, we match field conditions for the week of September 8 through September 15, 2017, i.e., two legacy PV units connected at unity power factor and two advanced inverter customers in volt/VAR. For validation, we look at voltage, power, and customer curtailment comparisons.

\subsection{Cluster 1: Measured versus Modeled Voltages and Powers}

We show that the created model for Cluster 1 matches well the measured field data for the week, with a maximum instantaneous error of 0.005 voltage p.u., as shown in Figure 35.

In Figure 36, we show the aggregated real and reactive power load at the service transformer. The active power modeled versus measured line up perfectly, as expected, because we used transformer active power to derive the unknown customer loads, However, the reactive power was harder to match because a fixed power factor was assumed for the unmetered customers, so the model was not able to capture the precise reactive power profiles of the unmetered customers. 


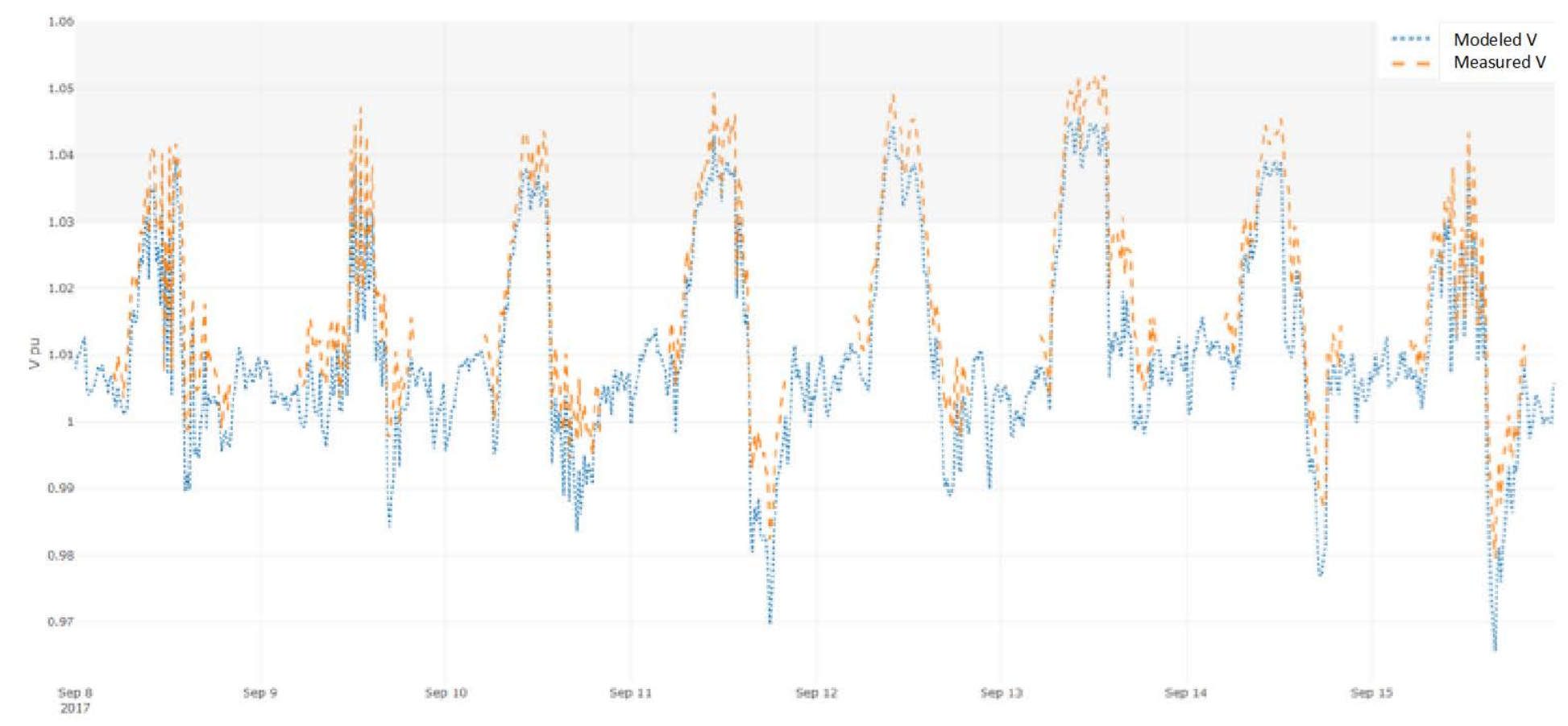

Figure 35. Measured voltage (dashed orange) versus modeled voltage (dotted blue line) at a customer in Cluster 1. The maximum instantaneous error between the measured and simulated voltage is 0.005 p.u. 


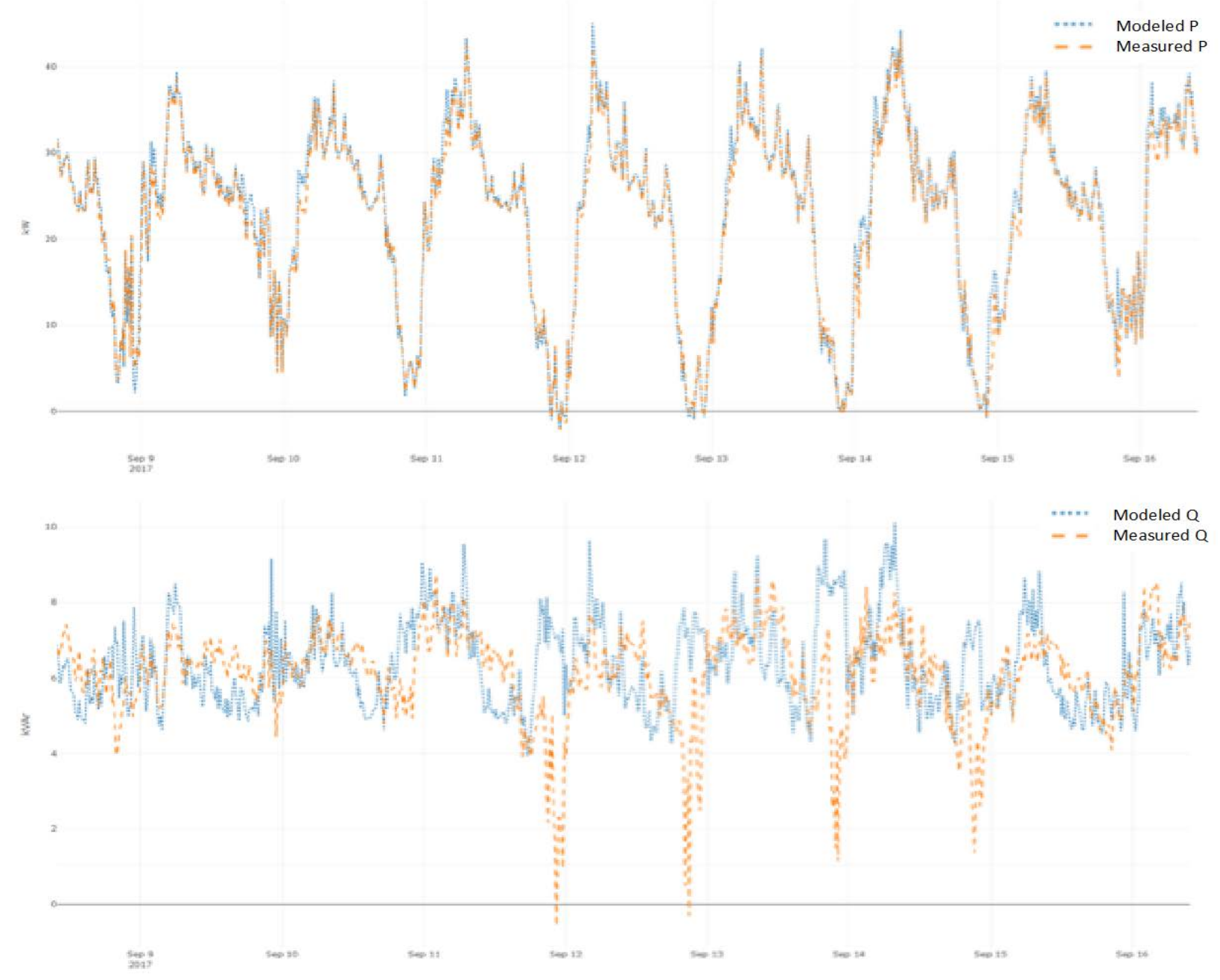

Figure 36. Measured versus modeled real (top) and reactive (bottom) power at the service transformer of the Cluster 1 secondary 


\subsection{Methodology to Estimate Energy Curtailment from Field Data}

The last metric we check for model validation with field data is the estimated customer PV curtailment at one of the Cluster 1 participants. To estimate curtailment from the field data, we look at the high-voltage period where the curtailment is clearly caused by volt/VAR. The dark blue dots in Figure 37 show 1-minute data points of measured irradiance versus measured power at the inverter. Each measured inverter power is compared to the linear interpolation fit of irradiance versus power (the straight-line portion of the plot marked as "estimated"). If it lies too far off the linear fit, then the dark blue dot is remarked in light blue as "Identified as curtailed." The light blue point is then replaced with the linear interpolated "estimated" value using the irradiance at that time point with an orange dot. The analysis was intentionally aggressive in identifying curtailment to avoid missing possible curtailment. The difference between the light blue dots and orange dots divided by the original assumed production (light blue + dark blue) for the time period is the total energy curtailment value.

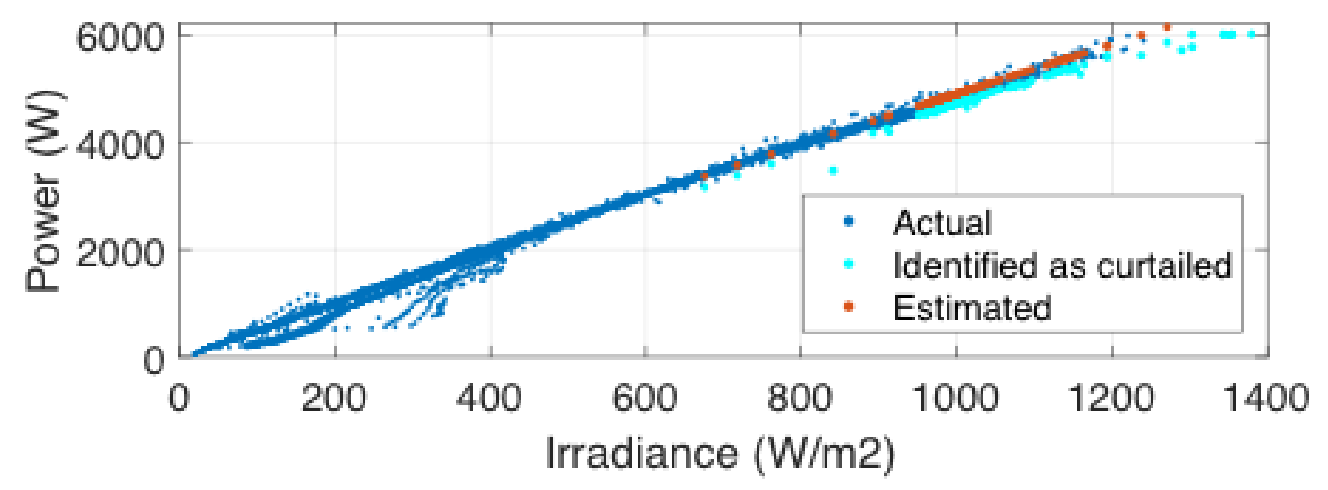

Figure 37. Inverter measured power versus irradiance (dark blue); estimation of expected inverter power based on measured irradiance (red); and, measured inverter power when identified as curtailed (light blue). Curtailment was identified when measured power fell below the expected power estimate by a small tolerance.

\subsection{Cluster 1: Measured versus Modeled Energy Curtailment}

The energy curtailment estimates for the customer during the week of September 9 through September 16, 2017, using the methodology described above is $0.20 \%$, which is nearly the same as the energy curtailment for the customer in Cluster 1 from the modeled data, which is $0.26 \%$.

\subsubsection{Scenario Modeling: PV Penetration 690\% of Daytime Minimum Load}

To the validated Cluster 1 model previously described, we add PV to the rest of the customers in the secondary to run scenario analysis on the highest PV penetration case (all customers have PV) with different penetrations and locations of legacy versus advanced inverters. 
Table 8. Scenarios for Cluster 1 with $690 \%$ PV Penetration of Day Time Minimum Load

\begin{tabular}{|c|c|c|c|c|c|c|}
\hline \multirow[t]{2}{*}{ Scenario Name } & \multicolumn{2}{|c|}{ Legacy PV } & \multicolumn{3}{|c|}{ Advanced Inverter PV } & \multirow{2}{*}{$\begin{array}{l}\text { Transformer } \\
\text { Nominal } \\
\text { Ratio }\end{array}$} \\
\hline & Total kW & Location & $\begin{array}{l}\text { Total } \\
\text { kW }\end{array}$ & Location & $\begin{array}{l}\text { Grid-Support } \\
\text { Function }\end{array}$ & \\
\hline $\begin{array}{l}5 \text { Legacy Far + } \\
8 \text { Grid-Support } \\
\text { Function Close }\end{array}$ & $24 \mathrm{~kW}$ & $\begin{array}{l}\text { Far from } \\
\text { Xfmr }\end{array}$ & $48 \mathrm{~kW}$ & $\begin{array}{l}\text { Close to } \\
\text { Xfmr }\end{array}$ & $\begin{array}{l}\text { Volt/VAR+ } \\
\text { volt/Watt }\end{array}$ & 1 \\
\hline $\begin{array}{l}5 \text { Legacy Close + } \\
8 \text { Grid-Support } \\
\text { Function Far }\end{array}$ & $48 \mathrm{~kW}$ & $\begin{array}{l}\text { Close from } \\
\text { Xfmr }\end{array}$ & $24 \mathrm{~kW}$ & $\begin{array}{l}\text { Far from } \\
\text { Xfmr }\end{array}$ & $\begin{array}{l}\text { Volt/VAR+ } \\
\text { volt/Watt }\end{array}$ & 1 \\
\hline $\begin{array}{l}\text { All Grid-Support } \\
\text { Functions }\end{array}$ & 0 & $\mathrm{~N} / \mathrm{A}$ & $72 \mathrm{~kW}$ & $\mathrm{~N} / \mathrm{A}$ & $\begin{array}{l}\text { Volt/VAR+ } \\
\text { volt/Watt }\end{array}$ & 1 \\
\hline $\begin{array}{l}5 \text { Legacy Close + } \\
8 \text { Grid-Support } \\
\text { Functions Far- } \\
\text { Xfmr Off-Nominal }\end{array}$ & $48 \mathrm{~kW}$ & $\begin{array}{l}\text { Close from } \\
\text { Xfmr }\end{array}$ & $24 \mathrm{~kW}$ & $\begin{array}{l}\text { Far from } \\
\text { Xfmr }\end{array}$ & Volt/VAR & 0.750 \\
\hline
\end{tabular}

\subsection{Five Legacy PV Units and Eight Advanced Inverter PV Units in Volt/VAR and Volt/VAR-Volt/Watt}

An imaginable future worst-case scenario for high-voltage rise is to analyze five customer legacy $\mathrm{PV}$ units connected at unity power factor (which is a realistic maximum number of legacy PV customers connected at unity power factor prior to the update of Rule $14 \mathrm{H}$ requiring advanced inverter functions), and the rest of the customers with advanced inverter functionalities. Figure 38 and Figure 39 show the voltage envelops for the legacy and advanced PV units in Cluster 1 and show that the worst-case high-voltages are when the legacy PV systems are all located toward the end of the branch. However, the worst-case voltages for the advanced inverter customers that would be supporting voltages and thus experiencing curtailment are created when the legacy PV is all connected between the advanced inverter customer and the transformer, driving voltages up for the customers providing voltage support.

As such, Figure 40 compares customer energy curtailment for the September week of study for the five legacy PV systems located close to the transformer (black dots) and the rest of PV systems located toward the edges in volt/VAR and volt/VAR-volt/Watt modes, respectively, showing that a worst-case curtailment experienced by a customer is when all the customers in a branch have PV and five of them are legacy PV systems (represented by black dots), reaching a maximum customer weekly energy curtailment of $0.84 \%$ in volt/VAR-volt/Watt modes. 

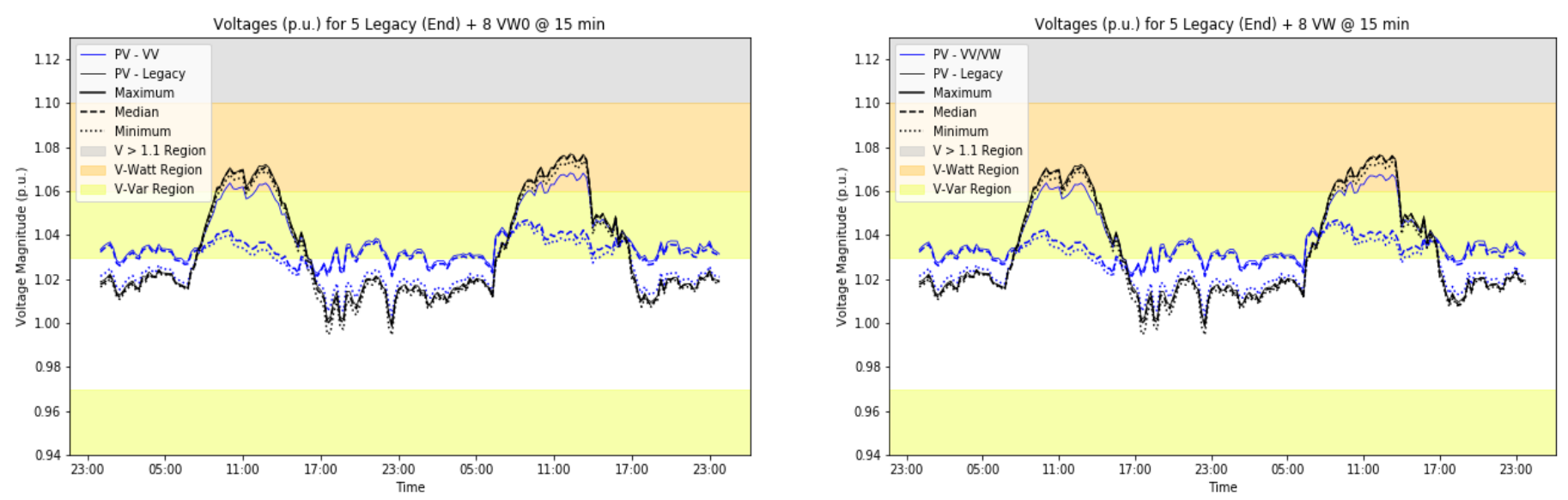

Figure 38. Voltage envelopes for Cluster 1 customers with five PV legacy systems connected at the end of Branch 2 (far from transformer) and eight PV systems in volt/VAR (left) versus volt/VAR-volt/Watt (right) for September 9 and September 10, 2017
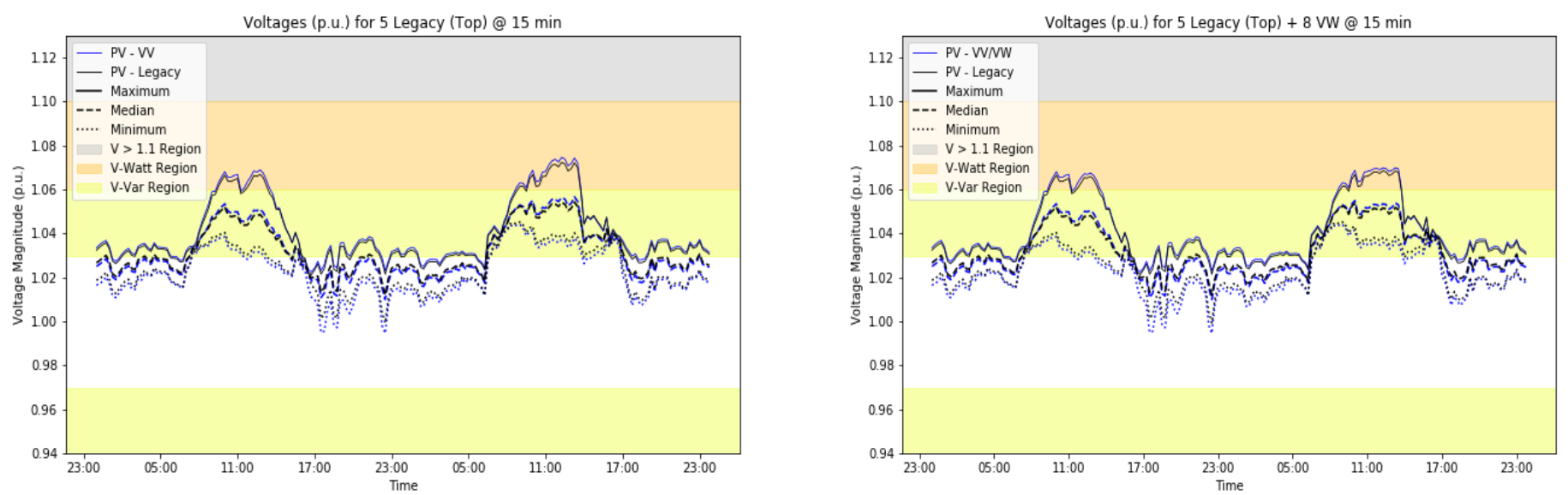

Figure 39. Voltage envelopes for Cluster 1 customers with five PV legacy systems connected towards the front of Branch 2 (close to the transformer) and eight PV systems in volt/VAR (left) versus volt/VAR-volt/Watt (right) for September 9 and 10, 2017 

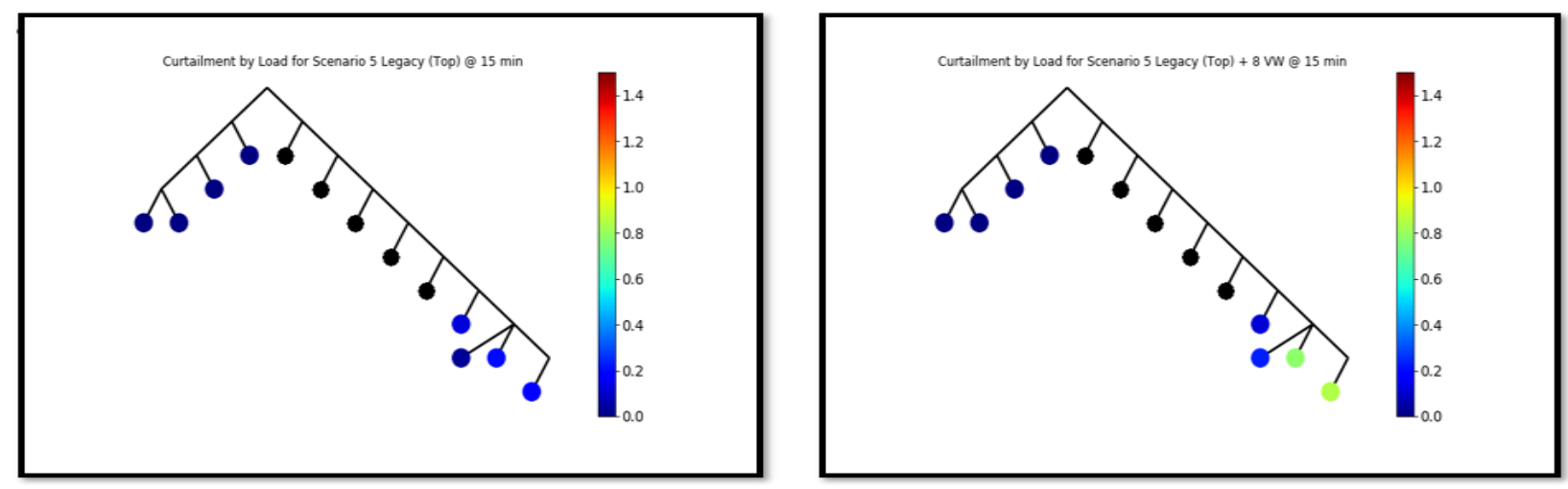

Figure 40. Energy curtailment percentage heat map for Cluster 1 with all customers with PV, five legacy PV systems connected first on Branch 2, and the remaining eight in volt/VAR (left) and Volt/VAR-Volt/Watt modes (right)

\subsection{All Advanced Inverters in Volt/VAR and Volt/VAR-Volt/Watt}

In this section, we present the case in which all customers have PV with advanced inverter functionalities. Figure 41 shows the voltage envelops for all PV systems in volt/VAR (left) and volt/VAR-volt/Watt (right) modes and shows the effectiveness at keeping customer voltages within the ANSI C. 84 Range A region. Figure 42 shows that with all advanced inverters, the energy curtailment is minimal, even for the extreme high PV penetration case (maximum of $0.17 \%)$.
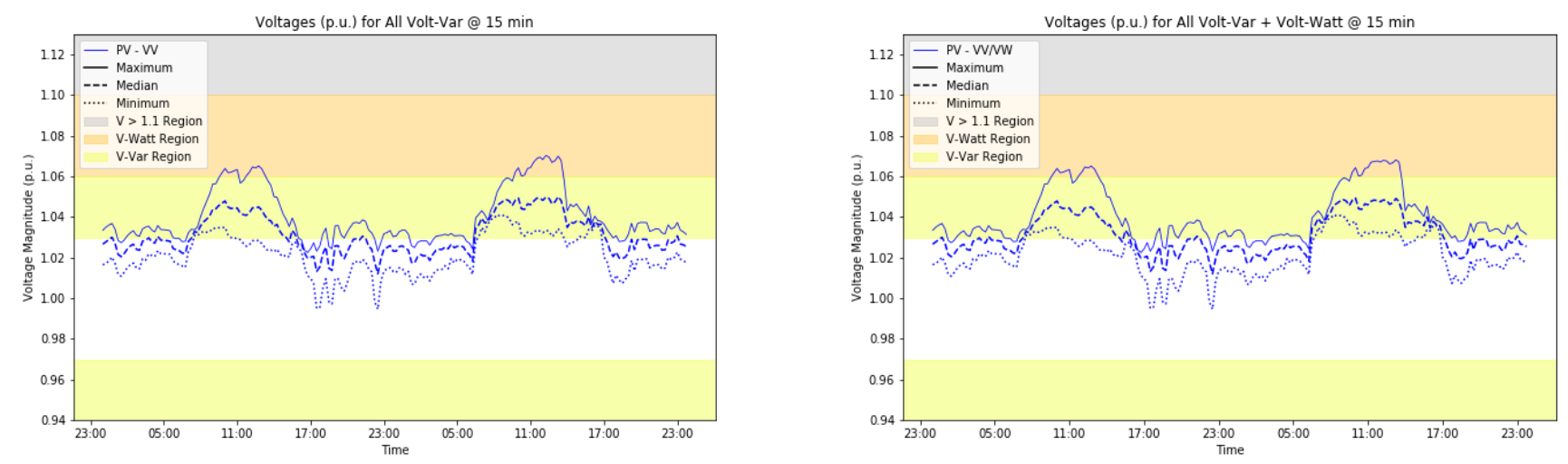

Figure 41. Voltage envelop for Cluster 1 with all customers with PV with advanced inverter functionalities in volt/VAR (left) and volt/VAR-volt/Watt (right) for two high-voltage days in September 

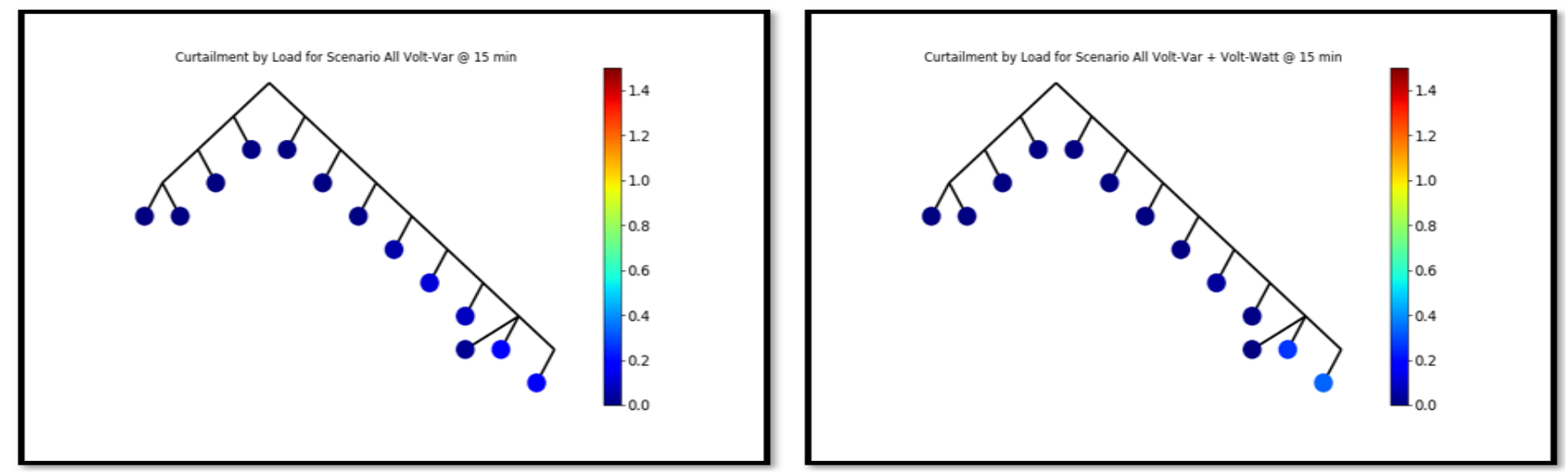

Figure 42. Customer energy curtailment heat map for Cluster 1 with all customers with PV with advanced inverter functionalities in volt/VAR (left) and volt/VAR-volt/Watt (right)

The summary energy curtailment metrics for the scenarios in Cluster 1 with all customers with PV at different locations and advanced inverter functionalities are shown in Table 9, and all customer energy curtailment values are less than $1 \%$.

Table 9. Customer Energy Curtailment Metrics for the Different Scenarios with All Customers with PV for Cluster 1

\begin{tabular}{|c|c|c|c|c|c|c|}
\hline \multirow[t]{2}{*}{ Metrics } & \multicolumn{2}{|c|}{$\begin{array}{l}5 \text { Legacy Far + } \\
8 \text { Grid-Support } \\
\text { Function - Close }\end{array}$} & \multicolumn{2}{|c|}{$\begin{array}{l}5 \text { Legacy Close + } \\
8 \text { Grid-Support Function - } \\
\text { Far }\end{array}$} & \multicolumn{2}{|c|}{$\begin{array}{l}\text { All Grid-Support } \\
\text { Functions }\end{array}$} \\
\hline & $\begin{array}{l}\text { Volt/VA } \\
\mathrm{R}\end{array}$ & $\begin{array}{l}\text { Volt/WAR+ } \\
\text { Volt/Watt }\end{array}$ & Volt/VAR & $\begin{array}{l}\text { Volt/VAR+ } \\
\text { Volt/Watt }\end{array}$ & Volt/VAR & $\begin{array}{l}\text { Volt/VAR+ } \\
\text { Volt/Watt }\end{array}$ \\
\hline $\begin{array}{l}\text { Max Grid- } \\
\text { Support } \\
\text { Function } \\
\text { Curtailment A }\end{array}$ & $0.20 \%$ & $0.84 \%$ & $0.14 \%$ & $0.17 \%$ & $0.16 \%$ & $0.34 \%$ \\
\hline $\begin{array}{l}\text { Average } \\
\text { Grid-Support } \\
\text { Function } \\
\text { Curtailment A }\end{array}$ & $0.06 \%$ & $0.25 \%$ & $0.02 \%$ & $0.02 \%$ & $0.05 \%$ & $0.05 \%$ \\
\hline $\begin{array}{l}\text { Average } \\
\text { Increased } \\
\text { Generation }^{B}\end{array}$ & $0.00 \%$ & $0.00 \%$ & $0.00 \%$ & $0.00 \%$ & $0.00 \%$ & $0.00 \%$ \\
\hline $\begin{array}{l}\text { Average Net } \\
\text { Generation } \\
\text { Change }{ }^{C}\end{array}$ & $-0.06 \%$ & $-0.24 \%$ & $-0.02 \%$ & $-0.02 \%$ & $-0.04 \%$ & $-0.05 \%$ \\
\hline
\end{tabular}

Note A: Curtailment values represent PV energy reduction due to the activation of grid support functions,

Note B: Increased PV generation that would have otherwise been disconnected due to systems tripping above 1.1 p.u. per IEEE 1547.

Note C: Positive values represent a net increase in PV generation. 


\subsubsection{One-Minute Versus Fifteen-Minute Simulation Time-Step Comparison}

In this section, we explore the impact on voltages and, as such, on customer energy curtailment of running the simulation at 15-minute versus 1-minute time-step resolutions. As expected, there is a slight underestimation of peak voltages causing volt/VAR curtailment and Volt/VARVolt/Watt curtailment from 15-minute to 1-minute resolutions, since the lower the time resolution, the less spiky the voltage profiles are. However, the underestimation is higher for the volt/VAR function because it is activated on a regular basis during PV production hours, whereas the volt/Watt function is activated only occasionally on this hypothetical worst case in Cluster 1 with all customers with PV and five legacy PV systems. The energy curtailment numbers at 1-minute resolution for the high-voltage week in September and extremely high PV penetration case in Cluster 1 remain very low, even at 1-minute resolution (maximum of 1\%) as shown in Table 10.

Table 10. Energy Curtailment Metrics Comparison Between 1-Minute and 15-Minute Time-Step Resolutions for Scenario "5 Legacy Close 8 Grid-Support Function Far"

\begin{tabular}{|c|c|c|c|c|}
\hline \multirow{2}{*}{ Metrics } & \multicolumn{2}{|c|}{ Volt/VAR } & \multicolumn{2}{|c|}{ Volt/VAR-Volt/Watt } \\
\hline & $1 \mathrm{~min}$. & $15 \mathrm{~min}$. & $1 \mathrm{~min}$. & $15 \mathrm{~min}$. \\
\hline $\begin{array}{l}\text { Max Grid-Support Function } \\
\text { Curtailment }{ }^{A}\end{array}$ & $-0.58 \%$ & $-0.20 \%$ & $-1.06 \%$ & $-0.84 \%$ \\
\hline $\begin{array}{l}\text { Average Grid-Support Function } \\
\text { Curtailment }{ }^{A}\end{array}$ & $-0.23 \%$ & $-0.06 \%$ & $-0.36 \%$ & $-0.25 \%$ \\
\hline Average Increased Generation ${ }^{B}$ & $+0.00 \%$ & $+0.00 \%$ & $+0.00 \%$ & $+0.00 \%$ \\
\hline $\begin{array}{l}\text { Average Net Generation } \\
\text { Change }{ }^{C}\end{array}$ & $-0.23 \%$ & $-0.06 \%$ & $-0.36 \%$ & $-0.24 \%$ \\
\hline
\end{tabular}

Note A: Curtailment values represent PV energy reduction due to the activation of grid support functions,

Note B: Increased PV generation that would have otherwise been disconnected due to systems tripping above 1.1 p.u. per IEEE 1547.

Note C: Positive values represent a net increase in PV generation. 


\section{Summary of Findings and Recommendations}

In summary, the updates to the modeling work and the field deployment results show that system-wide activation of volt/Watt in combination with the already approved volt/VAR function results in very low customer curtailment since volt/Watt is not active during normal operating conditions.

The initial phase of the field pilot confirmed the expectation from the VROS simulations that curtailment caused by volt/VAR-volt/Watt is typically low or negligible. This is largely because - at least for this sample of 15 customers - high voltages were rare in most cases. For one customer, non-negligible curtailment is expected to be found once irradiance data are available; this location will likely require mitigation (and was already scheduled for mitigation prior to the pilot).

Behind-the-meter voltage rise was found to be significant in some cases; however, all but one system had low enough meter voltages that even considering behind-the-meter voltage rise, inverter voltages were not high enough for volt/VAR-volt/Watt control to have a significant impact on PV energy production.

It was also observed that volt/Watt control can help mitigate occasional high-voltage conditions without significantly impacting annual PV energy production during temporary/abnormal grid conditions.

The advanced inverter pilot project has been operationalized to include additional customers and new business process improvement methods. Briefly, the new business process improvement includes installing smart meters as soon as possible after customers are identified, preferably before PV systems are installed. This enables analysis of site-specific voltage and impedance conditions to identify locations where voltages are frequently high (or expected to be high once $\mathrm{PV}$ is installed). Hawaiian Electric is also working to incorporate the lessons learned from the advanced inverter pilot into a new DER interconnection process for all new PV customers, allowing early identification and mitigation of voltage issues and avoidance of any significant PV curtailment.

The updates to the modeling work performed in the VROS 2017 study provide the following conclusions related to the impacts of volt/VAR and volt/VAR in combination with volt/Watt in feeder M34 for a hypothetical very high PV penetration case and all exporting PV systems:

- When volt/VAR-volt/Watt are activated system-wide, volt/VAR is very effective at reducing overall voltages during PV production hours, and there is minor volt/Watt activation during normal operating conditions.

- Volt/VAR and volt/VAR-volt/Watt increase total PV generation by preventing PV systems from tripping above 1.1 p.u.: average customer energy curtailment for a high-voltage week is $0.23 \%$ versus average increased generation (prevented from being disconnected above 1.1 p.u.) of $+2.97 \%$.

- In very high PV penetration cases, 99\% of customers experienced curtailment from volt/VAR-volt/Watt of less than $2 \%$ for a high-voltage week. Curtailment is expected to be typically much less on an annualized basis. 
- The $1 \%$ hypothetical customer outliers that could experience higher energy curtailment in the very high PV penetration case (between $2 \%$ and $6 \%$ curtailment for a high-voltage week) have approximated secondary designs that are likely under-designed ( $200 \mathrm{ft}$ apart on 1/0 cable). It is important to note that the underdesigned secondaries did not come from Hawaiian Electric.

- Maximum energy curtailment for residential suburban customers whose secondary circuits are approximated by circuits provided by Hawaiian Electric is $2 \%$ for a high-voltage week in June and is expected to be typically much less on an annualized basis.

- Current Hawaiian Electric technical sub-screens identify potential high-curtailment customers that can be monitored while secondary upgrades are underway.

- When comparing a future with $30 \%$ non-exporting tariffs to one with all new PV interconnected with exporting tariffs, overall voltages are lower. As such, energy curtailment values from grid-support functions to exporting systems are also lower in a future with nonexporting PV systems.

- Modeling and simulation findings on the full Oahu $12 \mathrm{kV}$ feeder are validated with the detailed secondary model built from data collected from the advanced inverter pilot project. The modeling effort performed in a re-created model of a distribution secondary cluster from the advanced inverter pilot project validates the current low curtailment values being measured in the field, and it projects low curtailment values for future PV scenarios in which all customers have PV.

The intent of the volt/Watt curve settings studied here is not to mitigate persistently high voltages, but rather to protect against occasional temporary high voltage conditions outside of tariff rules. Because events that occasionally result in high-voltage conditions in the field are very difficult to predict in advance, volt/Watt is only effective as a protection function if enabled system-wide. The majority of the time, voltages are in normal operating ranges and volt/Watt is not active. As shown in this report, non-negligible curtailment from volt/VAR and volt/Watt occurs only when voltages are persistently outside of tariff. In such cases, the utility has an existing obligation to fix the voltage issue, and that fix is expected also correct any curtailment issue. Active monitoring of customer meter voltages both before and after PV installation will ensure such cases are caught and proactively mitigated. Thus, combined system-wide activation of volt/VAR and volt/Watt control can enable very high levels of PV generation while helping ensure voltages remain within the allowed safe ranges, without significant impact on PV energy production. 


\section{References}

ANSI. (2016). ANSI C84.1-2016 - Electric Power Systems and Equipment - Voltage Ratings (60 $\mathrm{Hz}$ ). Washington, D.C.: American National Standards Institute.

Giraldez, J., Nagarajan, A., Gotseff, P., Krishnan, V., Hoke, A., Ueda, R., . . Ifuku, E. (2017). Simulation of Hawaiian Electric Companies Feeder Operations with Advanced Inverters and Analysis of Annual Photovoltaic Energy Curtailment (NREL/TP-5D00-68681). Golden, CO: National Renewable Energy Laboratory.

Gotseff, P., Wunder, N., Hoke, A., Ifuku, E., \& Ueda, R. (2018). Residential Advanced Photovoltaic Inverter Pilot Study Results for Select Distribution Secondaries in Hawai ' $i$.

Hoke, A., Elkhatib, M., Nelson, A., Johnson, J., Tan, J., Mahmud, R., . . . Fong, K. (2017). The Frequency-Watt Function: Simulation and Testing for the Hawaiian Electric Companies (NREL/TP-5D00-68884). Washington, D.C.: U.S. Department of Energy Grid Modernization Laboratory Consortium.

IEEE. (2003). IEEE 1547-2003 - Standard for Interconnecting Distributed Resources With Electric Power Systems. Piscataway, NJ: IEEE.

IEEE. (2018). IEEE 1547-2018 - Standard for Interconnection and Interoperability of Distributed Energy Resources with Associated Electric Power Systems Interfaces. Piscataway, NJ: IEEE.

Nelson, A., Nagarajan, A., Prabakar, K., Gevorgian, V., Lundstrom, B., Nepal, S., . . Ifuku, E. (2016). Hawaiian Electric Advanced Inverter Grid Support Function Laboratory Validation and Analysis (NREL/TP-5D00-67485). Golden, CO: National Renewable Energy Laboratory. 
Pseudo-Code for Inverter Controls

Appendix A contains the pseudo-codes for the three inverter controls used in the quasi-static time-series simulations.

\section{A.1 Volt/VAR}

The pseudo-code for the volt/VAR algorithms is shown in Figure A-1.

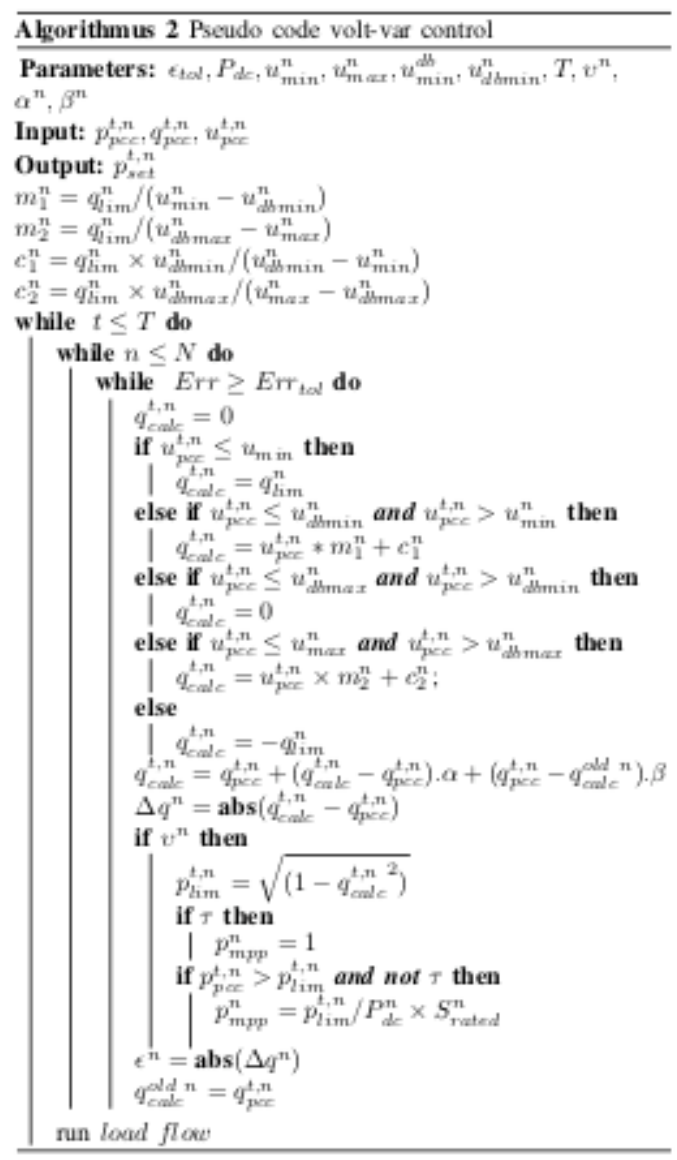

Figure A-1. 


\section{A.2 Volt/Watt}

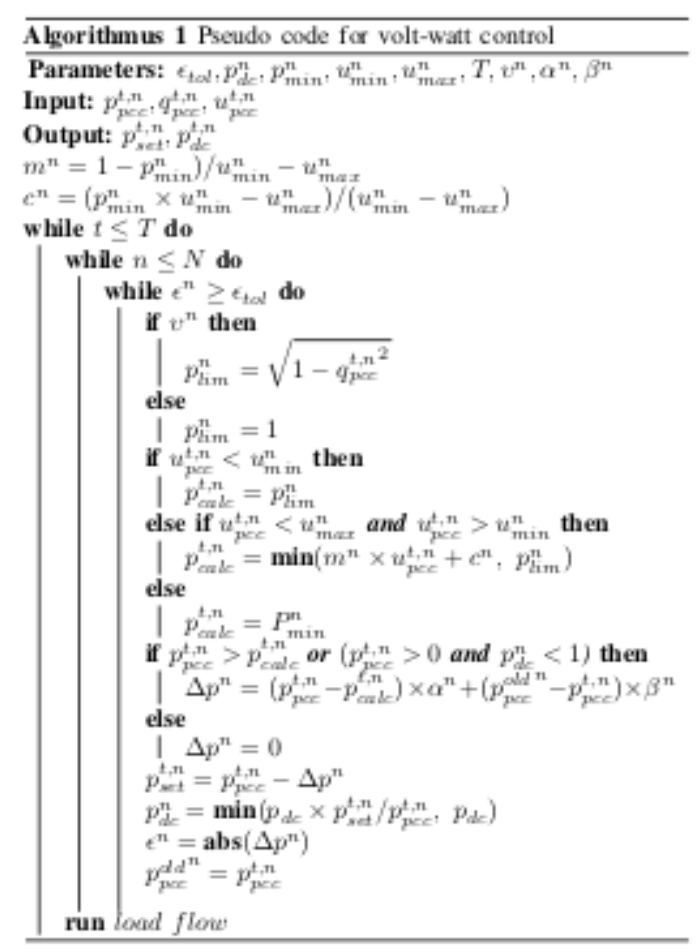

Figure A-2.

\section{A.3 Non-exporting}

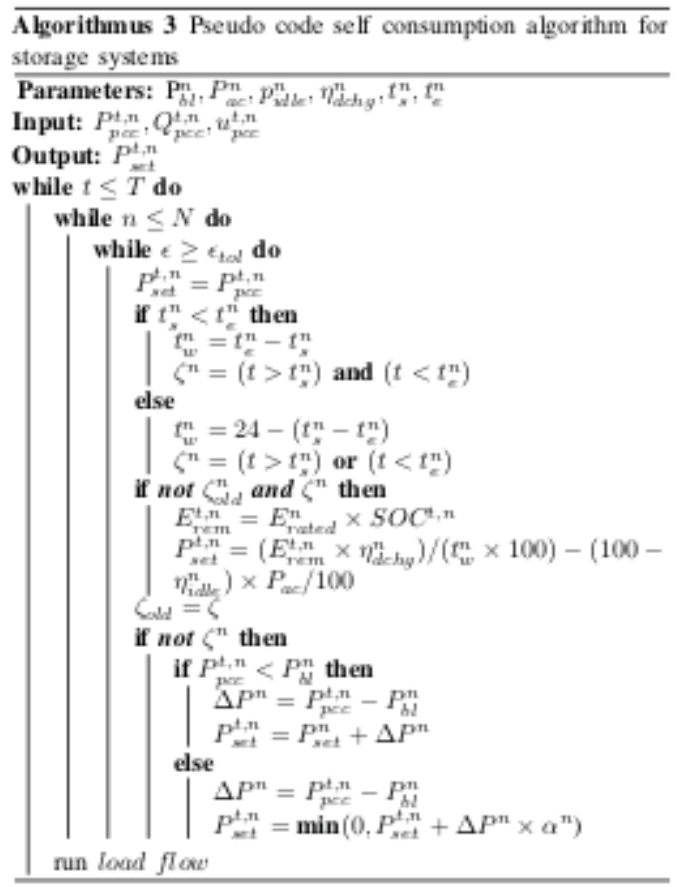

Figure A-3 